\title{
H2A Production Model, Version 2 User Guide
}

\section{Technical Report} NREL/TP-560-43983

September 2008

D. Steward and T. Ramsden

National Renewable Energy Laboratory

J. Zuboy

Independent Contractor

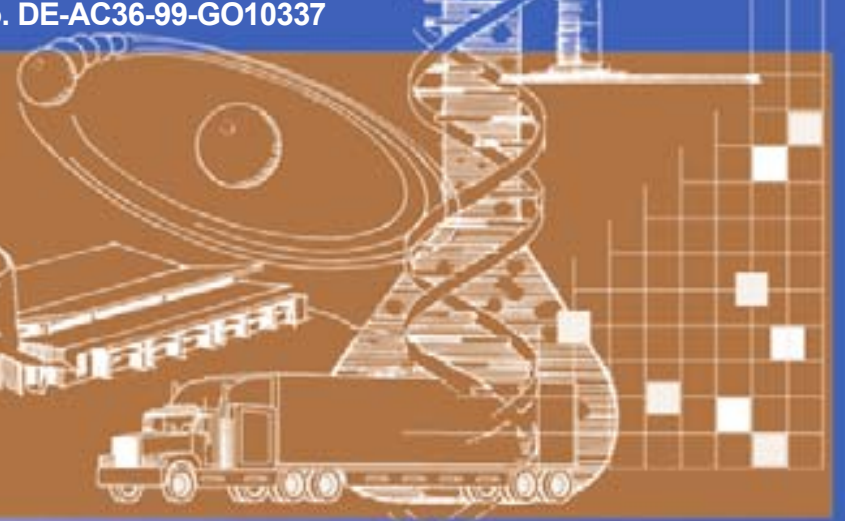




\section{H2A Production Model, Version 2 User Guide}

D. Steward and T. Ramsden

National Renewable Energy Laboratory

J. Zuboy

Independent Contractor

Prepared under Task No. H278.2150

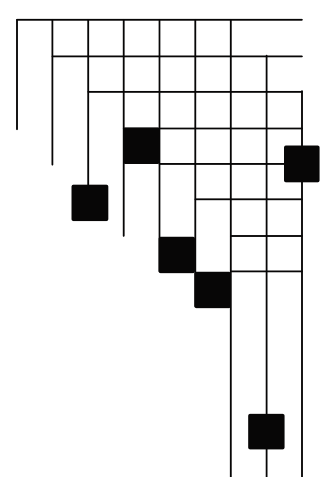




\section{NOTICE}

This report was prepared as an account of work sponsored by an agency of the United States government. Neither the United States government nor any agency thereof, nor any of their employees, makes any warranty, express or implied, or assumes any legal liability or responsibility for the accuracy, completeness, or usefulness of any information, apparatus, product, or process disclosed, or represents that its use would not infringe privately owned rights. Reference herein to any specific commercial product, process, or service by trade name, trademark, manufacturer, or otherwise does not necessarily constitute or imply its endorsement, recommendation, or favoring by the United States government or any agency thereof. The views and opinions of authors expressed herein do not necessarily state or reflect those of the United States government or any agency thereof.

Available electronically at http://www.osti.gov/bridge

Available for a processing fee to U.S. Department of Energy and its contractors, in paper, from:

U.S. Department of Energy

Office of Scientific and Technical Information

P.O. Box 62

Oak Ridge, TN 37831-0062

phone: 865.576 .8401

fax: 865.576 .5728

email: mailto:reports@adonis.osti.gov

Available for sale to the public, in paper, from:

U.S. Department of Commerce

National Technical Information Service

5285 Port Royal Road

Springfield, VA 22161

phone: 800.553 .6847

fax: 703.605.6900

email: orders@ntis.fedworld.gov

online ordering: http://www.ntis.gov/ordering.htm 
The H2A Production Model analyzes the technical and economic aspects of central and forecourt hydrogen production technologies. Using a standard discounted cash flow rate of return methodology, it determines the minimum hydrogen selling price (or levelized cost), including a specified after-tax internal rate of return from the production technology. Users have the option of accepting default technology input values-such as capital costs, operating costs, and capacity factor-from established $\mathrm{H} 2 \mathrm{~A}$ production technology cases or entering custom values. Users can also modify the model's financial inputs.

This new version of the H2A Production Model features enhanced usability and functionality. Input fields are consolidated and simplified. New capabilities include performing sensitivity analyses and scaling analyses to various plant sizes.

The model is actually two models: one Microsoft Excel spreadsheet to analyze central hydrogen production technologies and another to analyze forecourt hydrogen production technologies. The two models are very similar; the primary difference is that the central model performs carbon sequestration calculations, whereas the forecourt model performs refueling station compression, storage, and dispensing calculations. The models and detailed technology cases can be downloaded from www.hydrogen.energy.gov/h2a production.html.

This User Guide helps users already familiar with the basic tenets of $\mathrm{H} 2 \mathrm{~A}$ hydrogen production cost analysis get started using the new version of the model. It introduces the basic elements of the model then describes the function and use of each of its worksheets. More detailed and explanatory instructional materials are being developed.

\section{Contents}

Quick Start: Getting Around .................................................................

Quick Start: Performing Simple Production Cost Analyses ................................

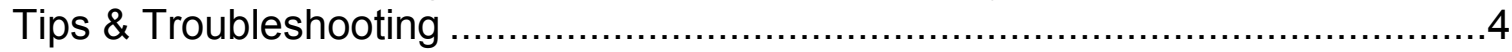

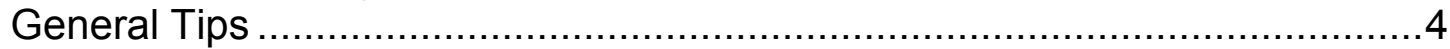

Solutions to Commonly Encountered Problems ...................................... 5

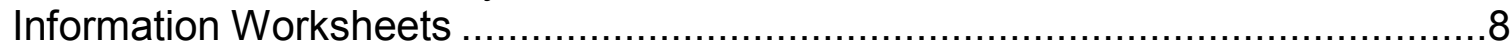

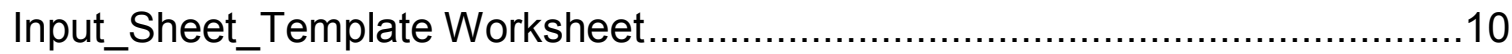

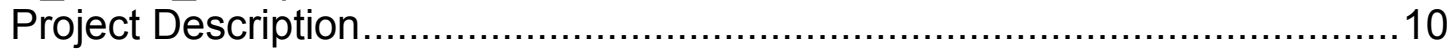

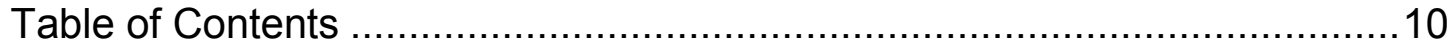

Technical Operating Parameters and Specifications ..................................11

Financial Input Values ........................................................................11

Energy Feedstocks, Utilities, and Byproducts......................................12

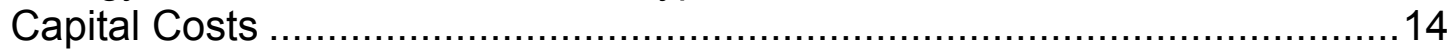

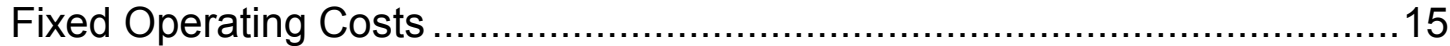

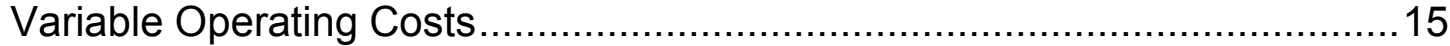

Other Materials and Byproducts ....................................................16

Other Variable Operating Costs ..........................................................17

Replacement Costs Worksheet...............................................................18

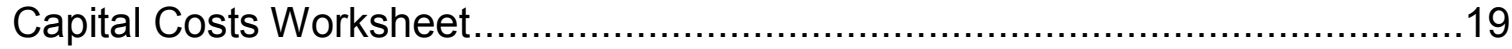

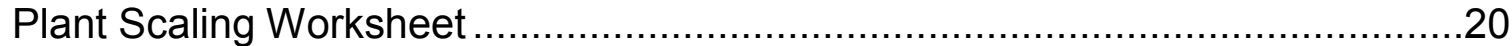

Carbon Sequestration Worksheet (Central Model Only) ..................................23 
Refueling Station Worksheet (Forecourt Model Only) .................................25

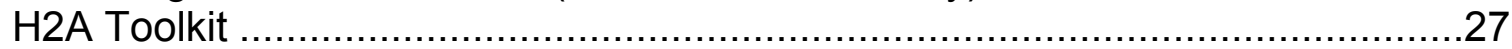

Importing Existing H2A Cases ................................................................27

Printing and Exporting Inputs and Results .........................................29

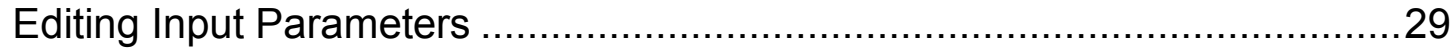

Delete Feed, Utility, and Byproduct Inputs .......................................29

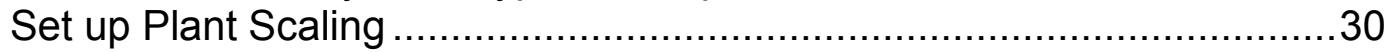

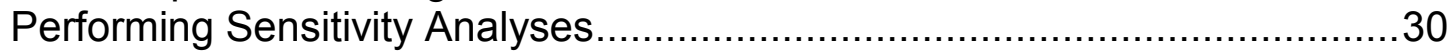

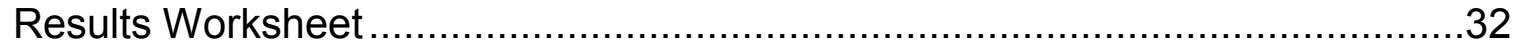

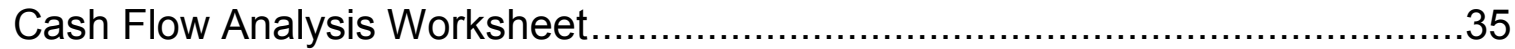

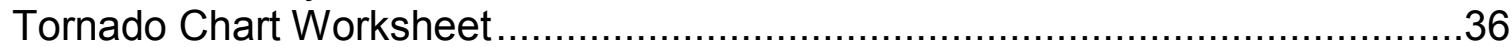

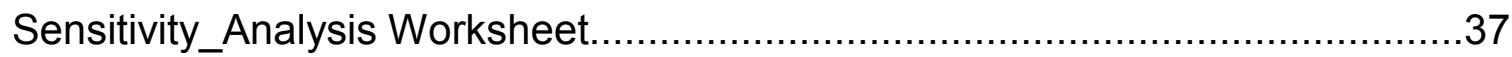

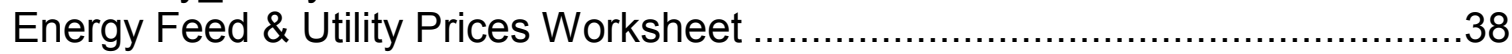

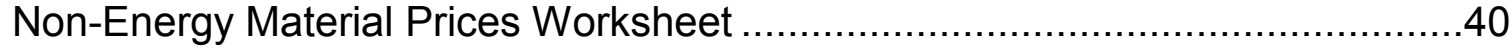

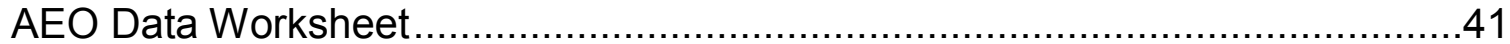

HyARC Physical Property Data Worksheet.................................................42

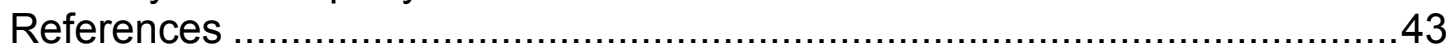

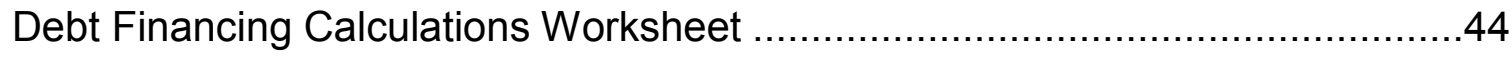

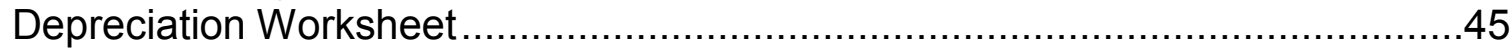

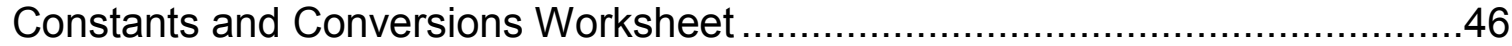

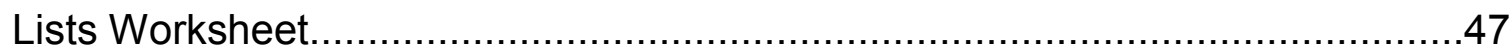

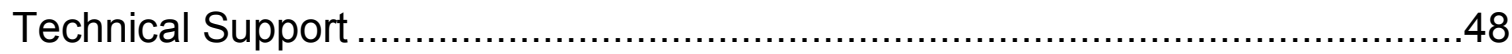

Appendix 1: Carbon Sequestration Calculations and Sources ..........................49

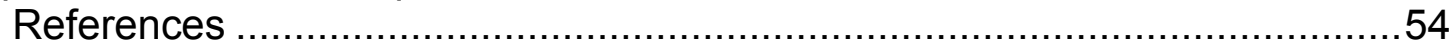

Appendix 2: Forecourt Hydrogen Delivery Calculations .................................56

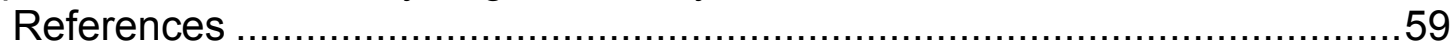

Appendix 3: Default Values and Assumptions .............................................60

Appendix 4: Derivations and Definitions..................................................62

Derivation of Forecourt Production Unit Operating Capacity Factor ..............62

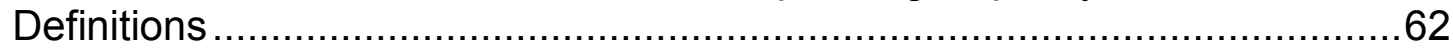

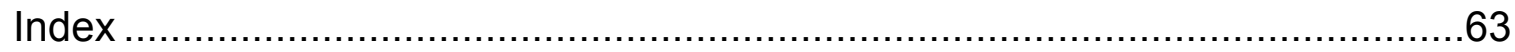




\section{Quick Start: Getting Around}

The spreadsheet is organized into 19 or more worksheets, which have tabs color coded according to their function, as shown below. The schematic on the following page shows a generalized data flow among the worksheets.

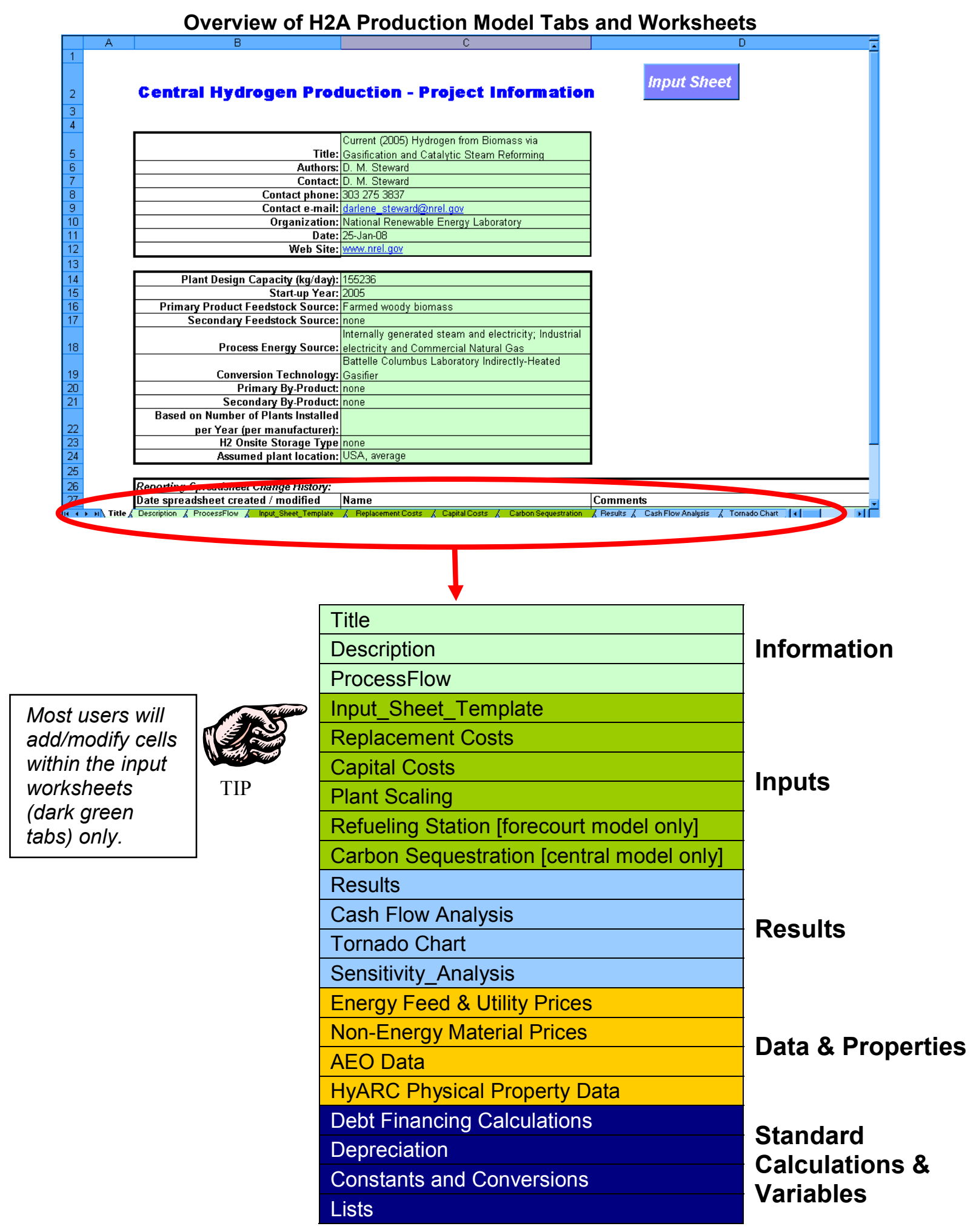


Schematic of Data Flow among H2A Worksheets

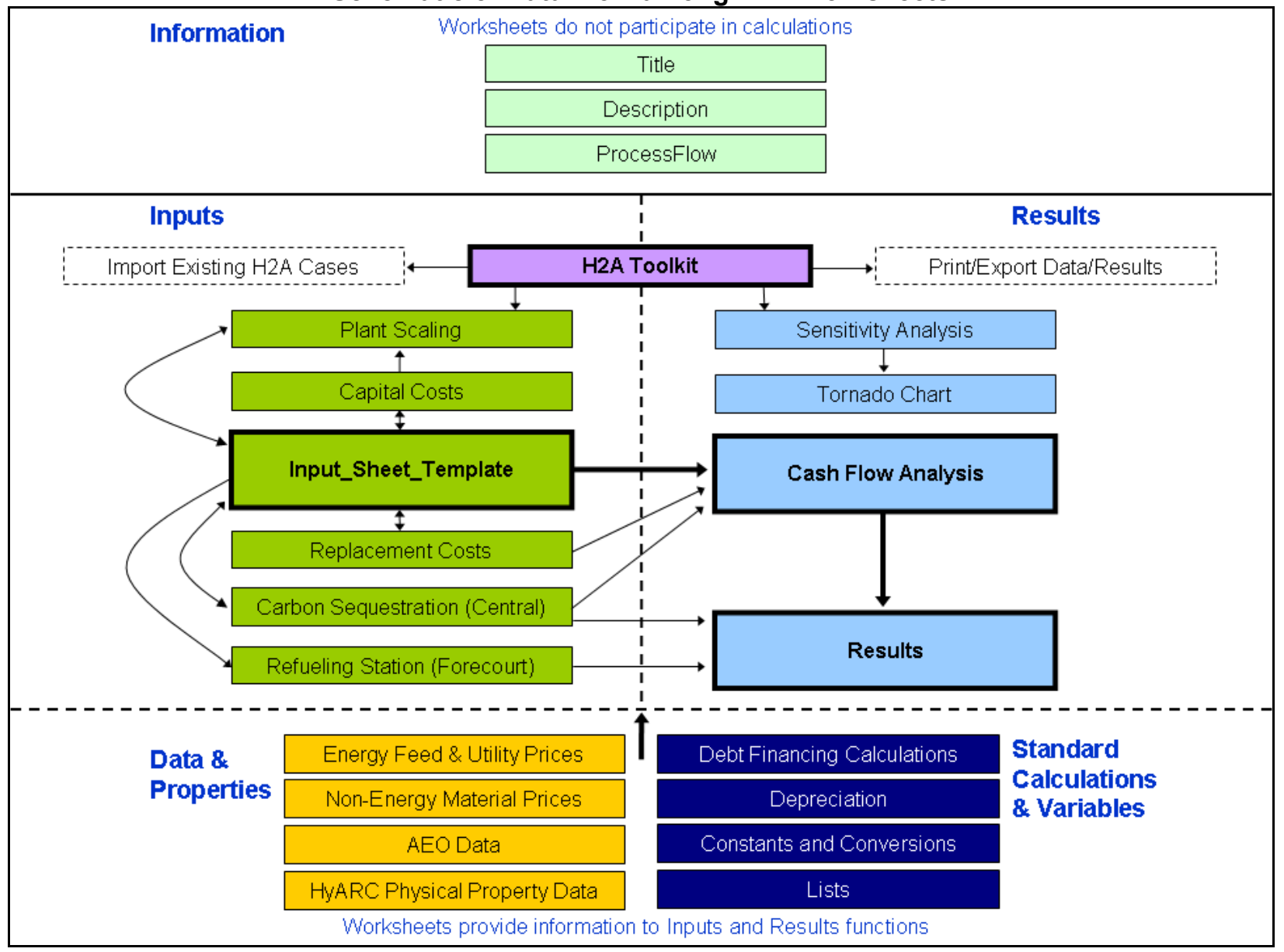




\section{Quick Start: Performing Simple Production Cost Analyses}

To perform a simple production cost analysis, select the Input_Sheet_Template tab. Accept the default (e.g., production technology case) values or enter new values into the orange cells. The contents of the blue cells are calculated automatically. Use the drop-down menus and buttons to enter information for Energy Feedstocks, Utilities, and Byproducts and Other Materials and Byproducts. Once all information is entered, click the Calculate Cost button at the top of the worksheet.

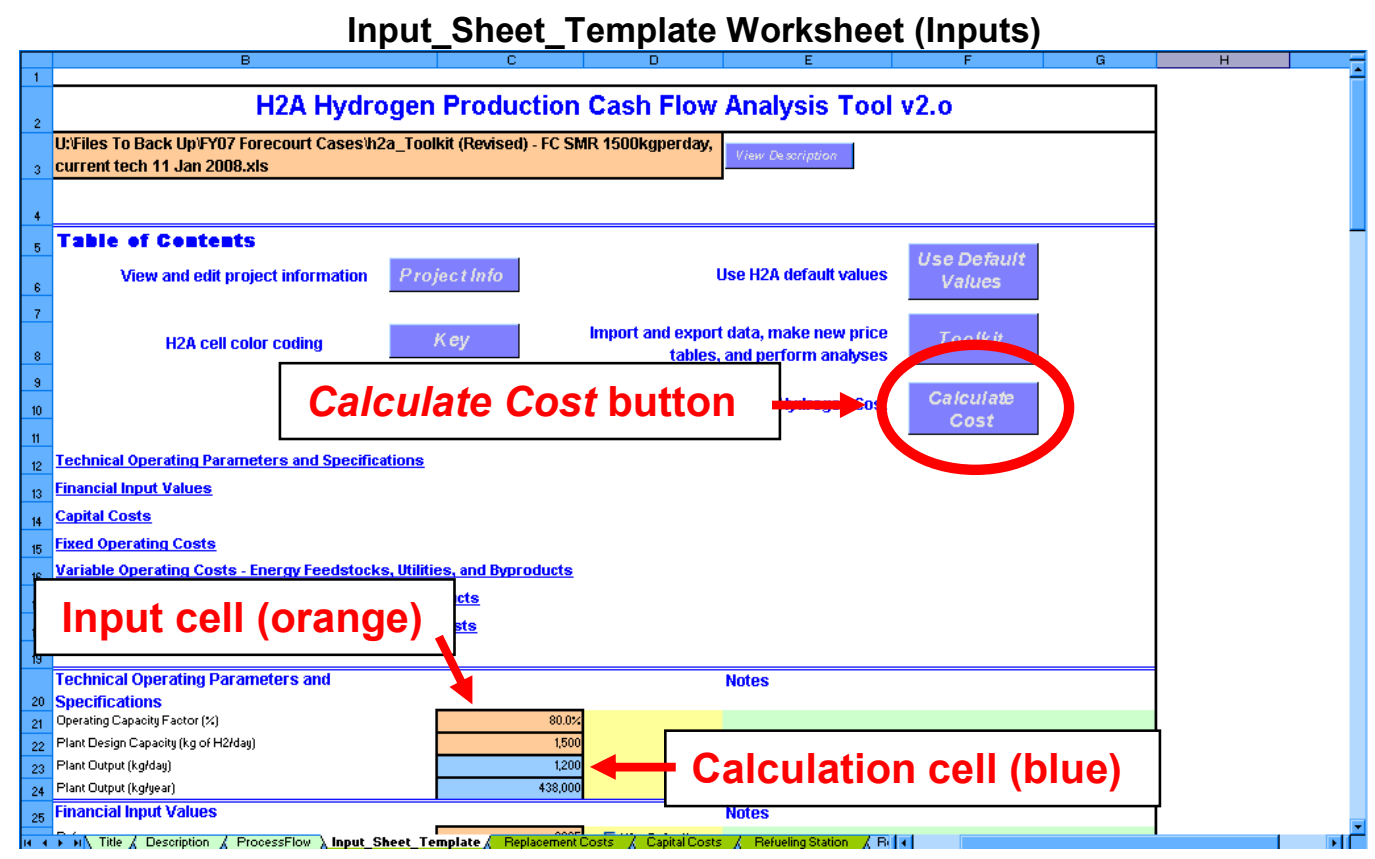

Clicking the Calculate Cost button sends you to the Results worksheet, which displays the production cost, energy, and emissions results.

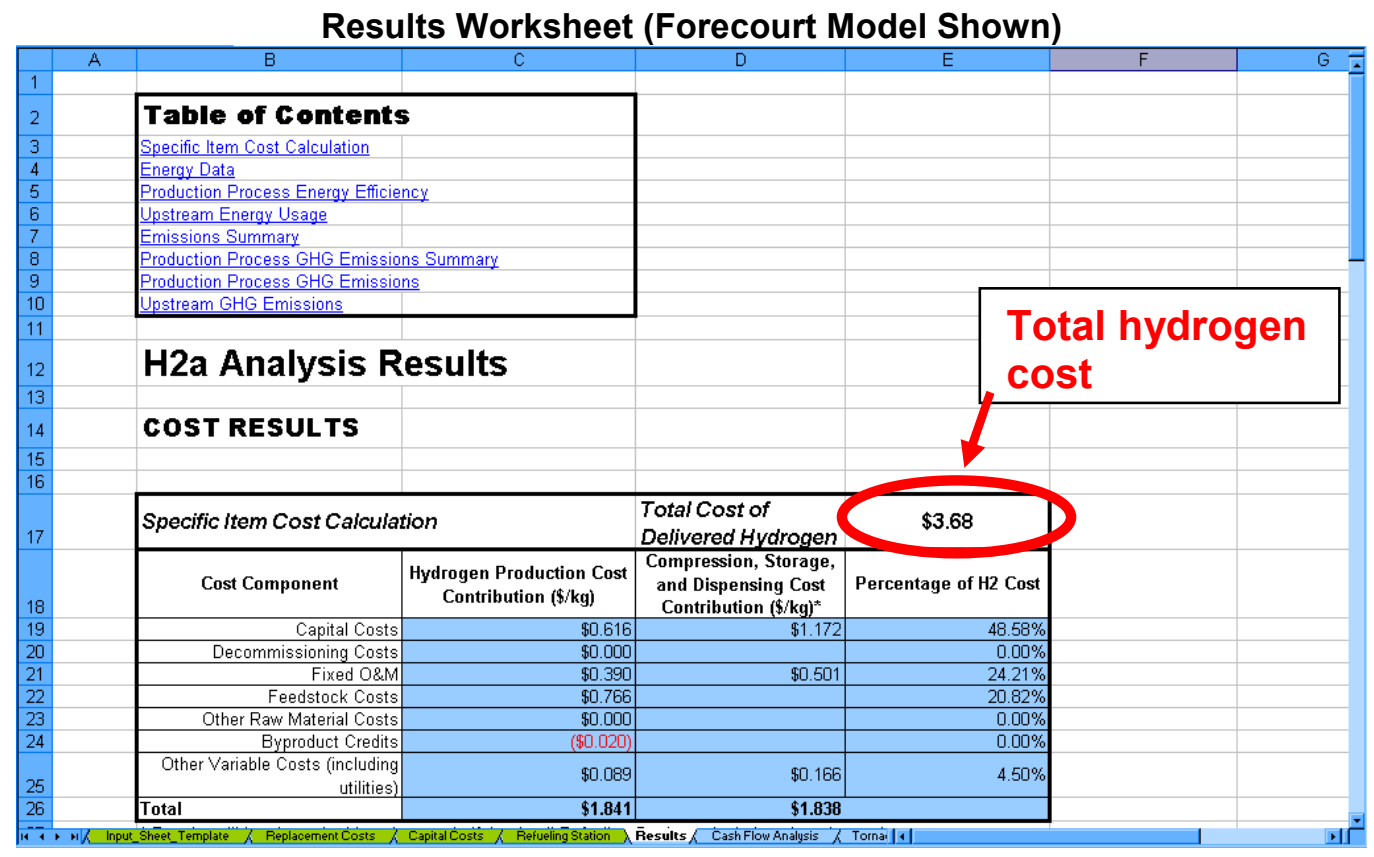




\section{Tips \& Troubleshooting}

\section{General Tips}

- Before you start modifying the model, save the file under a new name. This will make it simple to go back to the unmodified model later if necessary.

- If the file you are working with accumulates numerous errors, or if you delete information that you later find you need, etc., it might be easier to discard the file and start afresh with the original version of the model and/or production technology case. If you have not kept an original version, download the model again from the H2A Web site: www.hydrogen.energy.gov/h2a production.html.

- Throughout the model, orange cells are meant to accept static user-input values or userdefined equations, and blue cells are calculated automatically by the model. Use care if you overwrite the blue calculation cells with static values or your own equations; once overwritten, the original equation information is permanently deleted. Green cells are for user-input information and notes. Yellow cells contain H2A information and default values.

- Do not type values into cells with drop-down menus. Select only from values in the menu.

- If it is not obvious how to close or move on past a pop-up window, you can close it by clicking the $\mathrm{X}$ in the upper right corner.

- Mouse over small red triangles for useful notes as shown below.

\begin{tabular}{|l|l|}
\hline Energy Feedstocks, Utilities, and Byproducts \\
Select the Price Table to Use
\end{tabular} \begin{tabular}{|l|l|l|}
\hline AEO 2005 High A C ase & $\begin{array}{l}\text { dsteward: } \\
\text { To change the usage } \\
\text { units, change BOTH the } \\
\text { usage unit and the LHV in } \\
\text { Table A on the "HARC } \\
\text { Physical Property Data" } \\
\text { tab }\end{array}$ \\
Select the Feed
\end{tabular}

- The Input_Sheet_Template worksheet works best (i.e., has the least likelihood of errors) when you fill it out as completely as possible, starting with the top and working down. After filling out the worksheet completely, click the Calculate Cost button at top to view results.

- Tabs for the Plant Scaling and Tornado Chart worksheets do not appear until you initiate their use. See pages 20 and 36 for details.

User Guide Symbols

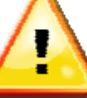

CAUTION

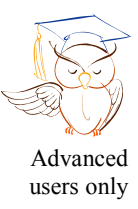

Skip this section if you are a novice user or want to perform only simple analyses.

Follow instructions carefully to prevent errors or unwanted results.

Read for useful information. 


\section{Solutions to Commonly Encountered Problems}

Problem

1. Clicking the Use Default Values button unintentionally replaced some of your user-defined values.
Possible Solution

To retain user-defined values while filling in blank cells with default values, click No in the Use Default Values pop-up window.
Relevant Worksheets

Input_Sheet_Template

Carbon Sequestration

Refueling Station
User Guide Sections

Table of Contents ( $\mathrm{p}$. 10)

Input_Sheet_Template

Energy Feedstocks, Utilities, and

Byproducts (p. 12) utilities, and byproducts in the Input_Sheet_Template worksheet, you received an error message and null results when you clicked the Calculate Cost button.
Make sure you use the same price table for each energy feedstock, utility, and byproduct you add. Using different price tables creates an error in the calculations.
3. After deleting energy feedstocks, utilities, and byproducts or other materials and byproducts in the Input_Sheet_Template worksheet using Microsoft Excel's delete functionality, you received an error message and null results when you clicked the Calculate Cost button.
Do not use Excel's delete functionality to delete entries under Energy Feedstocks, Utilities, and Byproducts or Other Materials and Byproducts within the Input_Sheet_Template worksheet. If you have used Excel's delete functionality in one or both of these sections, discard your current file and start afresh with the original version of the model and/or production technology case. In the future, make sure to use the H2A Model's Delete button to delete entries within these sections.
Input_Sheet_Template

Energy Feedstocks, Utilities, and Byproducts (p. 12) Other Materials and Byproducts (p. 16) 
4. You did not perform the actions described in problems 2 and 3 above, but you still received an error message when you clicked the Calculate Cost button.
Make sure to enter all critical values in the Technical Operating Parameters and Specifications and Financial Input Values sections before completing the rest of the Input_Sheet_Template worksheet and calculating cost. In particular, make sure values are present for reference year, startup year, and plant capacity.
5. You used the Delete button to delete an entry under Energy Feedstocks, Utilities, and Byproducts or Other Materials and Byproducts, and more entries-or different entrieswere deleted than you had intended.

6. You performed a sensitivity analysis, and the resulting tornado chart contained bad or nonsensical results.
Be careful to choose the correct item from the Delete drop-down menu within the H2A Toolkit. It deletes all entries of the selected type.
Input_Sheet_Template

Variable Operating Costs (p. 15)
Input_Sheet_Template H2A Toolkit
Energy Feedstocks, Utilities, and Byproducts (p. 12)

Other Materials and Byproducts (p. 16) Delete Feed, Utility, and Byproduct Inputs (p. 29)
Try switching the values you entered for "Value Reducing Hydrogen Price" and "Value Increasing Hydrogen Price" within the Sensitivity Analysis window. It is not always obvious how changing the value of a variable will affect the hydrogen price.
H2A Toolkit

Tornado Chart

Sensitivity Analysis
Performing Sensitivity Analyses (p. 30) 
7. You added your own energy feedstock, utility, or byproduct using the Energy Feed \& Utility Prices worksheet, but your new item did not appear in the Energy Feedstocks, Utilities, and Byproducts section within the Input_Sheet_Template worksheet.

8. You modified the Lists worksheet, and now the model does not work properly.
First, "refresh" the Energy Feedstocks, Utilities, and Byproducts section by selecting another price table from the drop-down menu then selecting the table in which your new item was added; use the next two drop-down menus to check if your item now appears. If your item still does not appear, go to the HyARC Physical Property Data worksheet, Table A, and make sure the item has values in every required column.
Input_Sheet_Template Energy Feed \& Utility Prices

Energy Feed \& Utility Prices Worksheet (p. 38)

HyARC Physical

Property Data

Do not add, delete, or change anything Lists

Lists Worksheet (p. 47) on the Lists worksheet. Modifying the lists can disable or introduce major errors into the model. If you have modified the lists, discard your current file and start afresh with the original version of the model and/or production technology case. 


\section{Information Worksheets}

Established H2A production technology cases contain information worksheets linked from the light-green tabs. These worksheets do not participate in the model's calculations but contain valuable information about the project file and the hydrogen production technology being modeled. Clicking the Input Sheet button on any of the information worksheets sends you to the Input_Sheet_Template worksheet to begin using the model.

\section{Example Title Worksheet (Central Biomass Gasification)}

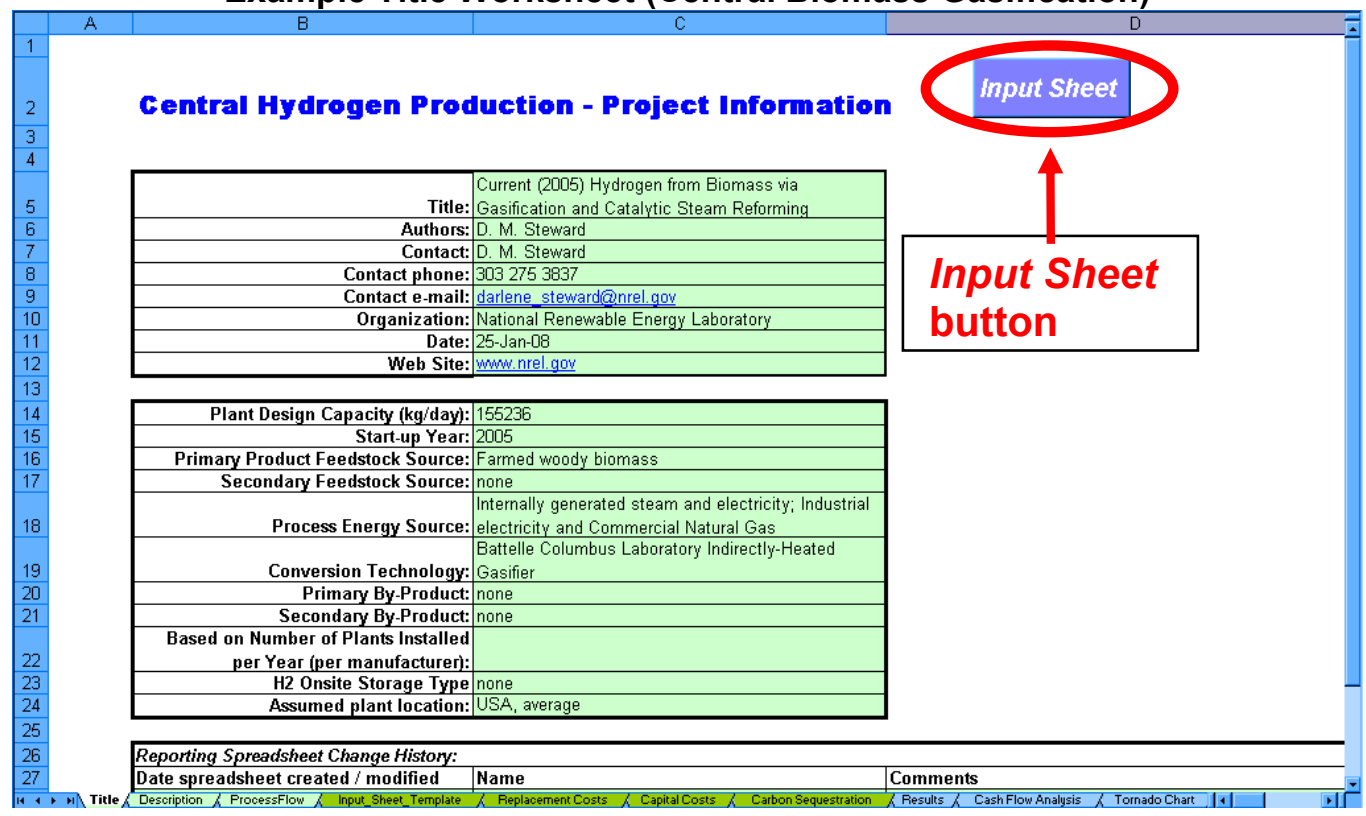

\section{Example Description Worksheet (Central Biomass Gasification)}

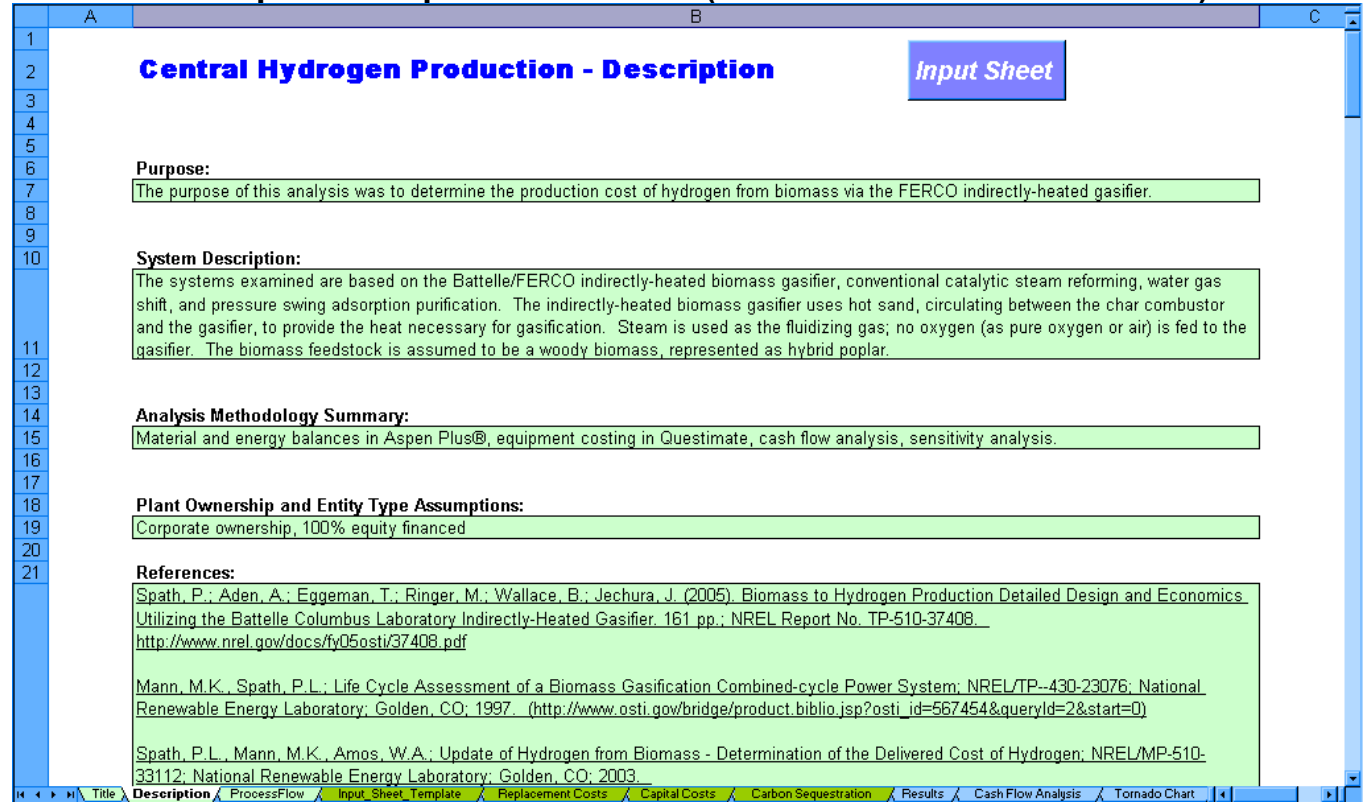


Example ProcessFlow Worksheet (Central Biomass Gasification)

\begin{tabular}{|c|l|l|}
\hline 1 & & \\
\hline & Central Hydrogen Production - Process Flow Diagram \\
\hline 4 & &
\end{tabular}

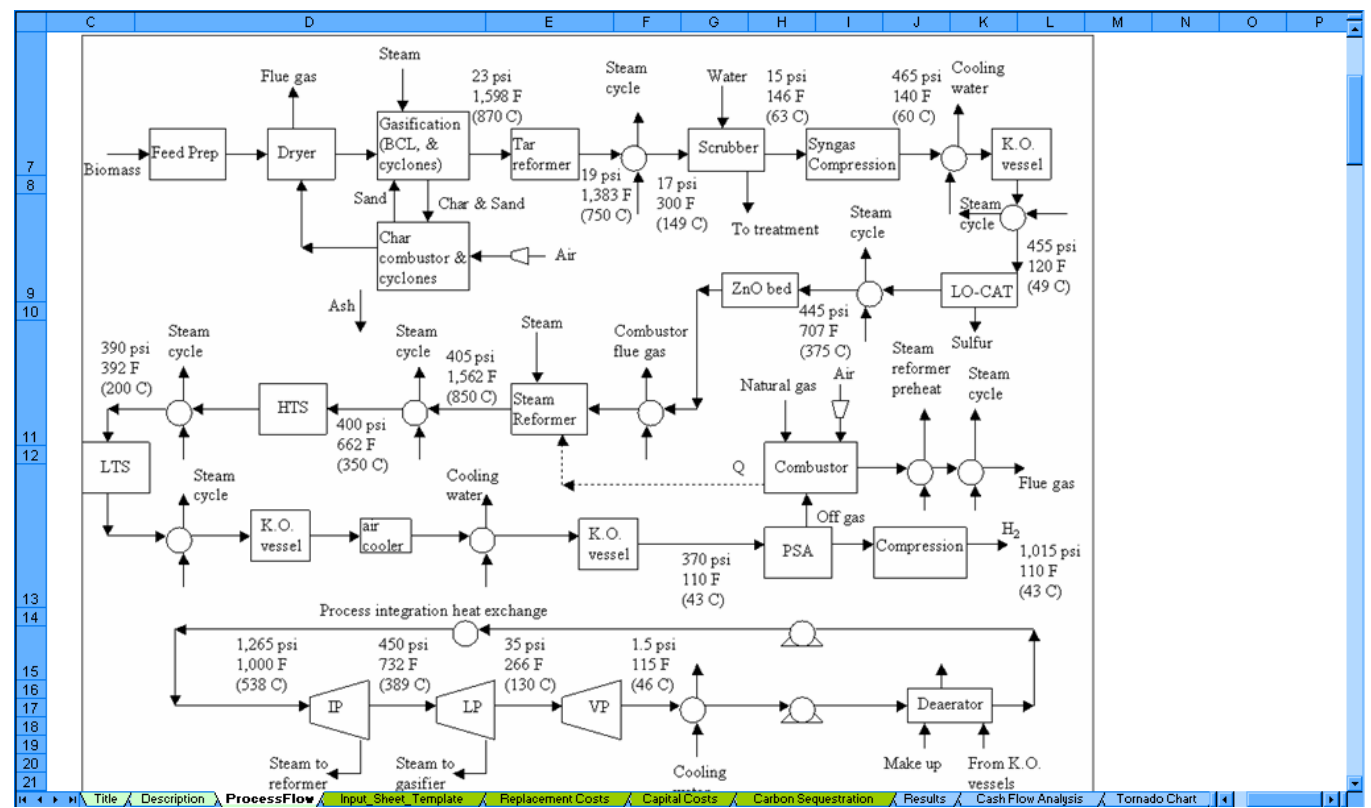




\section{Input_Sheet_Template Worksheet}

The Input_Sheet_Template worksheet is the H2A Model's primary user interface. You use this worksheet to input the data the model uses for calculations, perform analyses, and access the automated functions of the model through the $\mathrm{H} 2 \mathrm{~A}$ Toolkit utility. After filling out the worksheet, you click the Calculate Cost button to calculate and view results. The worksheet is organized into seven main sections plus the Toolkit, which are described below (see page 27 for details on the H2A Toolkit). Throughout the worksheet, entries in the Notes column describe calculations being performed or offer guidance on user inputs.

\section{Project Description}

The first line of the Input_Sheet_Template worksheet lists the name and date of the H2A file you are using. Click the View Description button to view a brief project description and history of updates in the Title worksheet (see page 8 for a sample Title worksheet).

\section{Table of Contents}

At the top of the Table of Contents are five buttons. The Project Info button sends you to the Title worksheet. The Key button describes the color coding used in the H2A Model.

The Use Default Values button links to a pop-up window, which provides two options for automatically using H2A default values. Clicking Yes replaces all Input_Sheet_Template

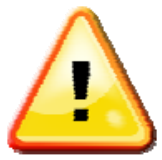
inputs for which default values exist with the default values. Clicking No enters default values only for those inputs that have default values and are blank (see illustration on page 11). Be careful when using this button so as not to replace CAUTION values unintentionally.

The Toolkit button brings up the H2A Toolkit window. Although this button is at the top of the worksheet, typically it is not the first thing you need to use-you will use it to perform a variety of important functions as described under H2A Toolkit (page 27) and in several other sections of this User Guide.

Use the Calculate Cost button after completing the Input_Sheet_Template worksheet and associated worksheets. For illustrations, read through the rest of this section or see Quick Start: Performing Simple Production Cost Analyses (page 3).

Beneath the row of buttons, the Table of Contents links to the major sections of the Input_Sheet_Template worksheet, which are described in the subsequent sections of this User Guide (the order of sections varies slightly between central and forecourt models). These sections include the following:

- Technical Operating Parameters and Specifications

- Financial Input Values

- Energy Feedstocks, Utilities, and Byproducts

- Capital Cost

- Fixed Operating Costs

- Variable Operating Costs - Other Materials and Byproducts

- Variable Operating Costs - Other Variable Operating Costs. 
Example of Automatically Entering Default Values in the Input_Sheet_Template Worksheet

\begin{tabular}{|c|c|c|}
\hline & F H2a Default & \\
\hline $100 \%$ & F H2a Default & \\
\hline $100 \%$ & \multirow{9}{*}{$\begin{array}{l}\square \text { H2a Default } \\
\square \text { H2a Default } \\
\nabla \text { H2a Default } \\
\nabla \text { H2a Default } \\
\nabla \text { H2a Default } \\
\nabla \text { H2a Default }\end{array}$} & \multirow{7}{*}{$\begin{array}{l}\text { The user has } \\
\text { entered a non- } \\
\text { default value into } \\
\text { cell } 1 \text { while } \\
\text { erasing the value } \\
\text { in cell } 2\end{array}$} \\
\hline $50 \%$ & & \\
\hline $75 \%$ & & \\
\hline (1) $20 \%$ & & \\
\hline (2) & & \\
\hline $1.9 \%$ & & \\
\hline $10.0 \%$ & & \\
\hline $6.0 \%$ & & \\
\hline $35.0 \%$ & & \\
\hline
\end{tabular}

\section{Clicking the Use Default Values button brings up this window}

Replace all values on this page with default values?

Click Yes to replace all values. Click No to only replace blanks with default values

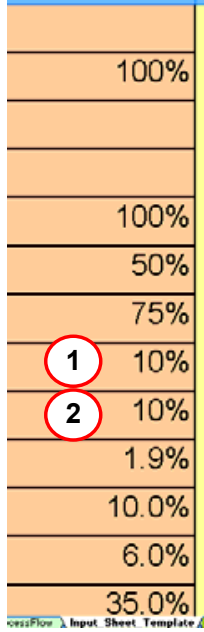

\section{F H2a Default \\ 『 H2a Default}

ॠ H2a Default

『 H2a Default

『 H2a Default

F H2a Default

$\checkmark$ H2a Default

Clicking Yes in the Use Default Values pop-up window enters default values into both cells

\section{Technical Operating Parameters and Specifications}

Here you define the hydrogen output of your plant. Enter values for capacity factor and plant design capacity. The model uses these values to calculate plant output.

\section{Financial Input Values}

Here you define the financial characteristics of your plant. Several of the fields have an "H2a Default" checkbox adjacent to them. Checking this box automatically fills the cell with the H2A Model default value for that input. The fields Reference Year, Length of Construction Period, Depreciation Schedule Length, and Depreciation Type have drop-down menus containing 
predefined values. Select a value from the drop-down menu for these fields; values not listed in the drop-down menus cannot be entered. The only field calculated by the model is Total Tax Rate.

\section{Energy Feedstocks, Utilities, and Byproducts}

This important section follows the Financial Input Values section in the central model and is part of the Variable Operating Costs section (see page 15) in the forecourt model. It allows you to define energy feedstock, utility, and byproduct costs and credits - up to four of each type. Each element is added by first defining it using the drop-down menus and data entry fields, then clicking the Add button.

The first drop-down menu selects the price data table that will be used to calculate feedstock, energy, and byproduct costs and credits. These U.S. Energy Information Administration (EIA) data are drawn from the model's Energy Feed \& Utility Prices worksheet (see page 38). Select one of the tables from the drop-down menu. The U.S. Department of Energy (DOE)

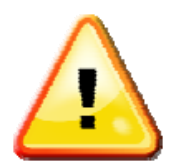

CAUTION has selected the AEO 2005 High A Case as the standard for all $\mathrm{H} 2 \mathrm{~A}$ production technology cases. For more information on the price data, see AEO Data Worksheet on page 41 . Note, you must use only one price table for each analysis, i.e., you must use the same price table for each energy feedstock, utility, and byproduct you enter.

Use the next two drop-down menus to select feedstocks, utility inputs, and byproducts; see Energy Feed \& Utility Prices Worksheet on page 38 for an easy way to add items that are not already in these menus. The lower heating value (LHV) is automatically drawn from the HyARC Physical Property Data worksheet, Table A (see page 42).

Next, accept the shown Price in Startup Year or click the Enter Price button to enter a different price. If you accept the Price in Startup Year, the model looks up the price for each year of the analysis in the selected price table and inflates that value using the inflation rate entered in the Financial Input Values section. If you enter your own price, the model inflates that price over the analysis period. For Usage/Production, enter the amount of energy or material required to produce a kilogram of hydrogen for sale-or the amount of byproduct produced per kilogram of hydrogen produced-in the unit shown ( $\mathrm{kg}, \mathrm{kWh}, \mathrm{Nm} 3$, or L). For feedstock, you can click the Enter Conversion Efficiency (\%) button to enter the feedstock conversion efficiency. (Note this is the efficiency of feedstock conversion only; if there are other energy inputs, the overall plant energy efficiency will be lower.) Once these fields are completed, click the Add button, which records your entry as shown in the screen capture on page 13.

Remember that a feedstock, utility, or byproduct does not become part of the model's calculations until you click the Add button and the entry is recorded. Values present in the input fields but not recorded in this manner do not participate in the calculations. Established $\mathrm{H} 2 \mathrm{~A}$ production technology cases include recorded feedstock, utility, and byproduct values. Some also include unrecorded values in the input fields (for example, see the screen capture on page 13). You can disregard these unrecorded values or select new values (then click the Add button) if you wish to add your own feedstocks, utilities, or byproducts. 
Energy Feedstocks, Utilities, and Byproducts (Input_Sheet_Template Worksheet)

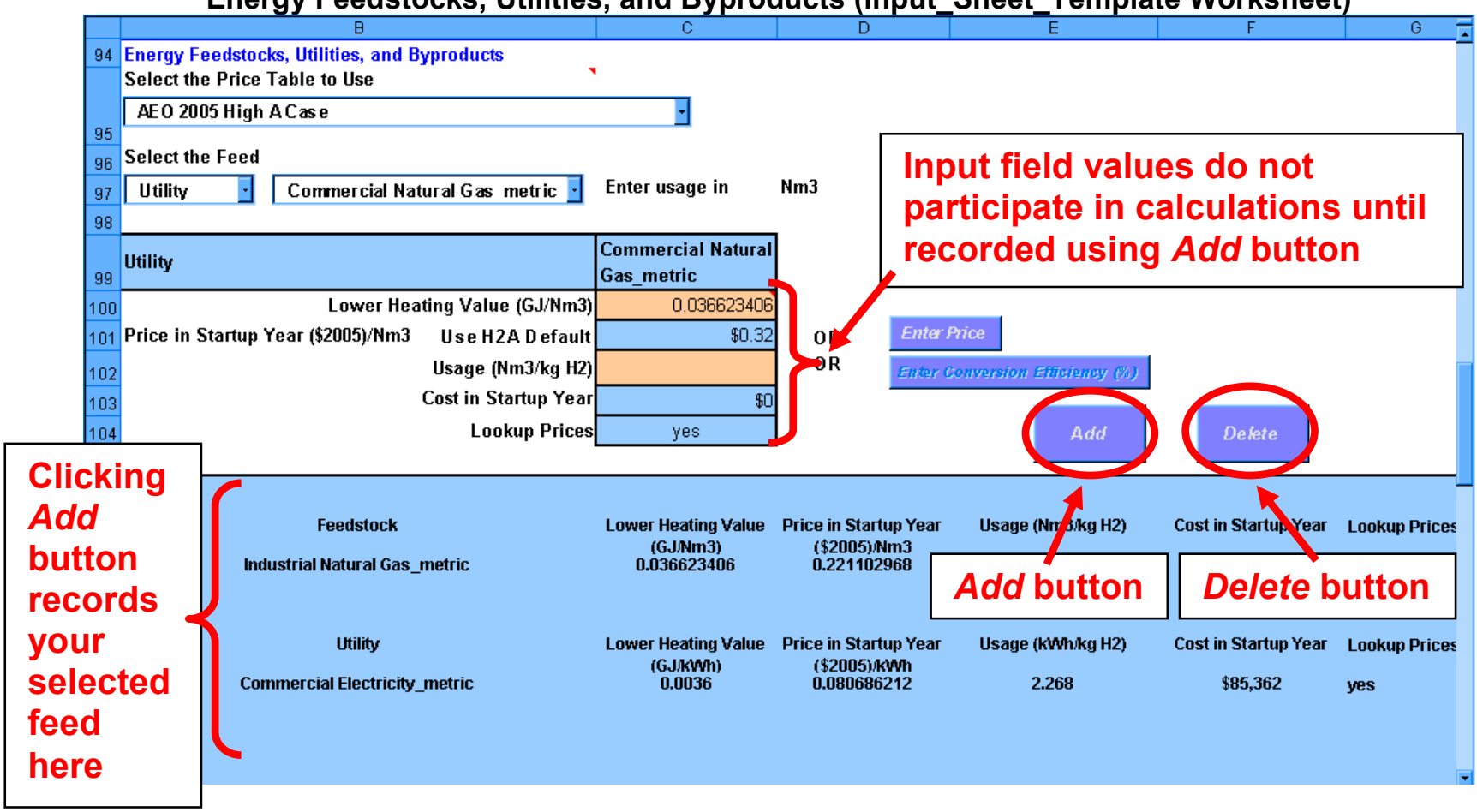

To delete entries, click the Delete button, which pulls up the Toolkit menu. Use the drop-down menu under Editing to select the type of entry you want to delete. Then click the Delete button. This deletes all entries of the selected type. For example, if you had selected three energy byproducts, choosing Energy Byproduct from the drop-down menu and clicking the Delete button will delete all three.

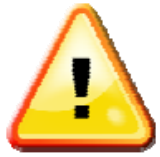

When deleting entries, it is critical to use the Delete button. Do not delete the rows using Excel's delete function. Also, be careful to choose the correct item from the Delete drop-down menu within the Toolkit. It can delete not only the energy feedstocks, utilities, and byproducts selected in this section, but also the CAUTION other materials and byproducts selected in the Variable Operating Costs section (page 15).

The model uses the selected entries to automatically calculate total energy feedstock and utilities costs and byproduct credits in the startup year. These values appear in the three blue cells at the bottom of the section but are not used in the cash-flow calculations. You can view the yearly values being used in the cash-flow calculations in the lowermost table of the Cash Flow Analysis worksheet (see the bottom screen capture in the schematic on page 15).

If desired, advanced users can change the units applied to each material selected in this section. For example, the units for natural gas feedstock could be changed from $\mathrm{Nm} 3$ to scf. This requires changes be made elsewhere in the model. Go to the HyARC Physical Property Data worksheet, Table $A$, and change the unit in the column $H 2 A$ Usage Input Unit/ $\mathrm{kg} \mathrm{H2}$. In the column H2A LHV (GJ or mmBtu/ H2A usage input unit),

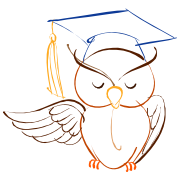

Advanced users only 
enter the numerical value of the LHV corresponding to the new input unit; the LHV must be entered as GJ/usage unit for metric values and $\mathrm{mmBtu} /$ usage unit for English values. Check that the calculated results accord with the new-unit input values.

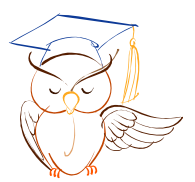

Advanced users only

Advanced users also can take advantage of a shortcut in this section. If you want to perform numerous modeling runs-for example, by modeling the hydrogen costs resulting from an array of feedstock, utility, and byproduct input price and production/usage values-you can save time by typing values directly into certain Excel cells instead of using the model's Add and Delete functions every time. Initially, add your chosen feedstocks, utilities, and byproducts using the Add function. If you want to vary items by typing over values, click the Enter Price button for those items and enter your own price; this automatically changes the Lookup Prices field to "no." After completing the rest of the model's sections and recording the resulting hydrogen cost, return to the Energy Feedstocks, Utilities, and Byproducts section. For any items with "no" in the Lookup Prices field, you can manually replace the values for Usage/Production and Price in Startup Year-simply type over the existing values. Once you have finished typing in values, click the Calculate Cost button to see the resulting hydrogen cost.

Advanced Users Can Manually Enter Certain Feedstock, Utility, and Byproduct Values

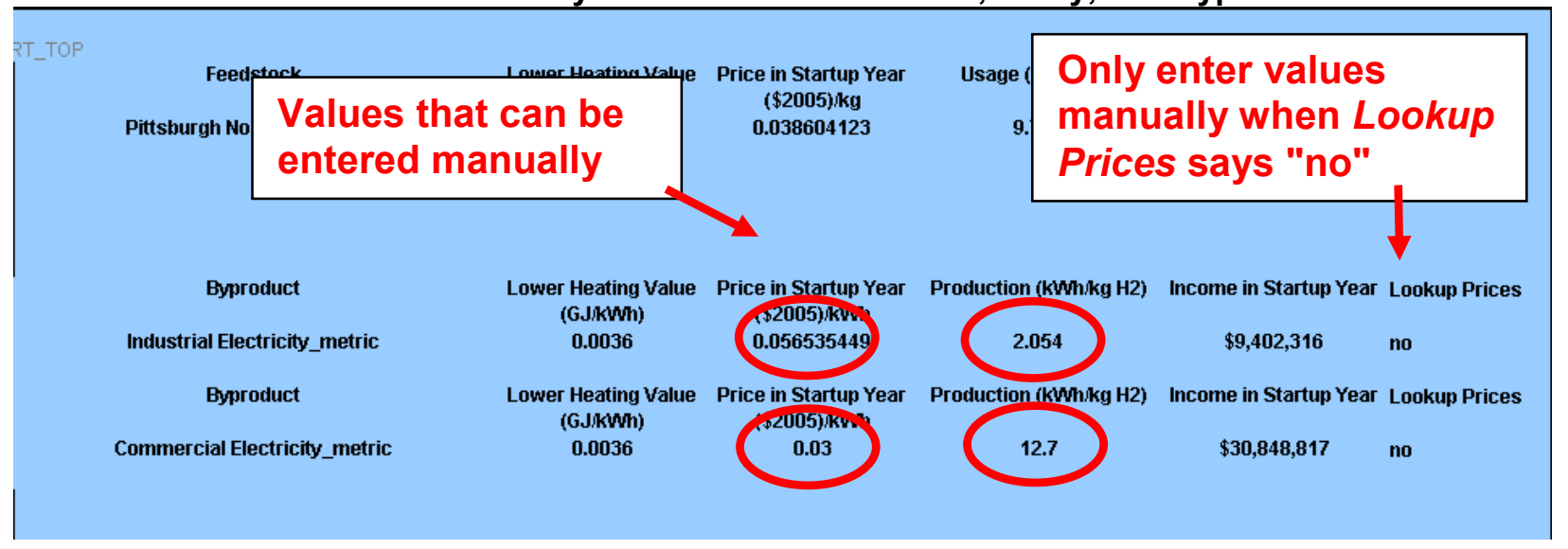

\section{Capital Costs}

Here you define the capital costs of your plant. For quick analyses, enter the total direct capital costs in the first input cell. When developing cases or detailed analyses, entering detailed capital costs is recommended. Click the first Link to Detail Sheet button, which takes

Orange cells are overwritten automatically when you import a new case (pg 27) or use the cell variable in plant scaling (pg 20).

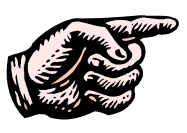

TIP you to the Capital Costs worksheet for data entry (see page 19). Clicking the second Link to Detail Sheet button takes you to the Carbon Sequestration worksheet (in the central model; see page 23) or the Refueling Station worksheet (in the forecourt model; see page 25) to calculate detailed capital costs for those functions. Note that some of the orange input fields can contain suggested equations. You can overwrite these with your own static values or equations. Once all applicable fields are filled with inputs and calculated values, the model calculates Total Depreciable Capital Costs, Total Non-Depreciable Capital Costs, and Total Capital Costs. 
Schematic of Data Flow to and from Energy Feedstocks, Utilities, and Byproducts Section

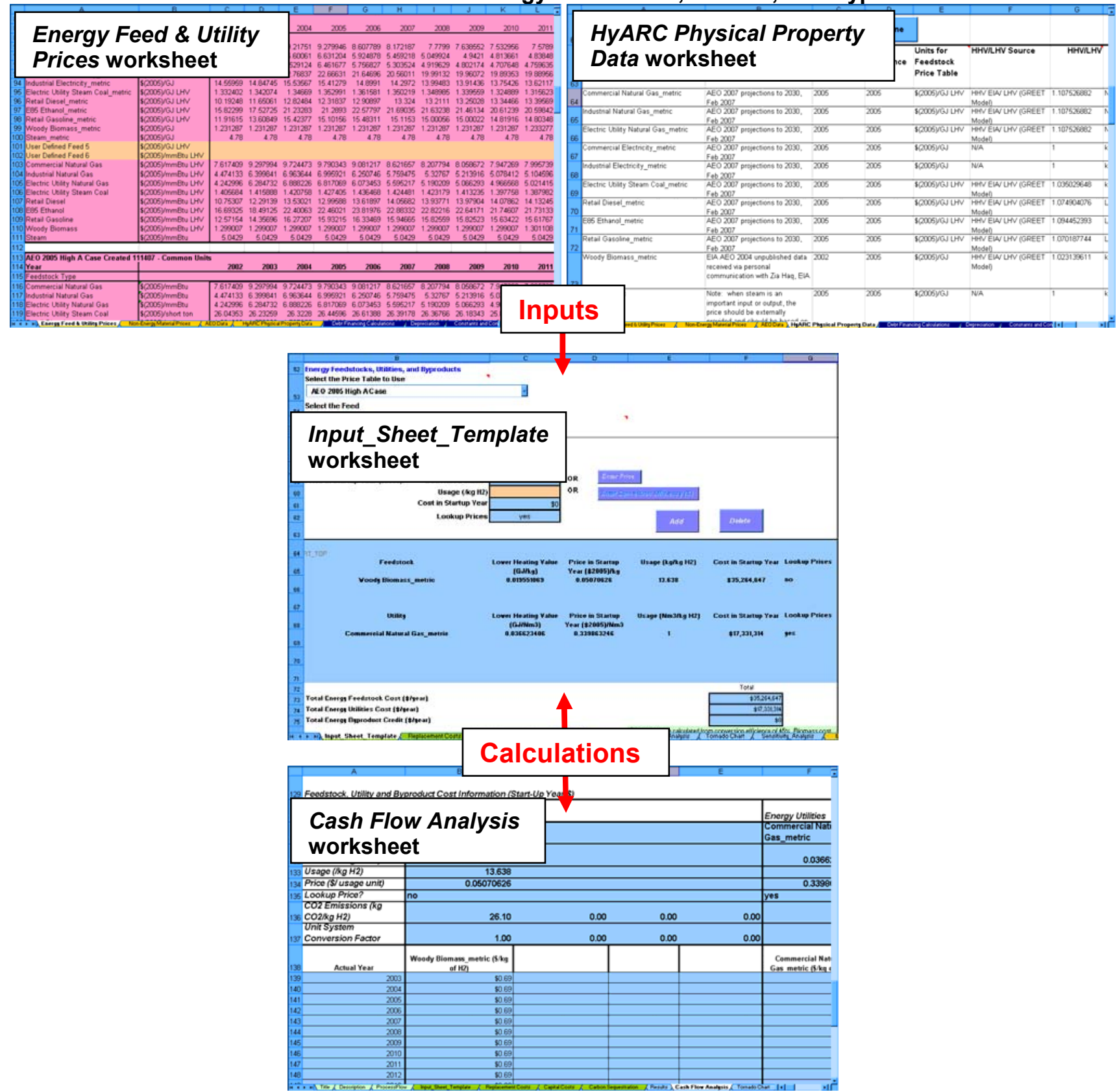

\section{Fixed Operating Costs}

Here you define your plant's fixed operating costs. Once values are entered or calculated for each field, the model calculates Total Fixed Operating Costs. In the forecourt model, enter information for the staff needed to run the hydrogen production equipment in the first two cells and for the filling station staff in the fourth and fifth cells. If you linked to the Refueling Station worksheet in the Capital Cost section (see above), the storage and dispensing labor costs will be set to zero here.

\section{Variable Operating Costs}

Here you define process material costs and other variable operating costs and the value of non-energy byproducts. In the forecourt model, this section also contains the function for 
defining energy feedstocks, utilities, and byproducts; this function is described for both the central and forecourt models on page 12. The remaining parts of the Variable Operating

Make sure values are present for reference year, startup year, \& plant capacity
Costs section are Other Materials and Byproducts and Other Variable Operating Costs. To prevent model errors, enter all critical values in the Technical Operating Parameters and Specifications (page 11) and Financial Input Values (page 11) sections before completing these sub-sections.

\section{Other Materials and Byproducts}

This sub-section works in a fashion similar to the Energy Feedstocks, Utilities, and Byproducts function described on page 12. It allows you to define up to three non-energy input materials and three byproducts. Each element is added by first defining it using the drop-down menus and data entry fields, then clicking the Add button.

This sub-section requires fewer user choices than the Energy Feedstocks, Utilities, and Byproducts function. You do not need to select price tables; prices are automatically drawn from the lists on the Non-Energy Material Prices worksheet, or you can enter your own price by clicking the Enter Price button.

The Byproduct check box allows you to switch between materials consumed as process inputs (which incur costs) and materials produced as byproducts (which produce income/credits). When the box is unchecked, the material in the drop-down menu (cooling water, demineralized water, etc.) is labeled as a feed or utility, and the number you input is usage per kilogram of hydrogen produced for sale. When the box is checked, the material in the drop-down menu is labeled as a byproduct, and the number you input is production per kilogram of hydrogen.

You can add materials to the drop-down menu simply by going to the Non-Energy Material Prices worksheet and adding information for the new material in the rows underneath the existing information. See Non-Energy Material Prices Worksheet on page 40 for an illustration. This is also where you can modify the material prices if desired.

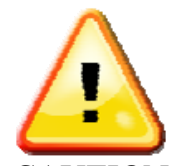

CAUTION
When deleting entries, you must use the Delete button. Do not delete the rows using Excel's delete functionality. Also, be careful to choose the correct item from the Delete drop-down menu within the H2A Toolkit. It can delete not only the other materials and byproducts selected in this sub-section, but also the energy feedstocks, utilities, and byproducts selected previously (see page 12).

Advanced users can take advantage of a shortcut in this section by typing values directly into certain Excel cells instead of using the model's Add and Delete functions every time. This is done in a fashion similar to that in the Energy Feedstocks, Utilities, and Byproducts section-see page 14 for instructions.

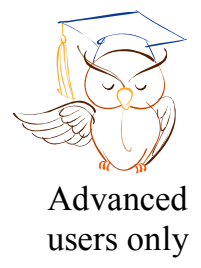


Other Materials and Byproducts (Input_Sheet_Template Worksheet)

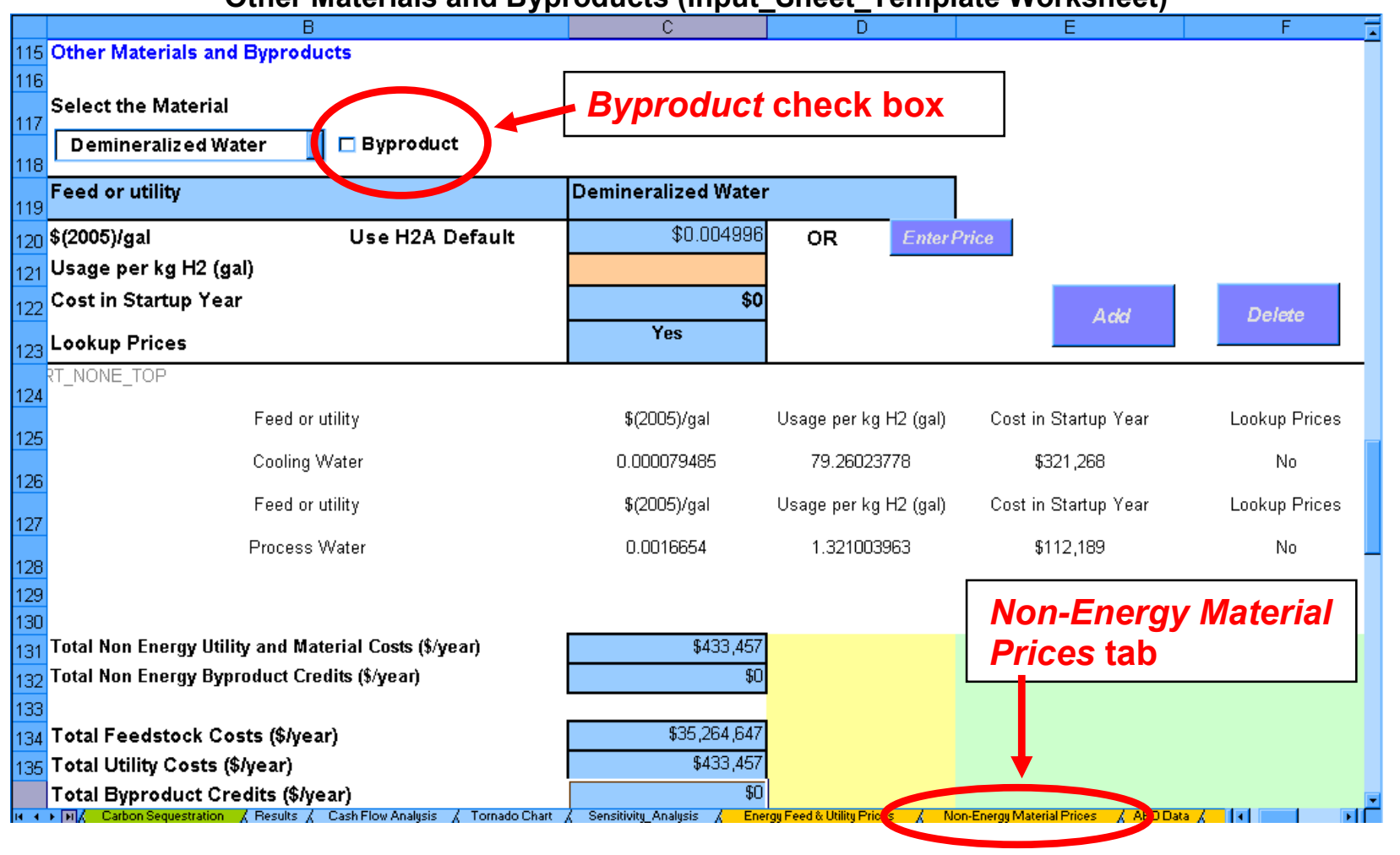

\section{Other Variable Operating Costs}

This sub-section defines additional variable operating costs. Fill in the appropriate input (orange) cells. The factor you enter in the field Total Unplanned Replacement Capital Cost Factor is transferred to the Replacement Costs worksheet (see page 18), which calculates replacement costs based on this factor and the value for total depreciable capital costs (see Capital Costs, page 14). Clicking the Enter Specific Costs button takes you to the Replacement Costs worksheet, where you can specify additional replacement costs.

For the central model, the field CO2 sequestration O\&M costs and credits is filled in automatically if you linked to the Carbon Sequestration worksheet in the Capital Costs section (see page 14). For the forecourt model, the field Refueling Station O\&M costs shows a value of zero if you linked to the Refueling Station worksheet in the Capital Costs section (see page 14). Note, these O\&M costs are not actually zero; rather, a separate cash flow analysis is performed for the refueling station (compression, storage, and dispensing), and the results are presented in a separate column in the Results worksheet.

Once you have entered all the information you want to enter, scroll to the top of the Input_Sheet_Template worksheet and click the Calculate Cost button. This sends you to the Results worksheet, which displays results as illustrated under Quick Start: Performing Simple Cost Analyses (page 3). 


\section{Replacement Costs Worksheet}

The Replacement Costs worksheet is the source of replacement cost information for the cash flow analysis calculations. It accounts for planned and unplanned replacement costs.

Enter planned
replacement
costs in
reference year
dollars-do not
inflate.

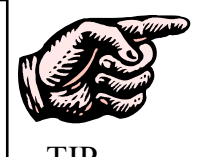

TIP
Enter planned replacement costs (in reference year \$) for each year in the Specified Yearly Replacement Costs column. The values in the Unplanned Replacement Costs column are calculated automatically in the following way:

1) The Total Unplanned Replacement Capital Cost Factor you entered in the Other Variable Operating Costs sub-section of the Input_Sheet_Template worksheet (see page 17) is automatically imported into the Replacement Costs worksheet (in the uppermost blue cell; see screen capture below). Clicking the Input Sheet button sends you directly to the relevant cost factor cell in the Input_Sheet_Template worksheet.

2) This cost factor is multiplied times the Total Depreciable Capital Costs value from the Input_Sheet_Template worksheet (see page 14); the result is automatically entered for each year in the Unplanned Replacement Costs column.

The inflation-adjusted sum of the specified (i.e., planned) and unplanned replacement costs is automatically entered into the Total Yearly Replacement Costs column. When finished, click the Input Sheet button to return to the Input_Sheet_Template worksheet.

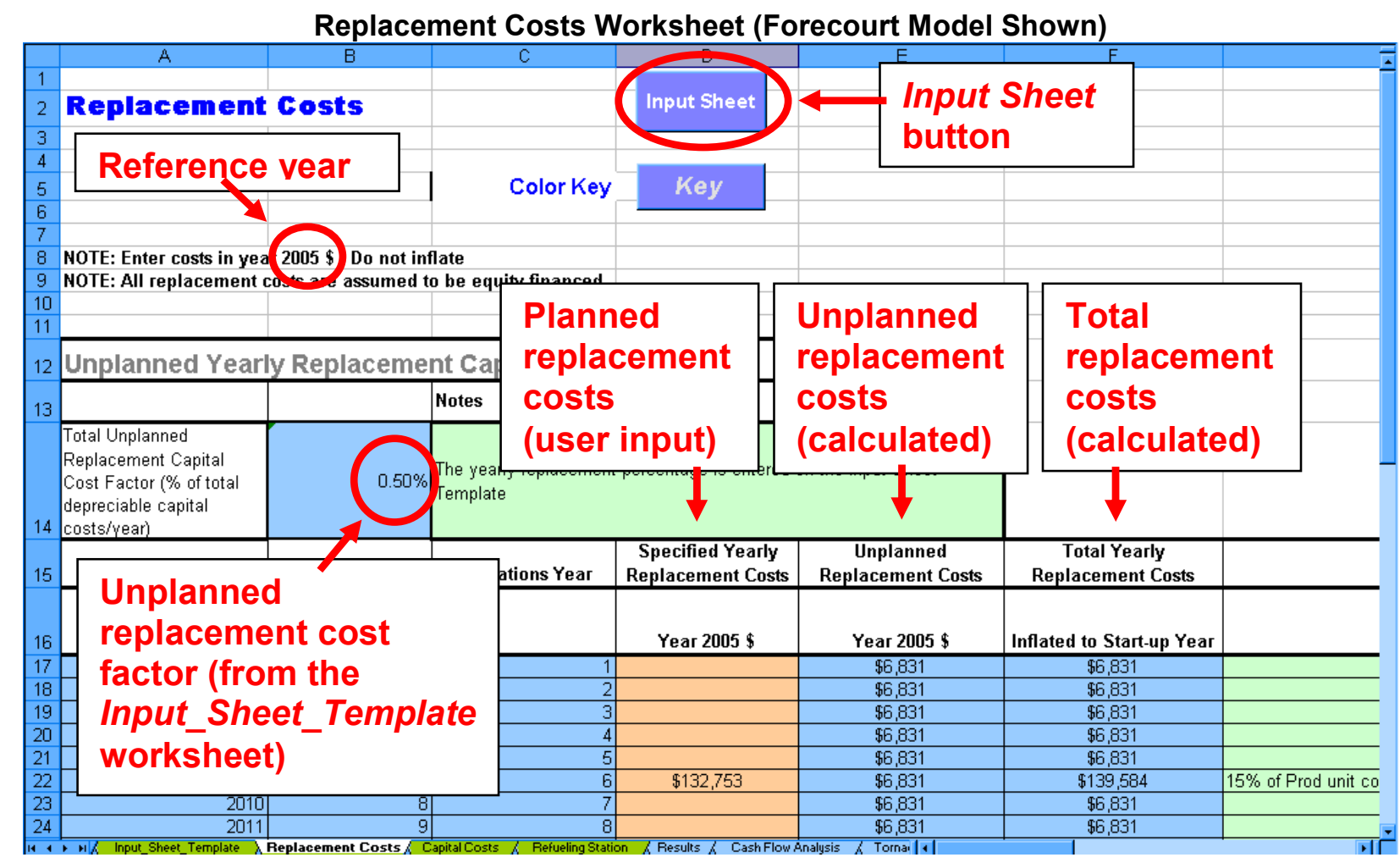




\section{Capital Costs Worksheet}

The Capital Costs worksheet accepts inputs for individual capital costs and calculates total direct capital cost. This total direct capital cost can then be imported into the Capital Costs section of the Input_Sheet_Template worksheet (see page 14). For the central model, this is the direct capital cost of the production equipment not including carbon sequestration equipment (see page 23 for carbon sequestration calculations). For the forecourt model, it is the direct capital cost of the production unit plus compression, storage, and dispensing if you choose to enter these costs using this worksheet; see page 25 for instructions on calculating optimal compression, storage, and dispensing costs using the Refueling Station worksheet.

Activate the Capital Costs worksheet by clicking the Link to Detail Sheet button next to the H2A Total Direct Capital Cost (for the central model) or H2A Production Process Total Direct Capital Cost (for the forecourt model) field in the Capital Costs section of the Input_Sheet_Template worksheet. Enter the names of capital equipment items in the column Major pieces/systems of equipment. Enter uninstalled costs for each item in the column Baseline Uninstalled Costs. Under the column Installation Cost Factor, enter values by which the uninstalled costs of each item will be multiplied to give installed costs. The model automatically calculates total installed direct capital cost in the Baseline Installed Costs column. When you are finished inputting values, click the Input Sheet button at top to return to the Input_Sheet_Template worksheet, where the total capital cost will appear; the screen captures below show the linkage.

\section{Capital Costs Worksheet (Central Model Shown)}

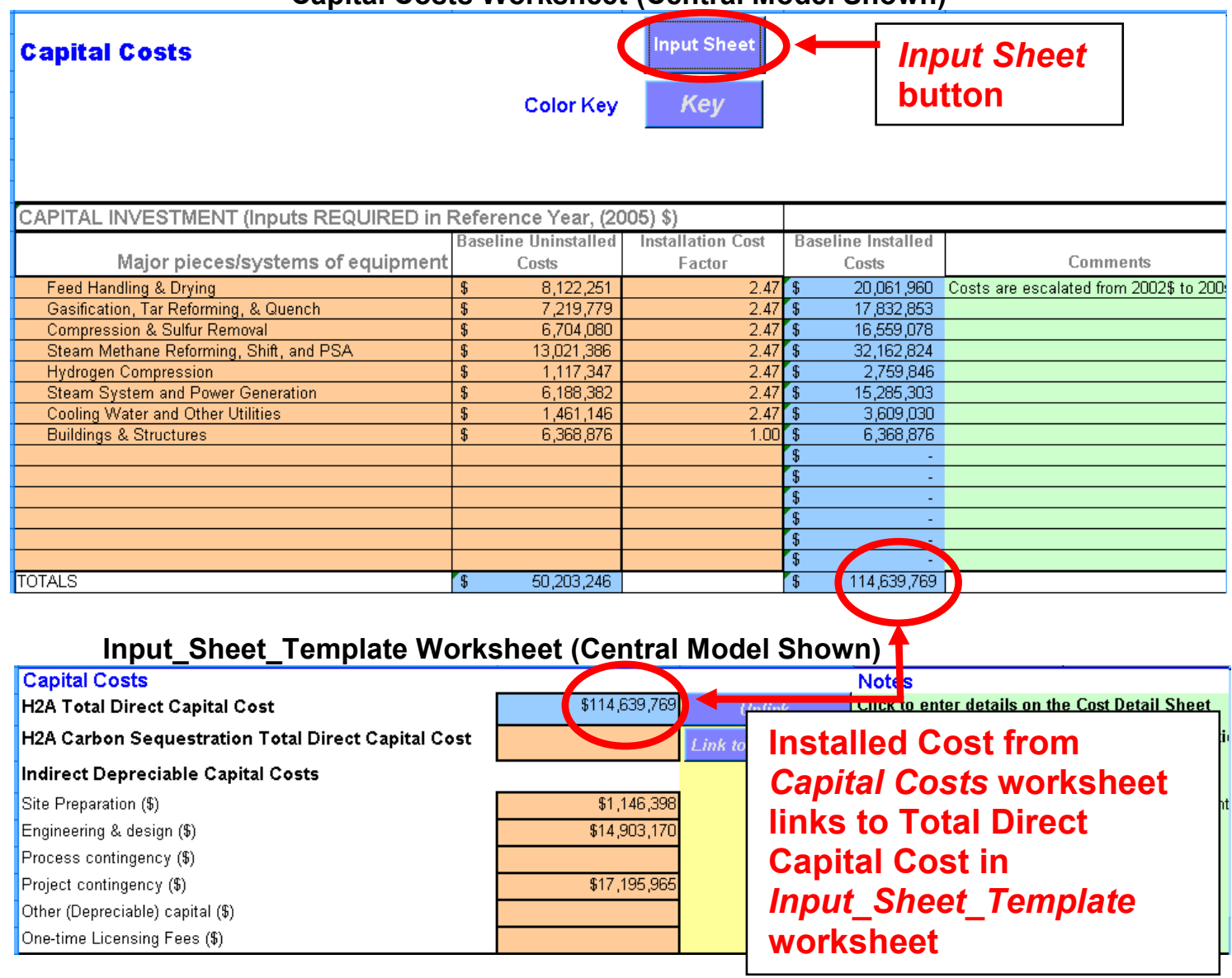




\section{Plant Scaling Worksheet}

The H2A Model is designed to determine the levelized cost of hydrogen from a facility with a specific hydrogen production capacity. Similarly, established H2A production technology cases model facilities with specific production capacities. The Plant Scaling worksheet makes it easy to analyze facilities with different production capacities. Complete the following steps in the order shown:

\section{1) Set Baseline Plant Values (Input_Sheet_Template Worksheet \& H2A Toolkit)}

Baseline plant values are imported into the Plant Scaling worksheet from the Input_Sheet_Template worksheet, so the first step is to fill out the Input_Sheet_Template worksheet completely (see page 10). Once you have finished, open the ${ }^{-}$2A Toolkit (by clicking the Toolkit button at the top of the Input_Sheet_Template worksheet) and click the Set up Plant Scaling button. Clicking this button exports values from the Input_Sheet_Template worksheet into the Plant Scaling worksheet (the Plant Scaling worksheet tab appears when you click the button), specifically into the first cell (Baseline Design Capacity) in the Plant Scaling Factors section and the baseline value cells within the Capital Investment and Plant Scaling Method sections.

\section{2) Establish Scaling Parameters (Plant Scaling Worksheet)}

After you click the Set up Plant Scaling button and answer OK to the query, you are sent to the Plant Scaling worksheet, where you establish your scaling parameters. In the Plant Scaling Factors section, accept the Default Scaling Factor Exponent or enter a new one.

Changing the Scaling Factor Exponent changes how the cost of each item of capital equipment varies in relation to the Scale Ratio (the ratio of new design capacity to baseline design capacity) as follows:

$$
\text { Scaled Cost }=\text { Baseline Cost } \times \text { Scale Ratio }{ }^{\text {Scaling Factor Exponent }}
$$

For example, a Scaling Factor Exponent of 1.0 means the cost of the equipment increases by the same ratio as the increase in plant capacity. Scaling Factor Exponents are typically 1.0 or less. If values for individual pieces of equipment are entered in the column Scaling Factor Exponent within the Capital Investment section, those values are used in the scaling calculations. If a value is not present in this column for a given item, the Default Scaling Factor Exponent in the Plant Scaling Factors section is used.

The Lower Limit for Scaling Capacity and Upper Limit for Scaling Capacity fields define the capacity range within which the scaling you are defining is valid. The model will alert you when you click the Calculate Cost button (in step 3, see below) if you attempt to scale your plant capacity outside the range you specify. 
Plant Scaling Worksheet: Plant Scaling Factors and Capital Investment Sections

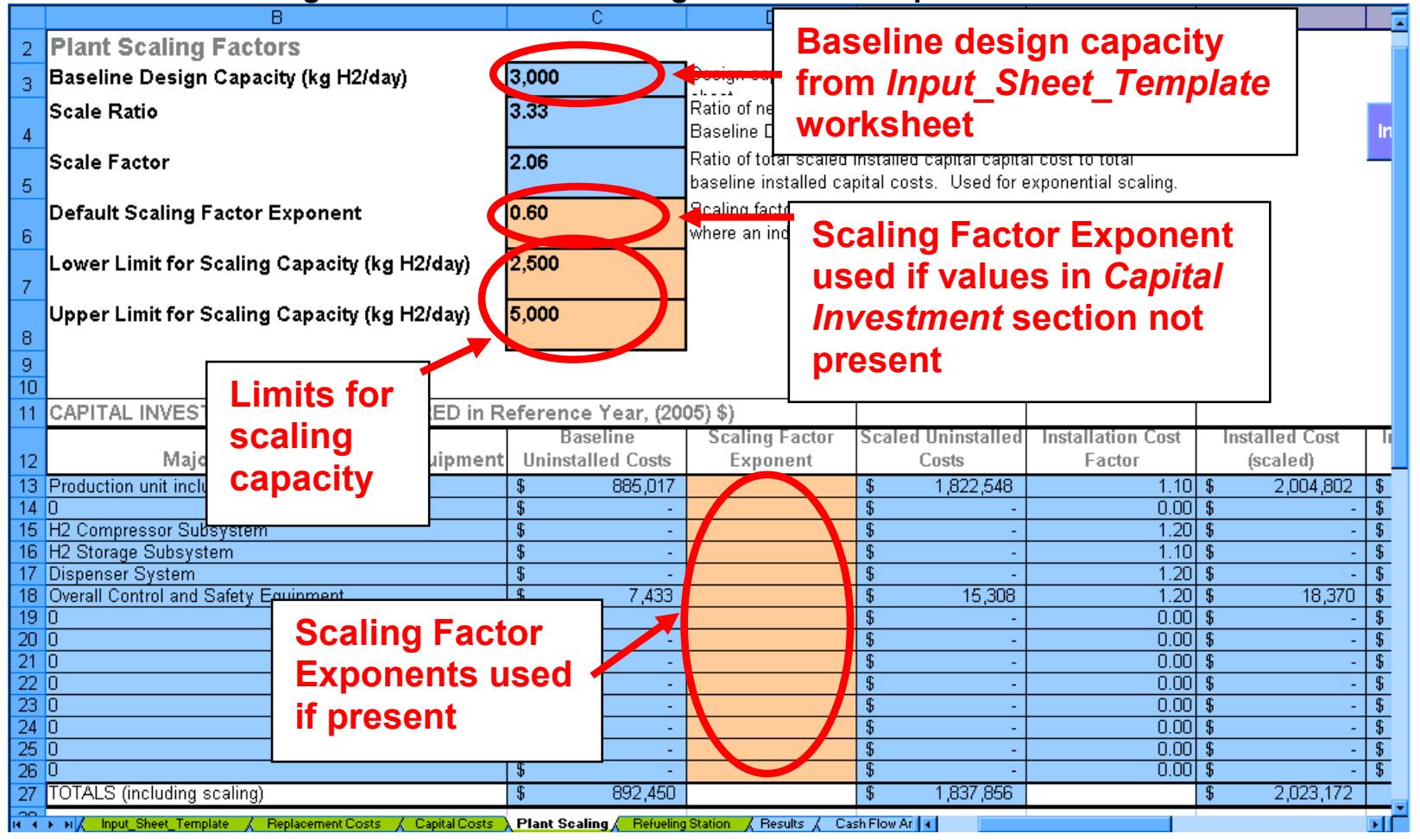

After you have added Scaling Factor Exponents to the Plant Scaling Factors and Capital Investment sections, go down to the next section to define scaling parameters for indirect and non-depreciable capital costs and operating costs. The baseline values for these items (Engineering \& Design, Site Preparation, etc.) were imported from the Input_Sheet_Template worksheet. Note that, in the forecourt model, the variables used in the Refueling Station worksheet are scaled within that worksheet and, therefore, do not appear in the Plant Scaling worksheet.

For each item in the table, choose one of the following scaling methods from the drop-down menus in the Select Method column:

- Use Scale Ratio-uses the scale ratio to scale the item cost in relation to plant capacity (i.e., linearly) (Scaled Value $=$ Baseline Value $\times$ Scale Ratio)

- Use Scale Factor-uses the scale factor (the ratio of total scaled installed capital cost to total baseline installed capital cost) to scale the item cost in relation to plant capital cost (i.e., scale with capital costs) (Scaled Value $=$ Baseline Value $\times$ Scale Factor)

- Use Baseline Value —uses the shown baseline value with no scaling

- Skip-skips the value, does not change the cell value or equation.

Once you have selected scaling methods for all items, click the Finish Scaling button. 


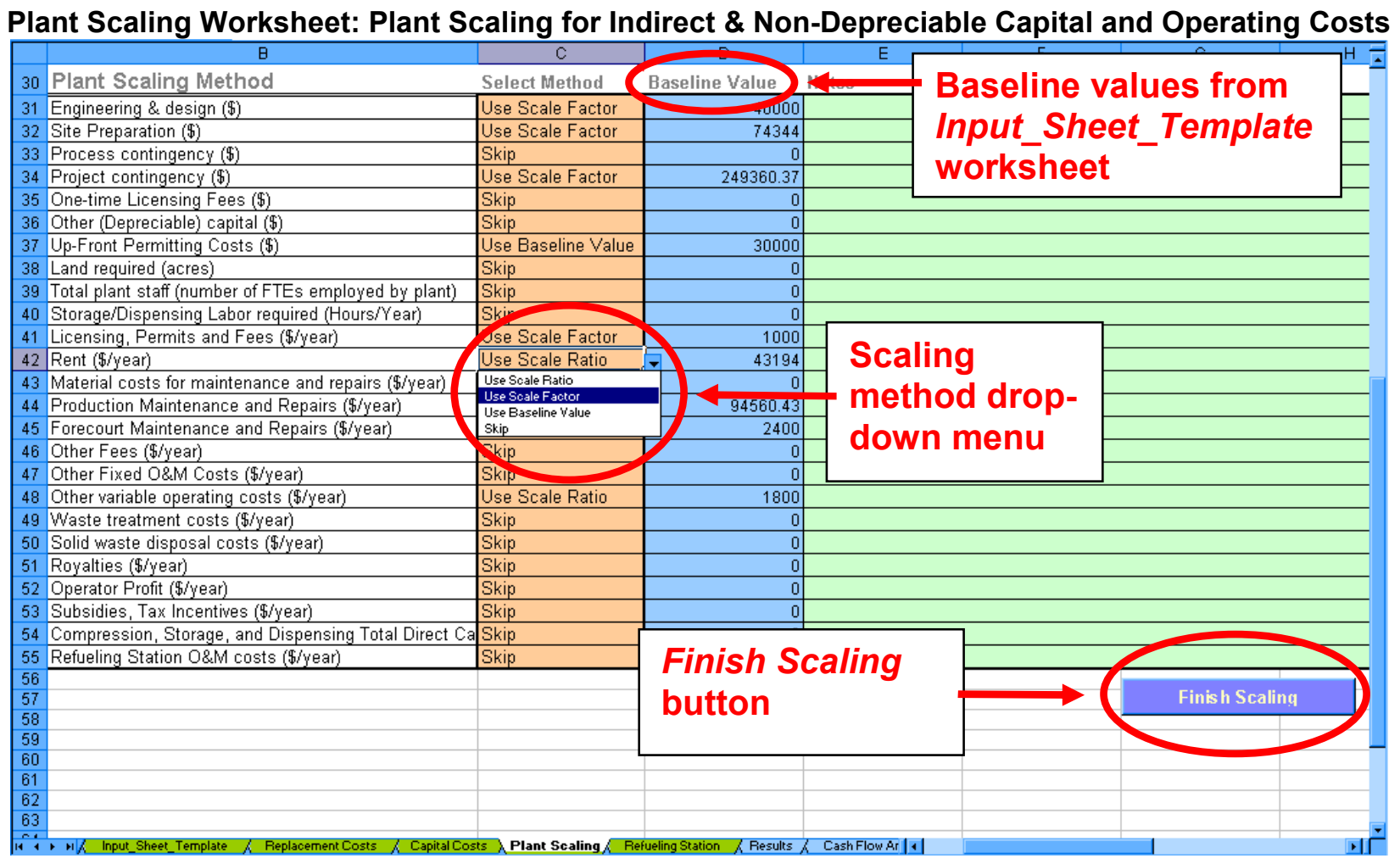

\section{3) Set Scaled Plant Capacity (Input_Sheet_Template Worksheet)}

After you click the Finish Scaling button, you are sent back to the Input_Sheet_Template worksheet. Enter a value for your new plant's design capacity in the Technical Operating Parameters and Specifications section (see screen capture below). If this value is larger than the baseline design capacity, the scale factor and ratio will be greater than 1.00 . If it is smaller, the scale factor and ratio will be less than 1.00. Once you have entered this value, the cost values in the Input_Sheet_Template and Plant Scaling worksheets are scaled automatically according to the parameters you set in the Plant Scaling worksheet (step 2 above). Click the Calculate Cost button to calculate the new hydrogen cost.

\section{Input_Sheet_Template Worksheet}

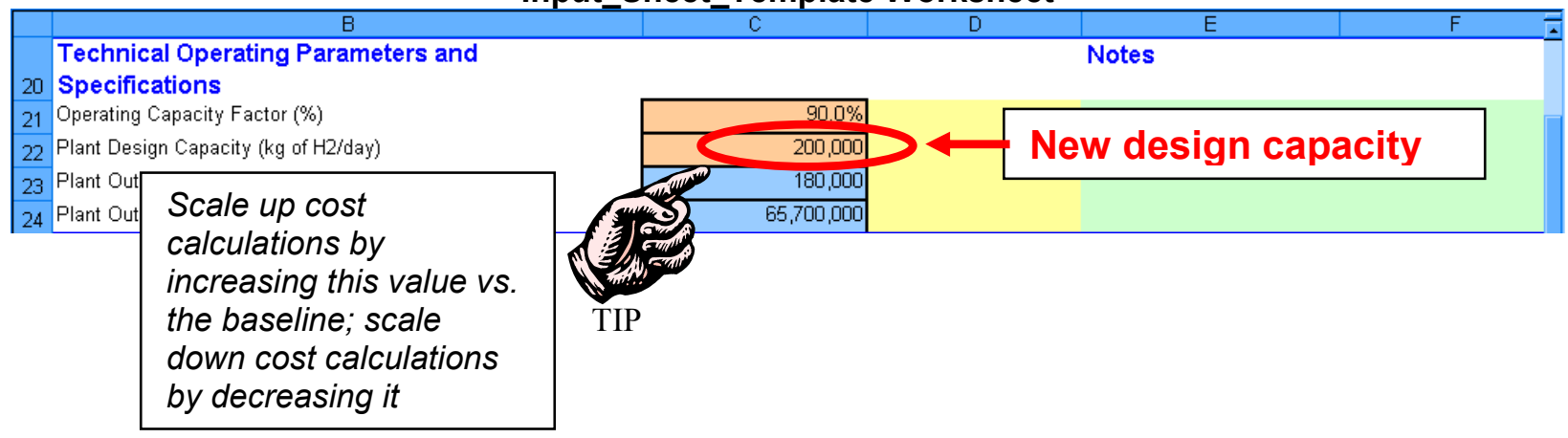

\section{Turning Off Plant Scaling}

To turn off plant scaling, click the Toolkit button at the top of the Input_Sheet_Template worksheet, and click the Turn Plant Scaling Off button within the H2A Toolkit. Your plant characteristics will revert to the previously established baseline values. 


\section{Carbon Sequestration Worksheet (Central Model Only)}

This worksheet is the source of values for carbon sequestration capital, operating, and electrical costs as well as carbon sequestration efficiency (proportion of carbon emissions captured from hydrogen production feedstocks) and energy use. It calculates costs for $\mathrm{CO}_{2}$ compression, transportation to the sequestration site, and injection. Costs for $\mathrm{CO}_{2}$ capture are assumed to be included in the production facility's capital and operating costs and are not included in this worksheet. Further, the worksheet only covers $\mathrm{CO}_{2}$ emissions from the hydrogen production feedstocks, not $\mathrm{CO}_{2}$ emissions from fuels used as utilities (e.g., natural gas used in a heater).

Before completing the Carbon Sequestration worksheet, specify all feedstocks and utilities in the Input_Sheet_Template worksheet (see Energy Feedstocks, Utilities, and Byproducts, page 12). After you have specified the feedstocks and utilities, activate the Carbon Sequestration worksheet by clicking the Link to Detail Sheet button next to the H2A Carbon Sequestration Total Direct Capital Cost field in the Capital Costs section of the Input_Sheet_Template worksheet (see screen capture below).

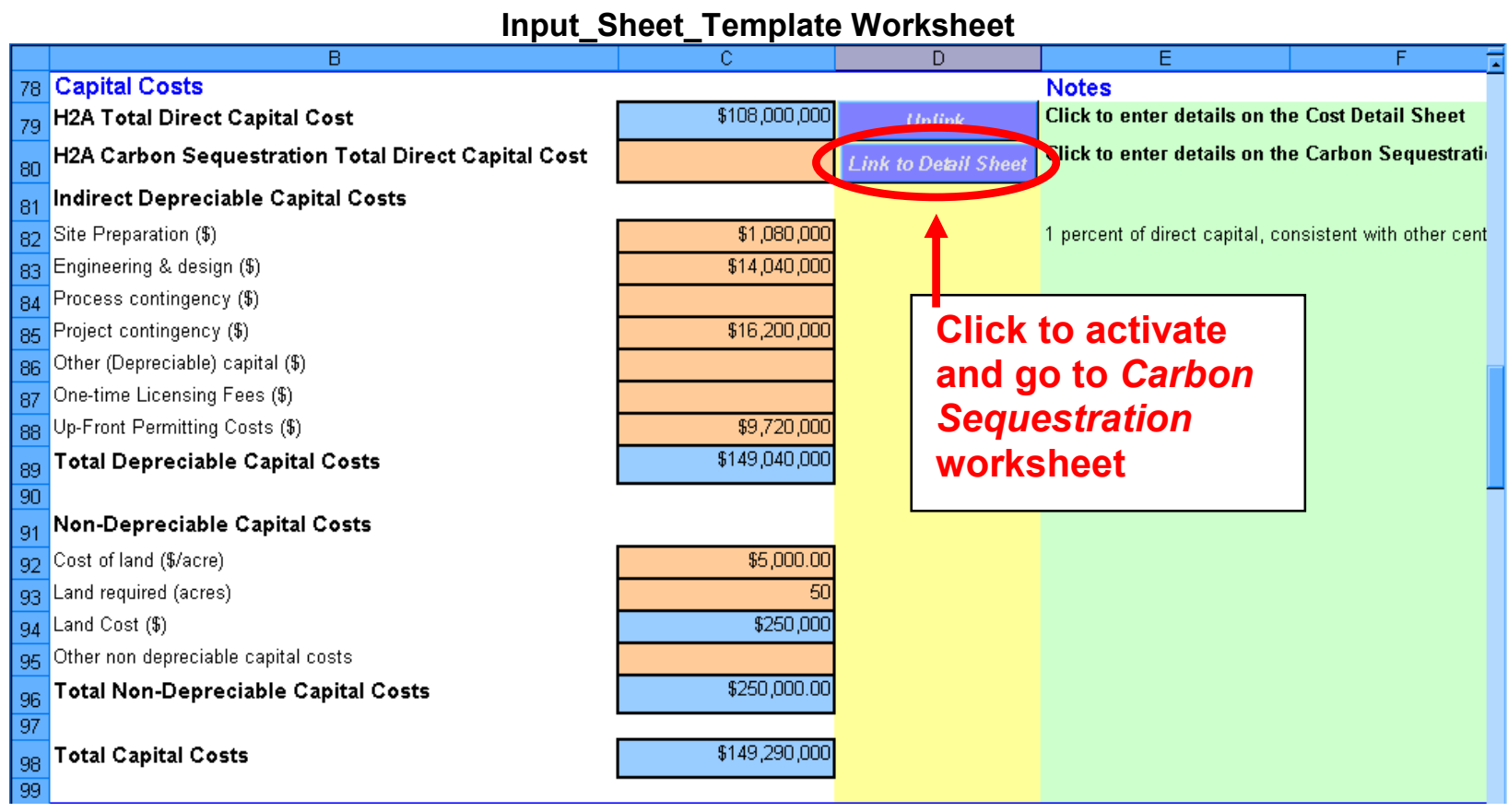

Clicking the Link to Detail Sheet button sends you to the Carbon Sequestration worksheet. At the top of the worksheet are notes, three self-explanatory buttons (see page 10 for a description of the Use Default Values functionality), and links to tables within the worksheet. Of the four tables, you will input values only into Carbon Sequestration Input Values; complete or accept the default values for the orange-shaded fields. The other tables display the calculations and results based on your inputs. When you are finished inputting values, click the Input Sheet button at top to return to the Input_Sheet_Template worksheet.

The cost results (seen in the Summary of Output Values table) are the source of carbon sequestration direct capital costs and $\mathrm{CO}_{2}$ sequestration operation and maintenance costs 
and credits within the Input_Sheet_Template worksheet as well as carbon sequestration electricity use, which is used in the cash flow analysis-see the schematic below. The calculations also feed the carbon sequestration cost, energy use, and emissions results within the Results worksheet.

See Appendix 1 (page 49) for more information about the carbon sequestration inputs, outputs, and calculations used in this worksheet plus references for further reading.

\section{Schematic of Cost Outputs from Carbon Sequestration Worksheet to Other H2A Worksheets}

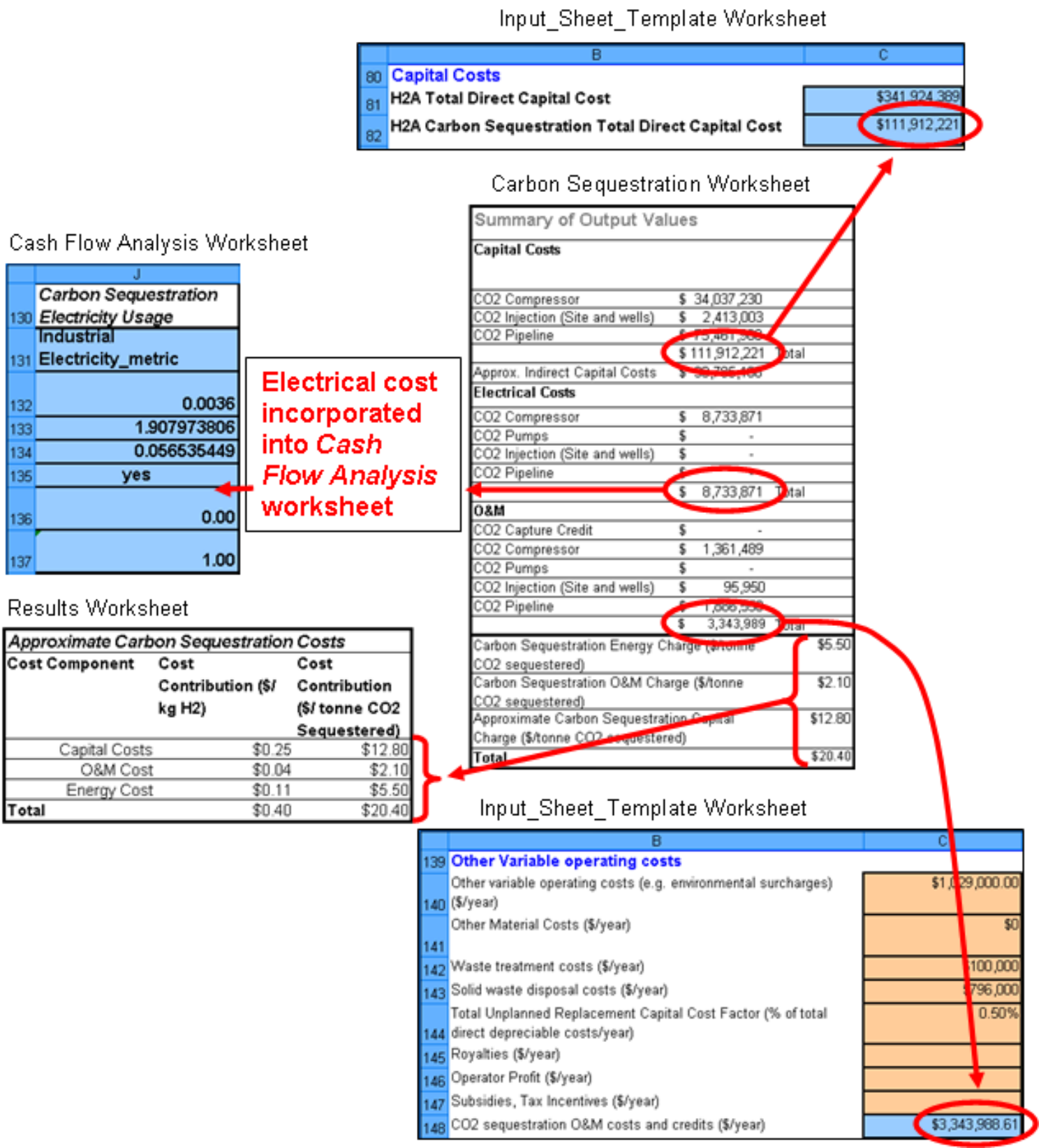




\section{Refueling Station Worksheet (Forecourt Model Only)}

This extensive worksheet calculates the optimal cost for compressing, storing, and dispensing hydrogen at a refueling station with a convenience store. Costs are calculated per kilogram of hydrogen dispensed. The average capacity can be varied up to $6,000 \mathrm{~kg} / \mathrm{day}$. Because the capital, fixed, and operating costs vary along with the varying capacity, none of the variables included in this worksheet appear in the Plant Scaling worksheet.

Activate the Refueling Station worksheet by clicking the Link to Detail Sheet button next to the H2A Compression, Storage, and Dispensing Total Direct Capital Cost field in the Capital Costs section of the Input_Sheet_Template worksheet (see screen capture below). When you have linked to the Refueling Station worksheet, the capital and operating costs for the model's cash flow analysis are calculated on that worksheet; thus, the corresponding fields within the Capital Costs and Other Variable Operating Costs sections of the Input_Sheet_Template worksheet show as zero.

Input_Sheet_Template Worksheet

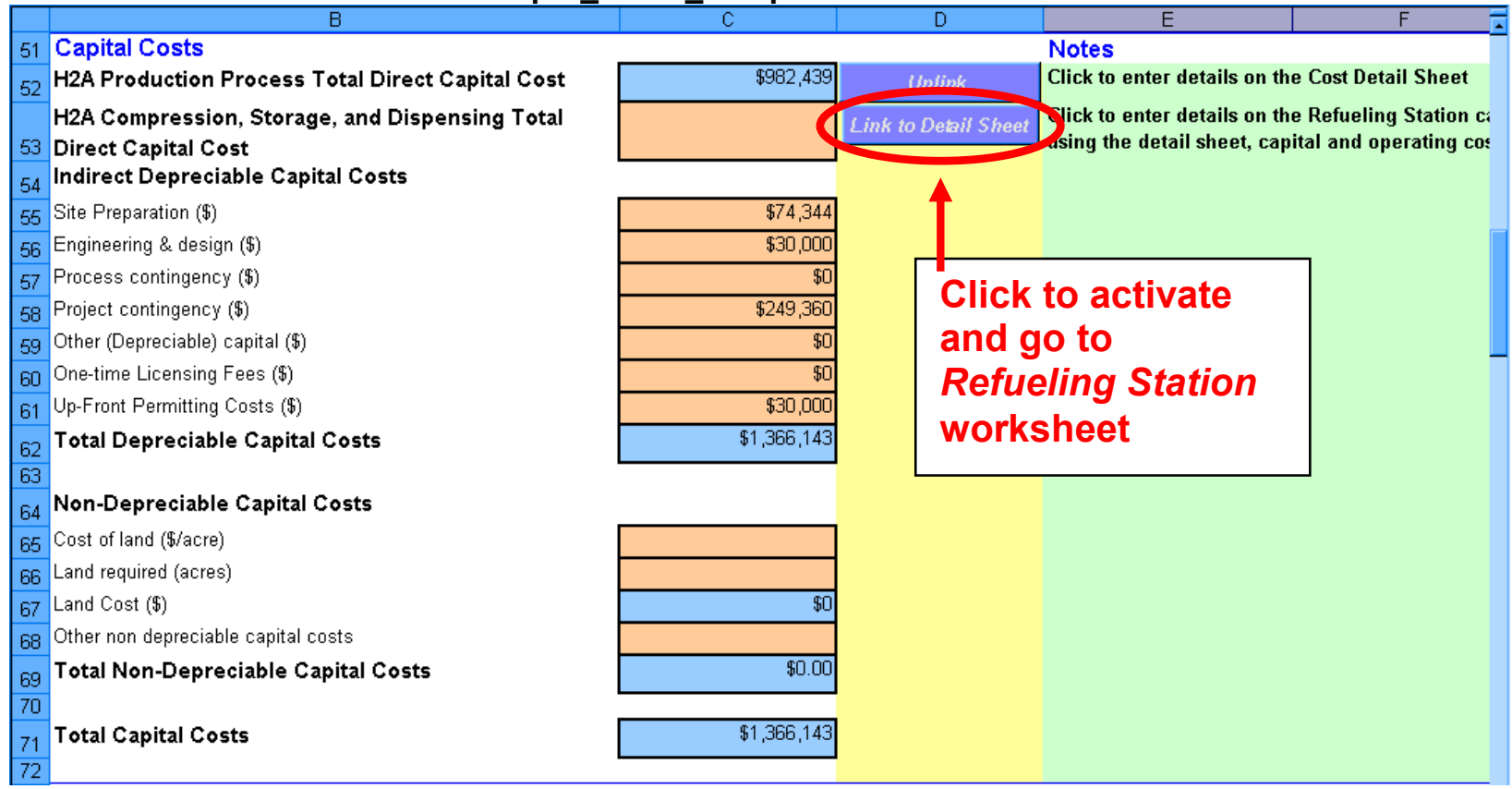

Clicking the Link to Detail Sheet button sends you to the Refueling Station worksheet. At the top of the worksheet are notes, three self-explanatory buttons (see page 10 for a description of the Use Default Values functionality), and links to tables within the worksheet. The following six tables are designed to accept user inputs; complete or accept the default values for the orange-shaded fields:

- Forecourt Specific Economic Assumptions

- Refueling Station Design Inputs

- Refueling Station Scenario Inputs

- CAPITAL INVESTMENT - Equipment Costs

- Other Compression, Storage, Dispensing Capital Costs

- Compression, Storage, Dispensing O\&M Costs. 
The other tables display the calculations and results based on your inputs. When you are finished inputting values, click the Input Sheet button at top to return to the Input_Sheet_Template worksheet.

The Refueling Station cost results (displayed in the Calculation Outputs table) are transferred to the Results worksheet-see the schematic below. The Refueling Station worksheet also provides the values needed to calculate energy use and emissions due to compression, storage, and dispensing.

See Appendix 2 (page 56) for more information about the refueling station inputs, outputs, and calculations used in this worksheet plus references for further reading.

\begin{tabular}{|c|c|c|c|c|c|c|c|c|}
\hline \multicolumn{9}{|c|}{ Refueling Station Worksheet } \\
\hline \multicolumn{2}{|l|}{ Results - Cost Breakdown per kg H2 } & Compressor & & torage & Dispenser & Rema & ainder of Station & Total \\
\hline \multicolumn{2}{|c|}{$\begin{array}{l}\text { Gaseous Refueling Station Portion of the Delivered Real } \\
\text { Levelized Hydrogen Cost ( } \$ 2005) / \mathrm{kg} \text { of Hydrogen) }\end{array}$} & $\$ 0.84$ & & $\$ 0.93$ & $\$ 0.03$ & & $\$ 0.11$ & $\$ 1.93$ \\
\hline \multicolumn{2}{|c|}{$\begin{array}{l}\text { Capital Cost Contribution to the Gaseous Refueling Station } \\
\text { Portion of the Delivered Real Levelized Hydrogen Cost } \\
(\$(2005) / \mathrm{kg} \text { of Hydrogen) }\end{array}$} & $\$ 0.50$ & & $\$ 0.72$ & $\$ 0.03$ & & $\$ 0.04$ & $\$ 1.29$ \\
\hline \multicolumn{2}{|c|}{$\begin{array}{l}\text { Energy/Fuel Contribution to the Gaseous Refueling Station } \\
\text { Portion of the Delivered Real Levelized Hydrogen Cost } \\
(\$(2005) / \mathrm{kg} \text { of Hydrogen) }\end{array}$} & $\$ 0.16$ & & $\$ 0.00$ & $\$ 0.00$ & & $\$ 0.00$ & $\$ 0.16$ \\
\hline \multicolumn{2}{|c|}{$\begin{array}{l}\text { Other Cost Contribution to the Gaseous Refueling Station } \\
\text { Portion of the Delivered Real Levelized Hydrogen Cost } \\
(\$(2005) / \mathrm{kg} \text { of Hydrogen) }\end{array}$} & $\$ 0.18$ & & $\$ 0.21$ & $\$ 0.01$ & & $\$ 0.07$ & $\$ 0.48$ \\
\hline \multicolumn{2}{|l|}{ Results - Capital and Operating Costs } & Compressor & & torage & Dispenser & Rema & ainder of Stati $n$ & Total \\
\hline \multicolumn{2}{|l|}{ Total installed capital cost } & $\$ 1,005,738$ & & 050,294 & $\$ 53,760$ & & $\$ 203,249$ & $\begin{array}{c}\$ 3,313,041 \\
\$ 73,679 \\
\$ 220,622 \\
\end{array}$ \\
\hline \multicolumn{9}{|l|}{ Results - Other CSD Parameters } \\
\hline \multicolumn{2}{|l|}{ CSD Mass Efficiency ( $\mathrm{H} 2$ out $/ \mathrm{H} 2 \mathrm{in})$} & $99.5 \%$ & & & & & & \\
\hline \multicolumn{2}{|l|}{ CSD System Energy Use (MJ/kg of $\mathrm{H} 2$ out) } & 7.083 & & & & & & \\
\hline \multicolumn{2}{|l|}{ CSD System Energy Use ( $\mathrm{kWh} / \mathrm{kg}$ of $\mathrm{H} 2$ out) } & 1.967 & & & & & & \\
\hline \multicolumn{2}{|c|}{$\begin{array}{l}\text { CSD System Energy Efficiency, LHV (\%, H2 out/( } \mathrm{H} 2 \text { in + } \\
\text { Energy/Fuel Use)) }\end{array}$} & $94.0 \%$ & & & & & & \\
\hline \multicolumn{2}{|c|}{ CSD labor requirement (FTE) } & 2.0 & & & & & & \\
\hline \multicolumn{2}{|l|}{ Total Storage Volume $(\mathrm{kg} \mathrm{H} 2)$} & 1741 & & & & & & \\
\hline \multicolumn{2}{|l|}{ CSD Land Area $\left(\mathrm{m}^{2}\right)$} & 1316 & & & & & & \\
\hline \multicolumn{9}{|c|}{ Results Worksheet } \\
\hline \multicolumn{4}{|c|}{ Specific Item Cost Calculation } & \multicolumn{3}{|c|}{$\begin{array}{l}\text { Total Cost of } \\
\text { Delivered Hydrogen }\end{array}$} & $\$ 3.5$ & \\
\hline Cost Component & $\begin{array}{r}\text { Hydrog } \\
\text { Co }\end{array}$ & $\begin{array}{l}\text { n Production } \\
\text { ribution }(\$ / \mathbf{k g})\end{array}$ & & $\begin{array}{r}\text { Com } \\
\text { and } \\
\text { Cor }\end{array}$ & $\begin{array}{l}\text { ession, Sto } \\
\text { ispensing } \\
\text { ibution }(\$ / 1\end{array}$ & $\begin{array}{l}\text { age, } \\
\text { cost } \\
\text { g) })^{*}\end{array}$ & Percentage o & f H2 Cost \\
\hline Capital Costs & & & 315 & & & 1.291 & & $45.69 \%$ \\
\hline Decommissioning Costs & & & 000 & & & & & $0.00 \%$ \\
\hline Fixed O\&M & & & 126 & & & 0.475 & & $17.11 \%$ \\
\hline Feedstock Costs & & & 959 & & & & $\sqrt{2}$ & $27.27 \%$ \\
\hline Other Raw Material Costs & & & 000 & & & & $>$ & $0.00 \%$ \\
\hline Byproduct Credits & & & 000 & & & & & $0.00 \%$ \\
\hline $\begin{array}{r}\text { Other Variable Costs (including } \\
\text { utilities) }\end{array}$ & & & 190 & & & 0.159 & & $4.51 \%$ \\
\hline Total & & & 591 & & & 1.925 & & \\
\hline
\end{tabular}




\section{H2A Toolkit}

The H2A Toolkit is not an Excel worksheet-it is a pop-up window accessed by clicking the Toolkit button at the top of the Input_Sheet_Template worksheet or by clicking the Delete buttons within the worksheet. The Toolkit performs a number of functions:

- Importing existing $\mathrm{H} 2 \mathrm{~A}$ cases

- Printing and exporting inputs and results

- Editing input parameters

- Setting up plant scaling

- Performing sensitivity analyses.

\section{H2A Toolkit}

\section{H2A Toolkit}

Import and Export Data

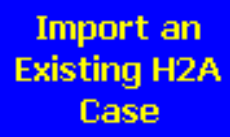

\section{-Editing}

-Delete Feed, Utility, and Byproduct Inputs

Select the type of input to delete

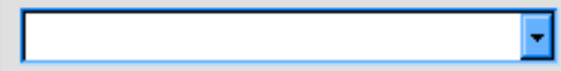

Delete

Analyses

\section{Importing Existing H2A Cases}

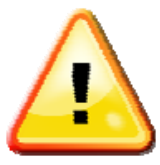

CAUTION
You can use the $H 2 A$ Toolkit to import technology cases that are stored in previous versions of the H2A Model into the new version of the model. In the Toolkit, click the Import an Existing H2A Case button. A window will pop up, which states, "The values in the current case will be deleted." If you have any 
information in the current file that you want to save, click Cancel and save your file to a new name before proceeding. If your file does not need to be saved, click OK. Another window will pop up stating, "Data may exist in the sheet(s) selected for deletion. To permanently delete the data, press Delete." Instead of clicking the Delete button, click the Cancel button to proceed.

Click OK on the next pop-up to select a case to import. Use the Browse window that appears to locate the technology case you want to import. Select the case and click OK. Values from the technology case you selected are automatically imported into the new model. During importation, the case you are importing data from will open, and a window will pop up asking if you want to save changes to it. Click the No button to close the case.

The model imports data by searching the technology case for variables present in the Import_Variable_List within the Lists worksheet (see page 47 for more information about the Lists worksheet). The model does not always find the target variables in this way; once the case is imported review the input fields and fill in missing values manually by referring to the old version of the technology case. Commonly missed values include Reference Year and several of the Indirect Depreciable Capital Costs within the Input_Sheet_Template worksheet and Specified Yearly Replacement Costs within the Replacement Costs worksheet. The detailed capital cost breakdown (Capital Costs worksheet) and information worksheets are not imported.

You must also manually add information to the Energy Feedstocks, Utilities, and Byproducts and Other Materials and Byproducts sections within the Input_Sheet_Template worksheet; the automatic importation function does not capture this information. The old version of the model draws from the same price tables as the new version, so this is a relatively easy process. See Energy Feedstocks, Utilities, and Byproducts (page 12) and Other Materials and Byproducts (page 16) for instructions on adding information to these sections.

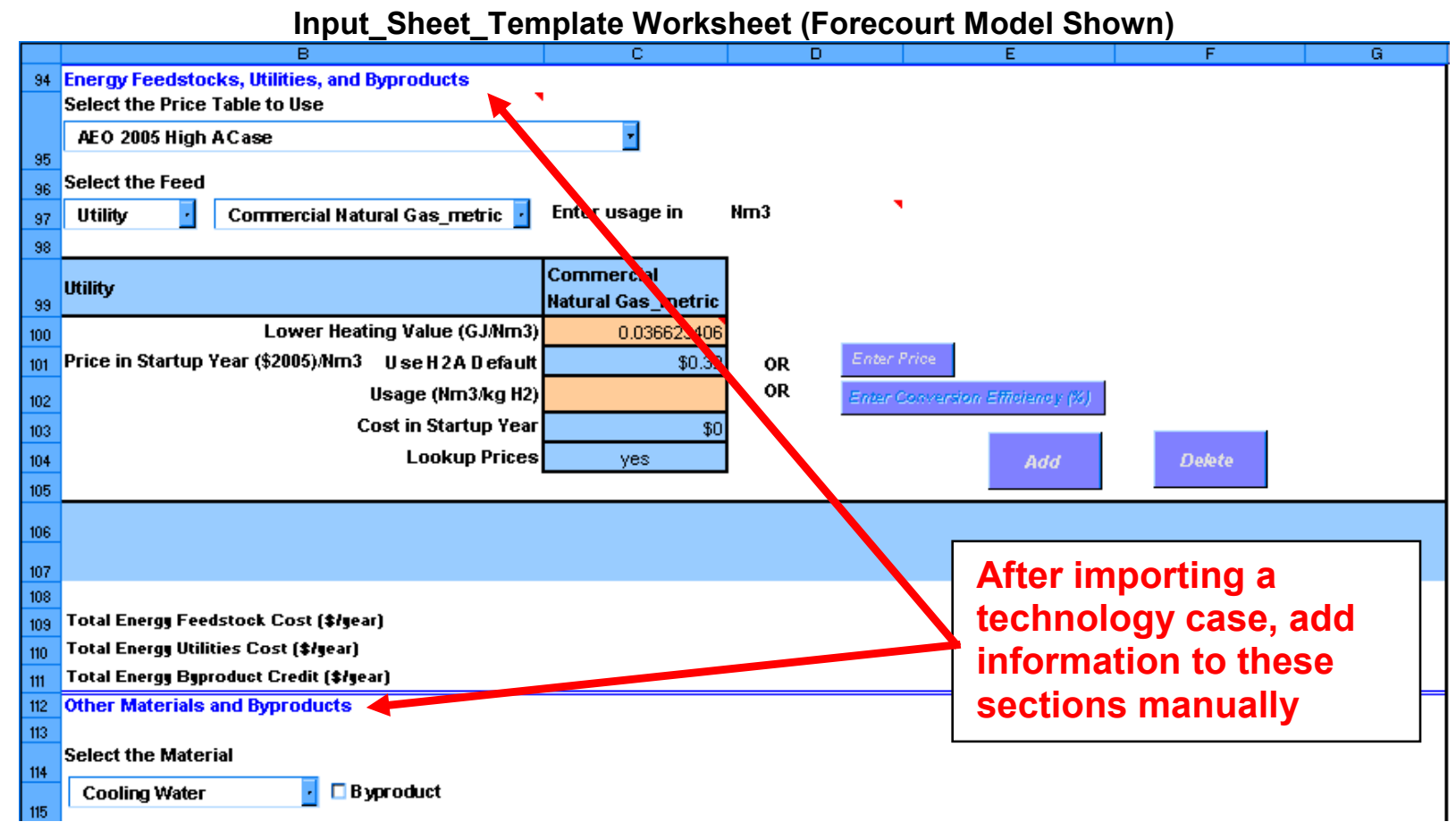




\section{Printing and Exporting Inputs and Results}

Clicking the Print Input Report and Print Result Report buttons automatically prints information from the Input_Sheet_Template and Results worksheets, respectively. Automatic printing does not work with all printers. If it does not work for you, simply go to the worksheet you would like to print, click File at the top of your Excel window, and then click Print.

You can also export the inputs and results from your analysis to an Excel file. Click the Export Data button. Click Yes in the pop-up window that asks if you want to save your file. After you save the file, it will close automatically. The resulting file contains input and result values in an easily importable format, which you can bring into other analysis models. You could also use the Importing an Existing Case function (see page 27) to import the values into another H2A Production Model file.

\section{Editing Input Parameters}

Two functions are available within the H2A Toolkit's Editing section: Delete Feed, Utility, and Byproduct Inputs and Set up Plant Scaling.

\section{Delete Feed, Utility, and Byproduct Inputs}

This function deletes items that have been added to the Energy Feedstocks, Utilities, and Byproducts and Other Materials and Byproducts sections within the Input_Sheet_Template worksheet (see pages 12 and 16). Use the drop-down menu under Editing to select the type of item you want to delete. Then click the Delete button. This deletes all items of the selected type. For example, if you had selected three energy byproducts, choosing Energy Byproduct from the drop-down menu and clicking the Delete button will delete all three.

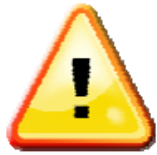

CAUTION

When deleting items, it is critical to use the Toolkit's Delete button. Do not delete the corresponding rows within the Input_Sheet_Template worksheet using Excel's delete function. Also, be careful to choose the correct item from the Delete drop-down menu. All items of the selected type are deleted within the Energy Feedstocks, Utilities, and Byproducts or Other Materials and Byproducts sections. Choosing "All" at the bottom of the drop-down menu deletes all energy and nonenergy feeds, utilities, and byproducts.

H2A Toolkit: Delete Feed, Utility, and Byproduct Inputs

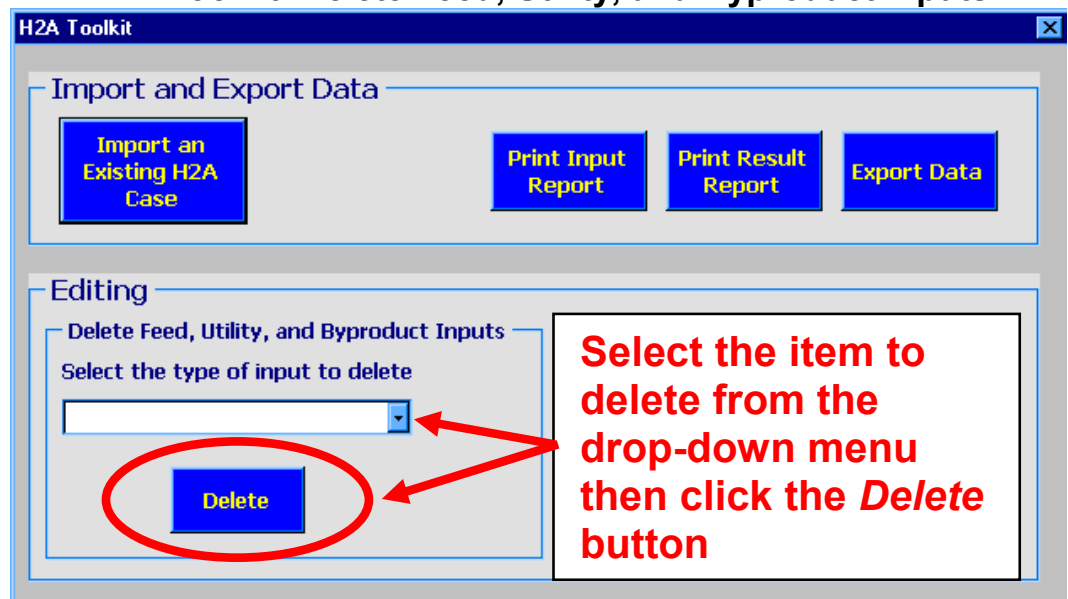




\section{Set up Plant Scaling}

The H2A Toolkit's Set up Plant Scaling button is part of the process that scales your capital and operating costs to smaller or larger plant sizes. Do not click this button except as part of the scaling process. See Plant Scaling Worksheet (page 20) for details.

\section{Performing Sensitivity Analyses}

To perform a sensitivity analysis - which helps you understand how sensitive the cost of hydrogen is to changes in key input variables-click the Sensitivity Analysis button in the $\mathrm{H} 2 \mathrm{~A}$ Toolkit. In the Sensitivity Analysis window, use the first drop-down menu to select a variable you will use for the analysis (only variables that have a value in the base case will appear in the drop-down menu). Highlighting the variable selects it and adds it to the second drop-down menu. With your variable now shown in the first line of the second drop-down menu, its value

It's not always obvious what will reduce vs. increase hydrogen price; if you get bad results

(e.g., a blank tornado chart), switch your "Reducing" \& "Increasing" values and try again. from the current case is displayed in the Value from Base Case field. Enter a value for Value Reducing Hydrogen Price and a value for Value Increasing Hydrogen Price. For example, for After-tax Real IRR with a base case value of 0.1 , you might enter 0.08 for the Value Reducing Hydrogen Price and 0.12 for the Value Increasing Hydrogen Price (see screen capture below). Repeat this process for up to 50 variables.

H2A Toolkit: Sensitivity Analysis Window

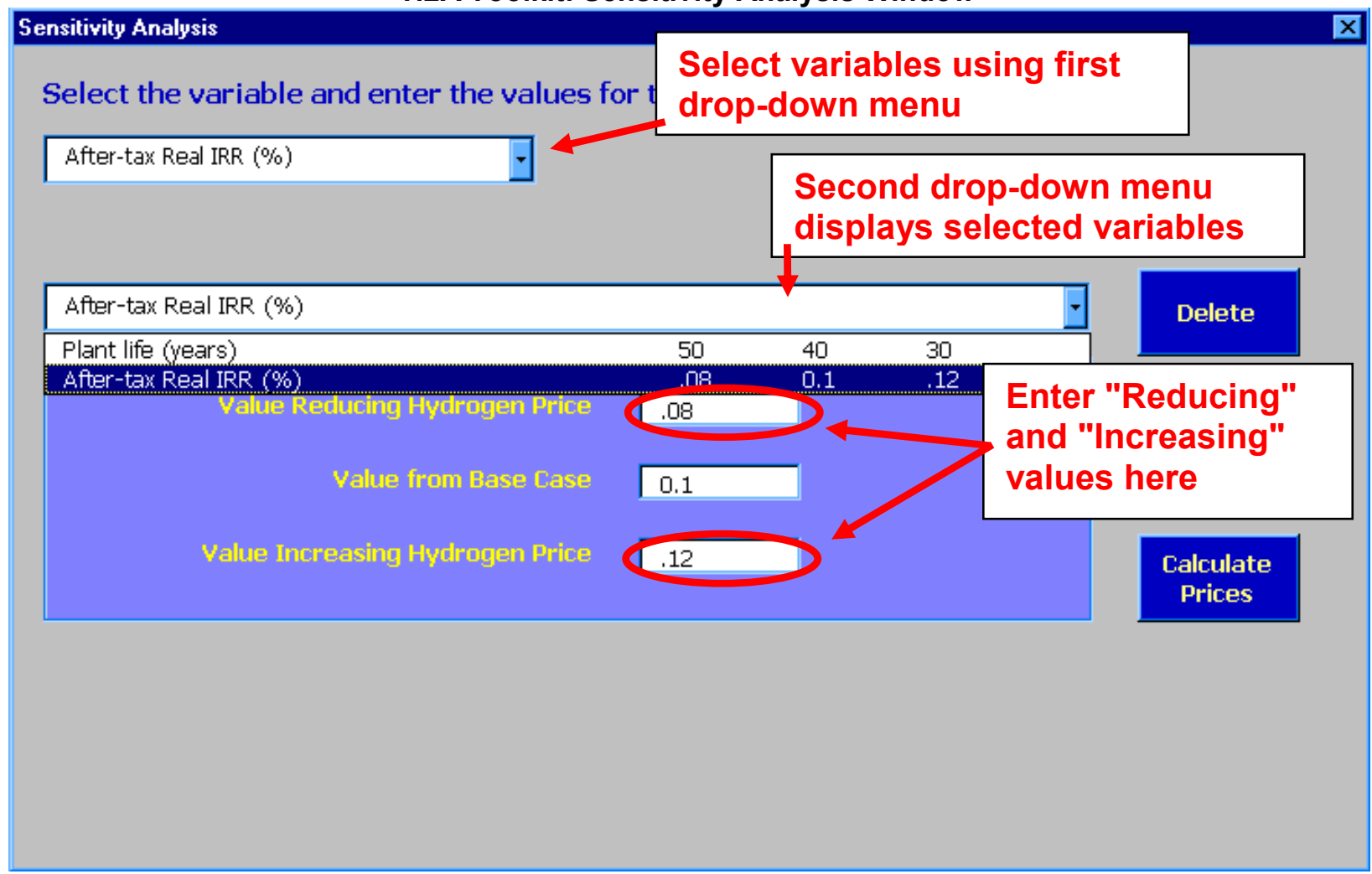

To delete a variable from the analysis, select the variable in the second drop-down menu and click the Delete button. Click Yes in the pop-up window that asks if you want to delete the variable. Remember, variables are added simply by highlighting them in the first drop-down 
menu, so check the second drop-down menu and delete unwanted variables before running your analysis. Also, make sure that three values are entered for each variable you do want to analyze.

Once you are satisfied with the variables you have selected and the "Reducing" and "Increasing" values you have entered, click the Calculate Prices button. A pop-up window will state, "Data may exist in the sheet(s) selected for deletion. To permanently delete the data, press Delete." Click the Delete button. Next, close the Sensitivity Analysis window and H2A Toolkit. You are now in the Sensitivity Analysis worksheet (see page 37), where you see how much the minimum hydrogen selling price varies when your "Reducing" and "Increasing" values are entered into the model while holding all other variables constant at their base values. To the left of the Sensitivity Analysis tab is the Tornado Chart tab. The Tornado Chart worksheet shows the results of the sensitivity analysis graphically (see page 36 ).

If there were values in the Sensitivity Analysis and Tornado Chart worksheets before you performed your sensitivity analysis, they will be overwritten with your new results. Each time you perform a sensitivity analysis, the values in these worksheets are overwritten with the new values, so you can only have one set of values and one valid tornado chart at a time. If you want to create multiple sensitivity analyses/tornado charts, perform your first analysis then save your Excel file under a new name, perform your second analysis then save this file under a different name, and so forth. 


\section{Results Worksheet}

The Results worksheet tabulates the results of your H2A Model analysis. No user input is required within this worksheet. You are sent here after you click the Calculate Cost button in the Input_Sheet_Template worksheet. The hydrogen cost results are in the Specific Item Cost Calculation table at the top (see screen captures below). Note that, in the central model, the costs shown in the Approximate Carbon Sequestration Costs table are included in the total cost shown in the Specific Item Cost Calculation table.

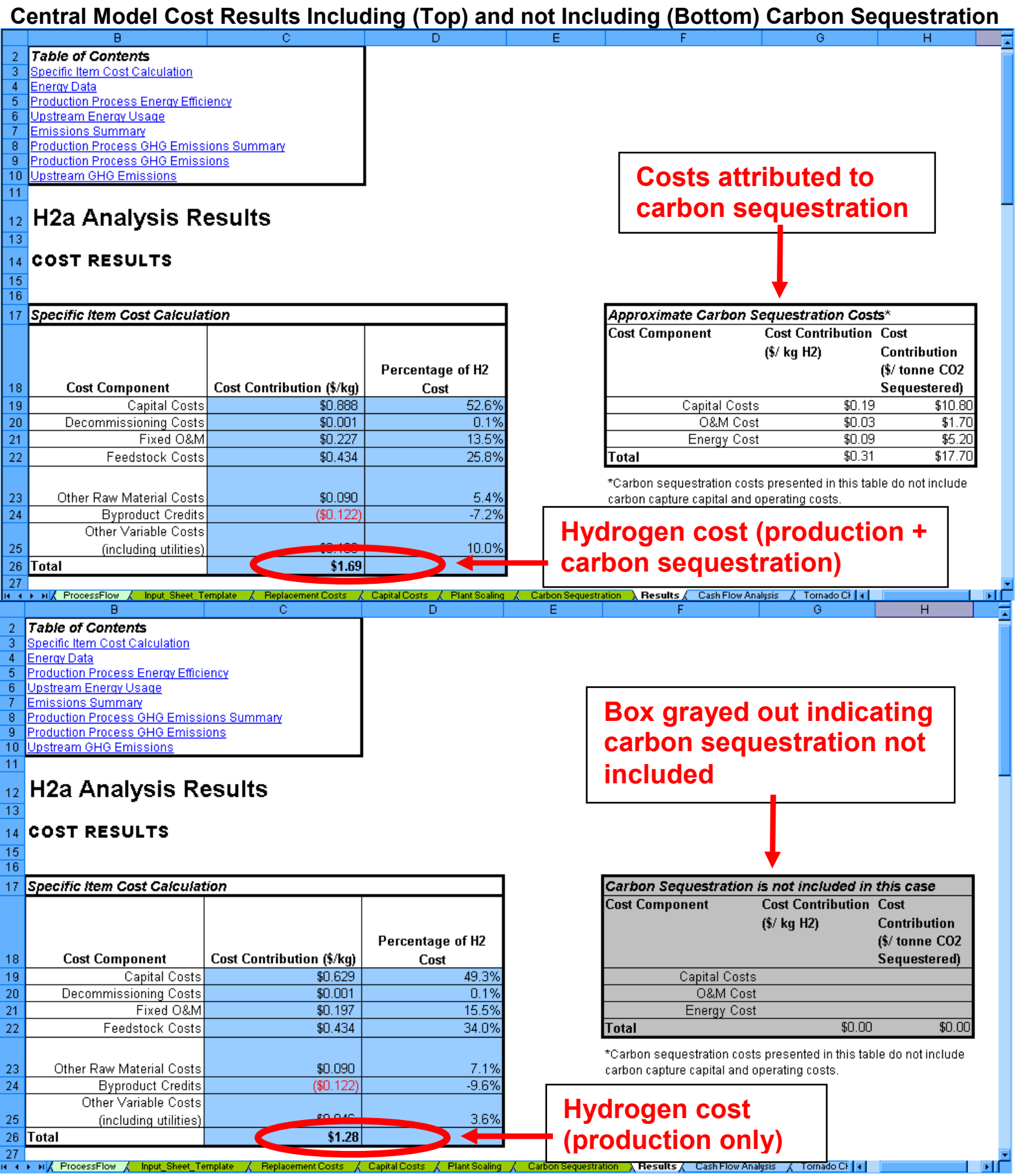


Forecourt Model Cost Results

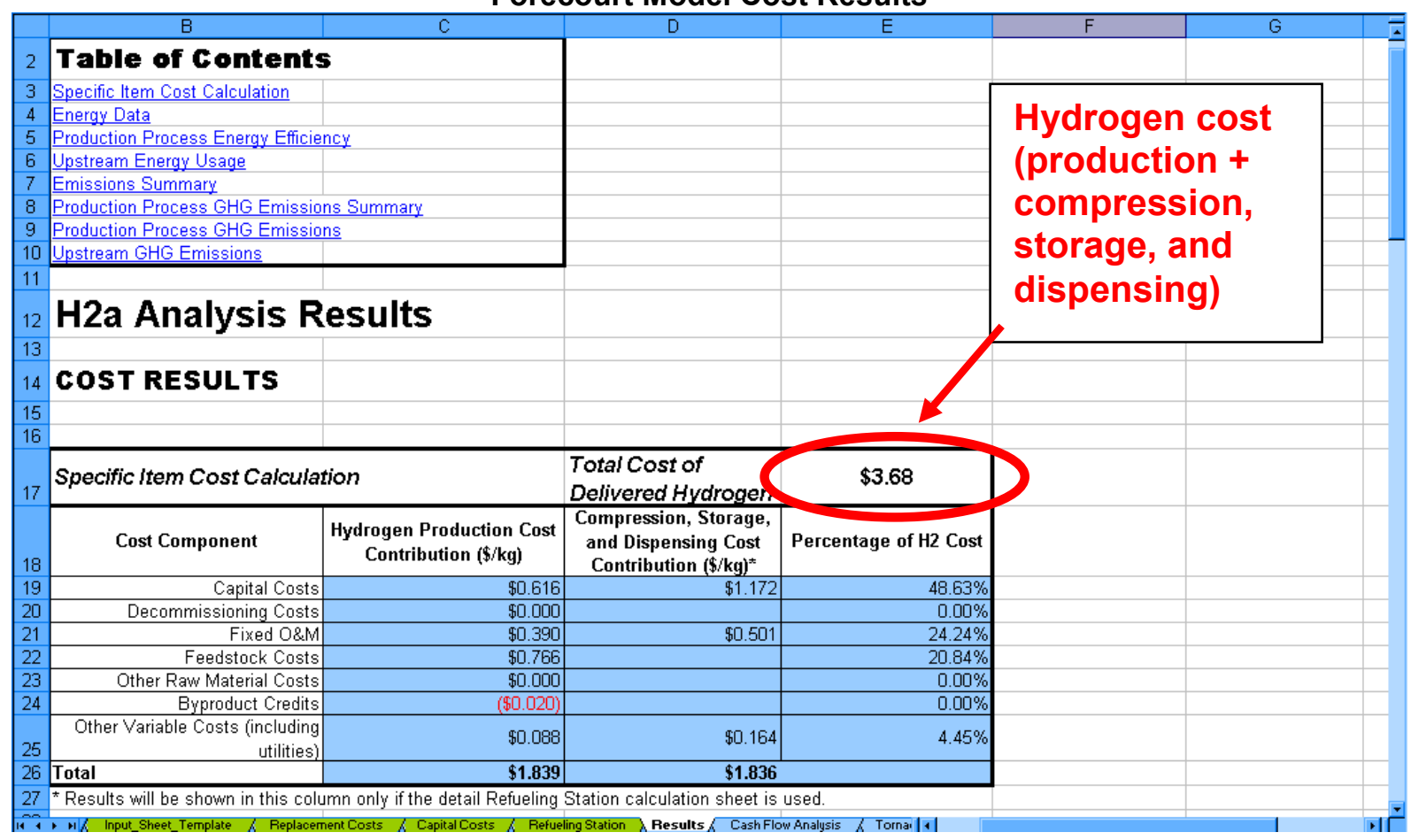

The remaining tables show energy and emissions results. The Energy Data table summarizes the energy inputs in the form of feedstocks, utilities, carbon sequestration (for the central model), and compression, storage, and dispensing (for the forecourt model). It also summarizes the energy outputs in the form of hydrogen and byproducts. The Production Process Energy Efficiency (for the central model) and Facility Energy Efficiency (for the forecourt model) tables show a percentage efficiency calculated by dividing energy outputs by energy inputs. Unless otherwise specified, efficiencies are reported on an LHV basis.

The Upstream Energy Usage table shows total, fossil fuel, and petroleum energy consumed by energy inputs during their upstream processing (e.g., natural gas extraction, ethanol production, or coal-fired electricity generation). These estimates of upstream energy use are calculated based on the GREET (Greenhouse gases, Regulated Emissions, and Energy use in Transportation) Model, version 1.86. The GREET Model is continually being updated. For the most accurate upstream energy results, download and use the most recent GREET version at www.transportation.anl.gov/modeling simulation/GREET.

The Emissions Summary table summarizes upstream and process greenhouse gas emissions. The next two tables-Production Process GHG Emissions Summary and Production Process GHG Emissions-detail the process greenhouse gas emissions. Note that the default is to have all process emissions counted as $\mathrm{CO}_{2}$, as defined in the HyARC Physical Property Data worksheet, Table A. If you want to add information about $\mathrm{CH}_{4}$ and $\mathrm{N}_{2} \mathrm{O}$ emissions to the energy feeds, enter values in the last two columns of Table $A$ (see screen capture below). 
HyARC Physical Property Data Worksheet, Table A: Entering $\mathrm{CH}_{4}$ and $\mathrm{N}_{2} \mathrm{O}$ Values

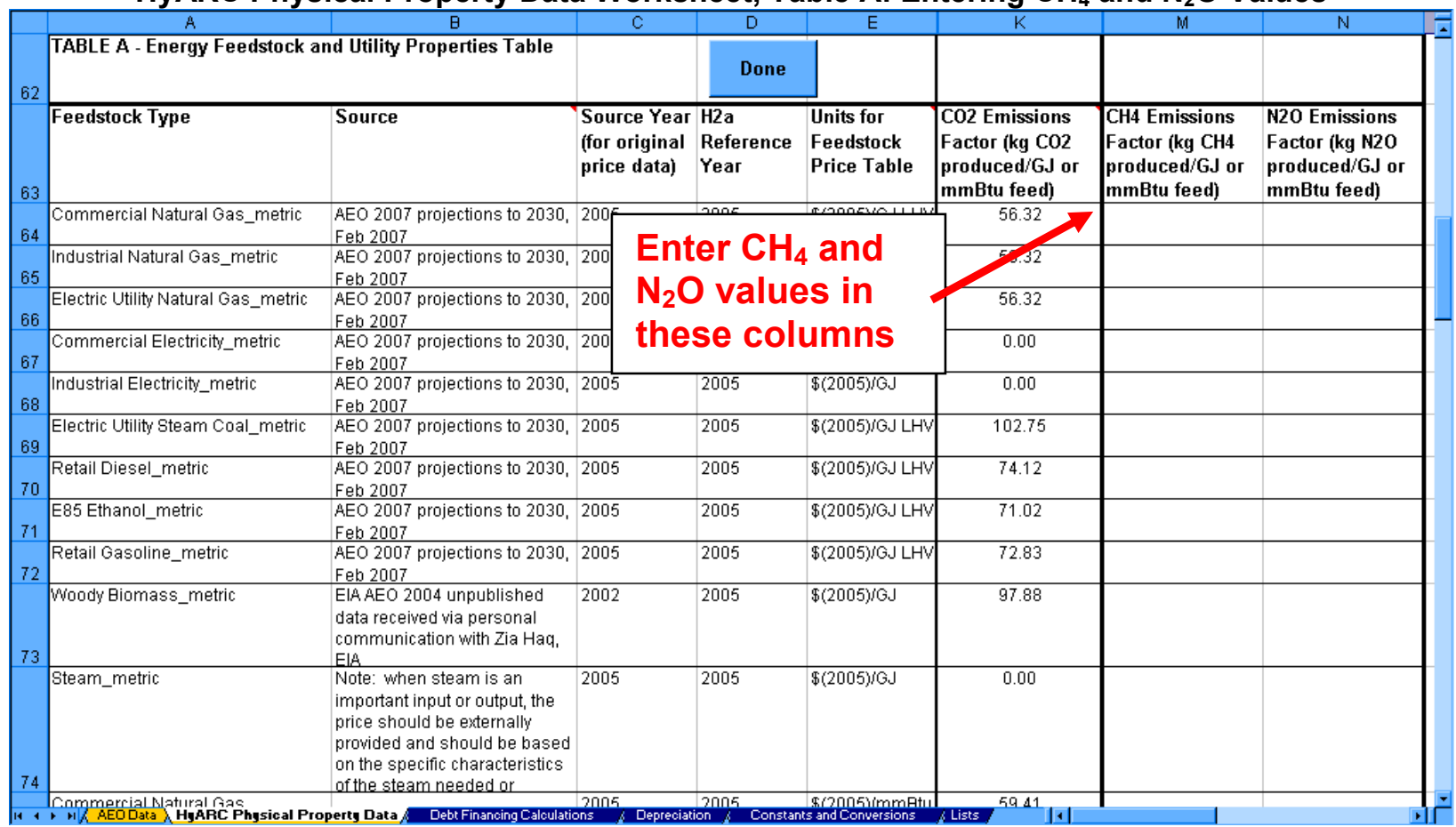

Note: some table columns have been hidden for illustrative purposes.

The Upstream GHG Emissions table shows greenhouse gas emissions $\left(\mathrm{CO}_{2}, \mathrm{CH}_{4}, \mathrm{~N}_{2} \mathrm{O}\right.$, and total) produced by energy inputs during their upstream processing. These estimates of upstream emissions are calculated based on the GREET Model, version 1.7. The GREET Model is continually being updated. For the most accurate upstream emissions results, download and use the most recent GREET version at www.transportation.anl.gov/modeling simulation/GREET.

Results Worksheet, Upstream GHG Emissions Table

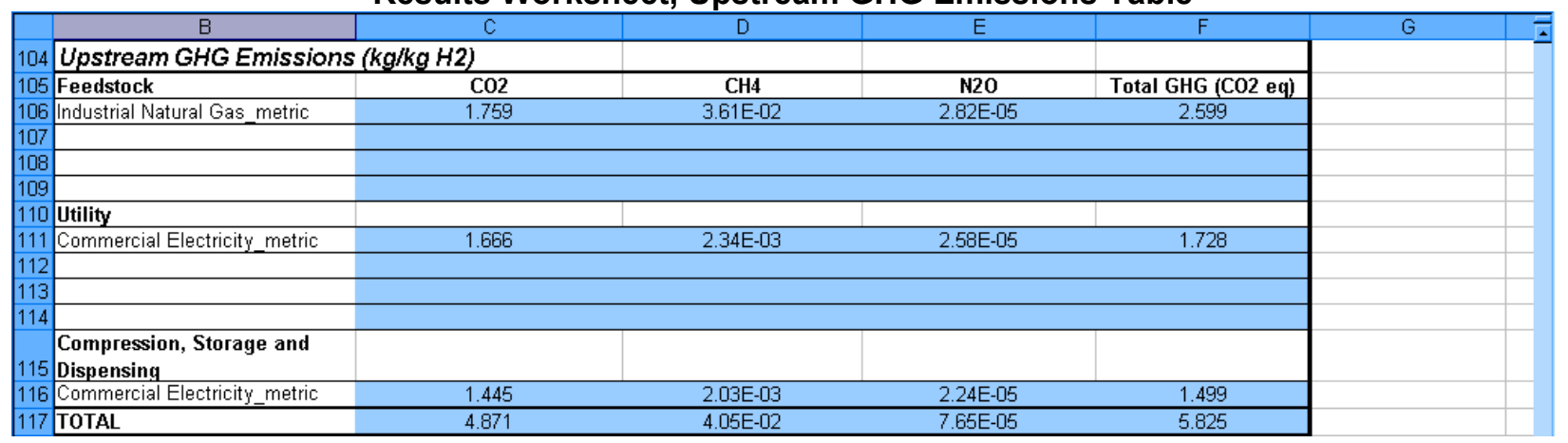




\section{Cash Flow Analysis Worksheet}

The Cash Flow Analysis worksheet shows the inputs, outputs, and calculations of the discounted cash flow analysis used to generate the hydrogen cost results (see page 32). No user input is required within this worksheet.

The worksheet contains the following information, which is linked from a table of contents at the top:

- Discounted Cash Flow (DCF) Calculations

- Yearly Cash Flow Calculations

- Specific Item Cost Calculation

- Feedstock, Utility, and Byproduct Cost Information.

Cash Flow Analysis Worksheet

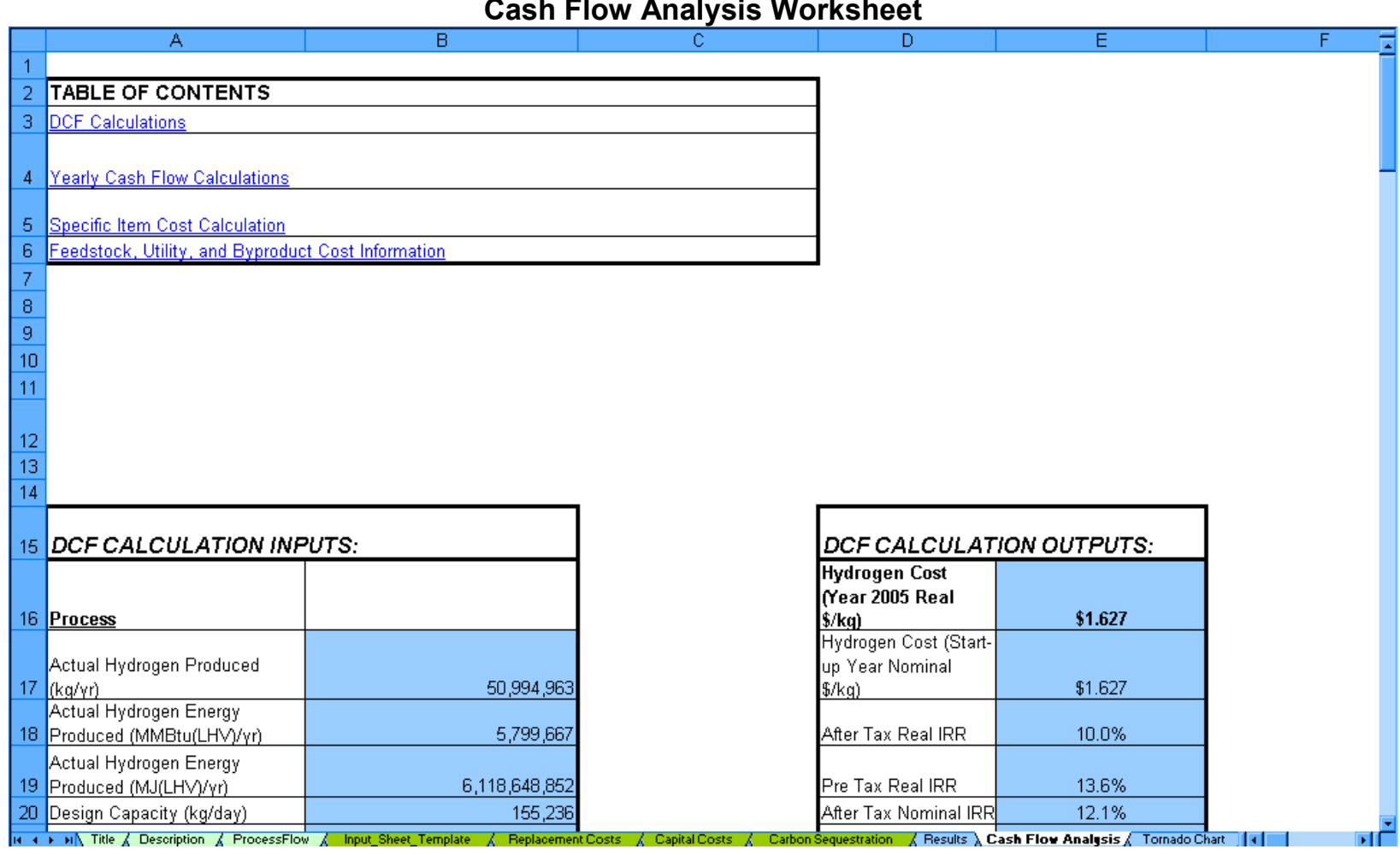




\section{Tornado Chart Worksheet}

The Tornado Chart worksheet shows sensitivity analysis results graphically; see page 30 for information about performing sensitivity analyses and page 37 for the Sensitivity_Analysis worksheet, which shows the results numerically. The bars within the tornado chart show the

Unless you are using an
H2A technology case
that has a default
tornado chart, the
Tornado Chart tab will
not appear until you
perform your first
sensitivity analysis.

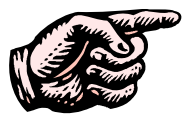

TIP range of minimum hydrogen selling price values obtained by entering - for each specified variable - a base value, a "reducing" value (i.e., a value that reduces the hydrogen price), and an "increasing" value (i.e., a value that increases the hydrogen price) while holding all other variables constant at their base values. No user input is required within this worksheet.

For established $\mathrm{H} 2 \mathrm{~A}$ production technology cases, a default sensitivity analysis/tornado chart is included. The input value ranges used in these analyses are based on feedback from analysts consulted as part of the H2A development process and on ongoing DOE research into the uncertainties inherent to the various hydrogen production variables.

Tornado Chart Worksheet

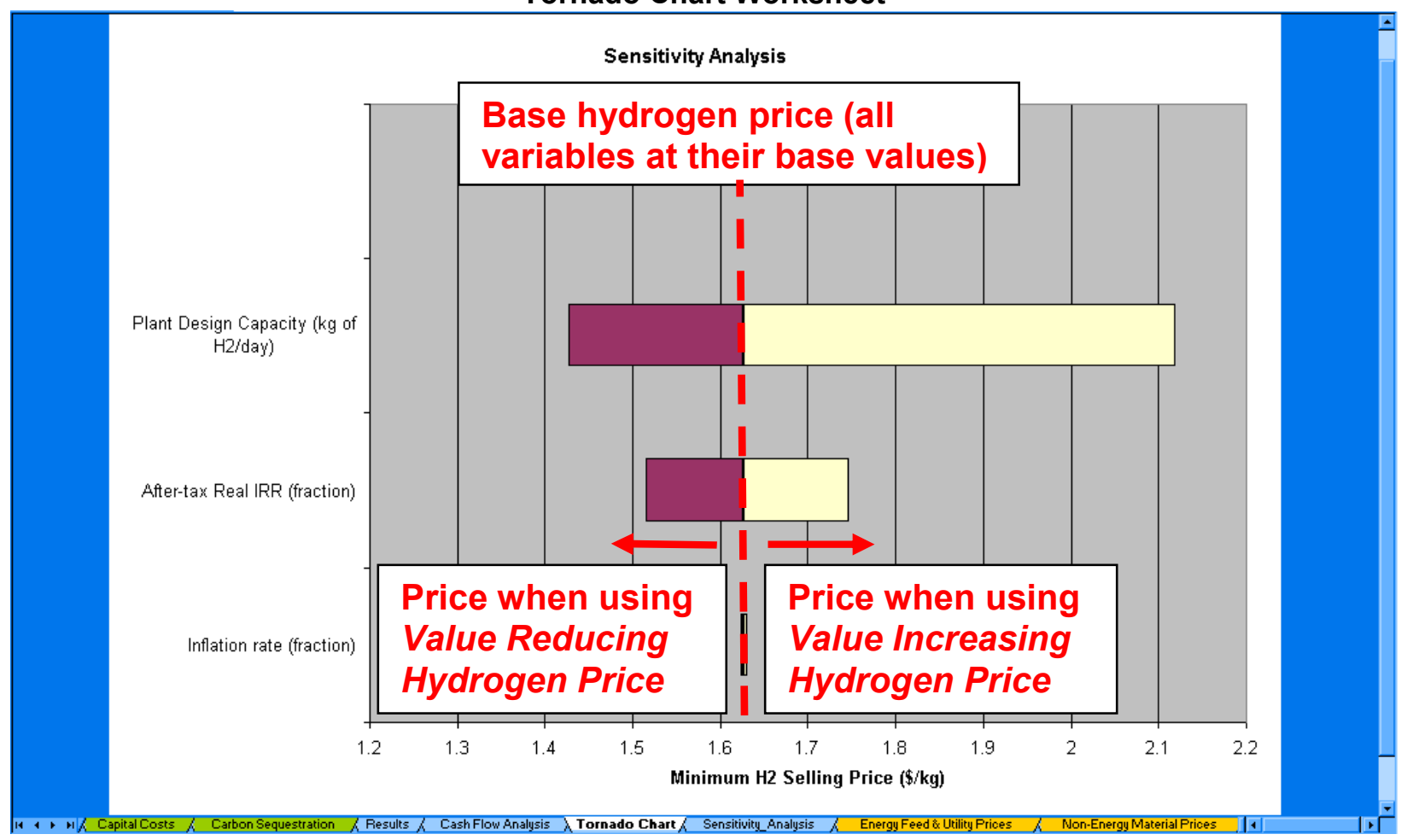




\section{Sensitivity_Analysis Worksheet}

The Sensitivity_Analysis worksheet shows sensitivity analysis results numerically; see page 30 for information about performing sensitivity analyses and page 36 for the Tornado Chart worksheet, which shows the results graphically.

The worksheet's columns show the range of minimum hydrogen selling price values obtained by entering -for each specified variable-a nominal (i.e., base) value, a lower value (i.e., a value that reduces the hydrogen price), and an upper value (i.e., a value that increases the hydrogen price) while holding all other variables constant at their base values. The columns at the far right show the difference in price between the lower-value and upper-value hydrogen prices and the nominal-value price.

It is best not to modify anything directly within this worksheet. Use the H2A Toolkit's sensitivity analysis function (page 30 ) to make changes.

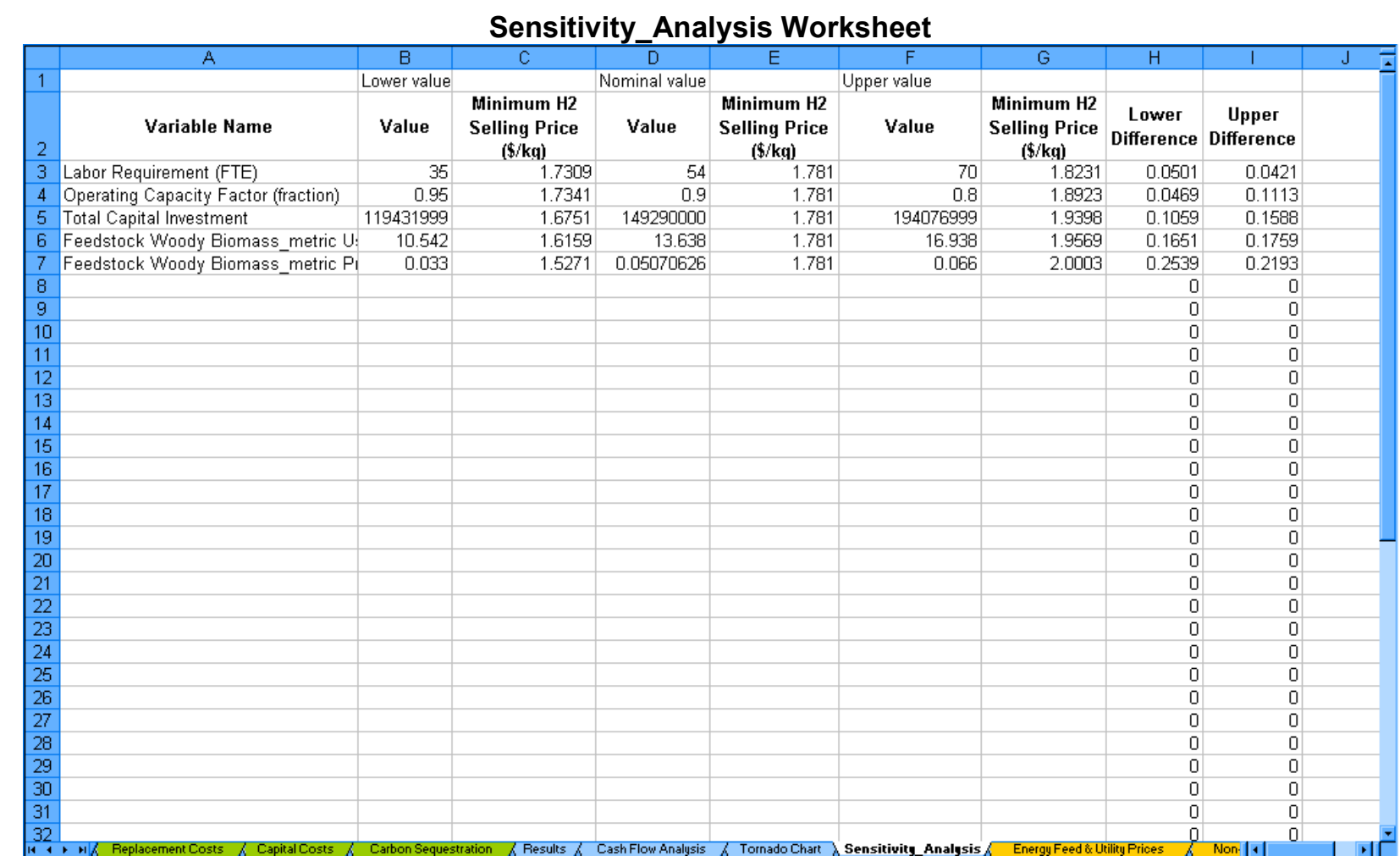




\section{Energy Feed \& Utility Prices Worksheet}

The Energy Feed \& Utility Prices worksheet is the source of price information for the Energy Feedstocks, Utilities, and Byproducts calculations within the Input_Sheet_Template worksheet (see page 12). It contains three pairs of tables, which list projected prices in \$2005 for 11 energy inputs/byproducts through the year 2070:

- AEO 2007 Energy Prices \& AEO 2007 Energy Prices Common Units

- AEO Reference Case 2005 \& AEO Reference Case 2005 Common Units

- AEO 2005 High A Case \& AEO 2005 High A Case Common Units

The AEO 2005 High A Case is the default for all established H2A production technology cases.

The raw prices used to make these tables, through the year 2025 (for AEO Reference Case 2005 and AEO 2005 High A Case) and 2030 (for AEO 2007 Energy Prices), were drawn from the EIA's Annual Energy Outlook (AEO). The year 2026/2031-2070 prices were projected using Pacific Northwest National Laboratory's (PNNL's) Mini-CAM model. See AEO Data Worksheet (page 41) for more information.

You can add your own energy feedstocks, utilities, byproducts, and prices to the tables in the Energy Feed \& Utility Prices worksheet. Complete the following steps (illustrated in the screen captures below):

1) In the table of your choice (i.e., any table but a "common units" table), scroll down to the orange-shaded rows labeled User Defined Feed 1, User Defined Feed 2, etc. in the Feedstock Type column. Overwrite one of these User Defined Feed labels with a name for your first item (feedstock, utility, or byproduct). Do not use special characters (such as parentheses) in the name. Fill in price values for each year in the reference year \$/unit shown; you can change the unit, but it must be either $\$ / G J$ LHV or $\$ / m m B t u$ LHV. Repeat the process for up to five more items (two user-defined feeds in each table).

2) Go to the HyARC Physical Property Data worksheet, Table A. Your new item's name and units will appear automatically near the bottom of the table. Complete all orange-shaded cells for your new item. In the List column, select from the drop-down menu.

3) Optional step: If you want to add upstream energy and emissions values for your item, enter them next to the item's name near the bottom of Table C1 (for startup years 20052019) and C2 (for startup years 2020 and beyond).

4) Within the Input_Sheet_Template worksheet, "refresh" the Energy Feedstocks, Utilities, and Byproducts section by selecting another price table from the first drop-down menu

If your item does not appear, go back to the HyARC Physical Property Data worksheet, Table A, and make sure the item has values in every required column. then selecting the table in which your new item was added. Your new item will now appear as part of that table; find it using the two drop-down menus under the heading Select the Feed. 
Energy Feed \& Utility Prices Worksheet

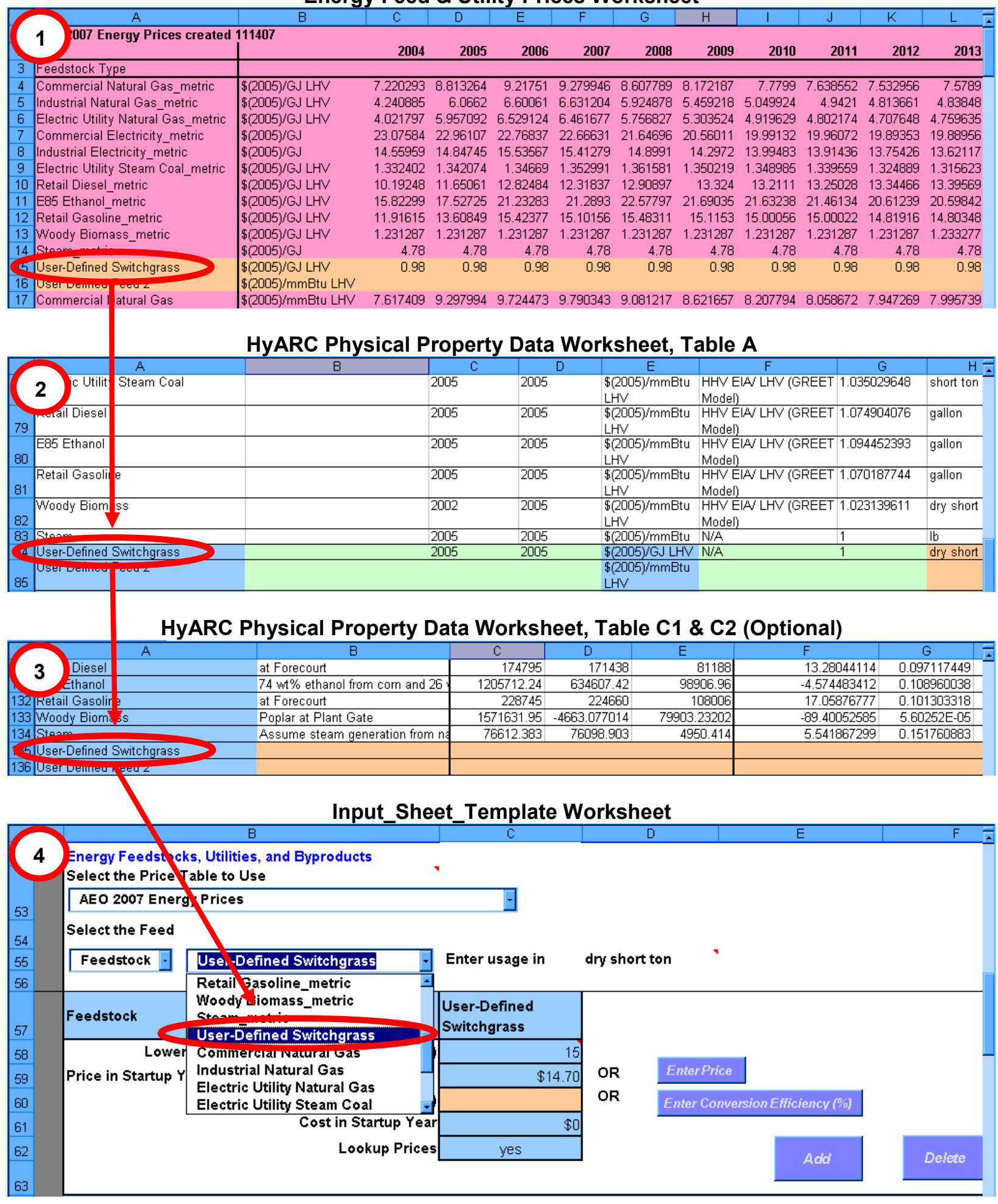




\section{Non-Energy Material Prices Worksheet}

The Non-Energy Material Prices worksheet is the source of price information for the Other Materials and Byproducts calculations within the Input_Sheet_Template worksheet (see page 16). Add new materials simply by adding information in the rows underneath the existing information. You can also modify the prices of materials here if desired.

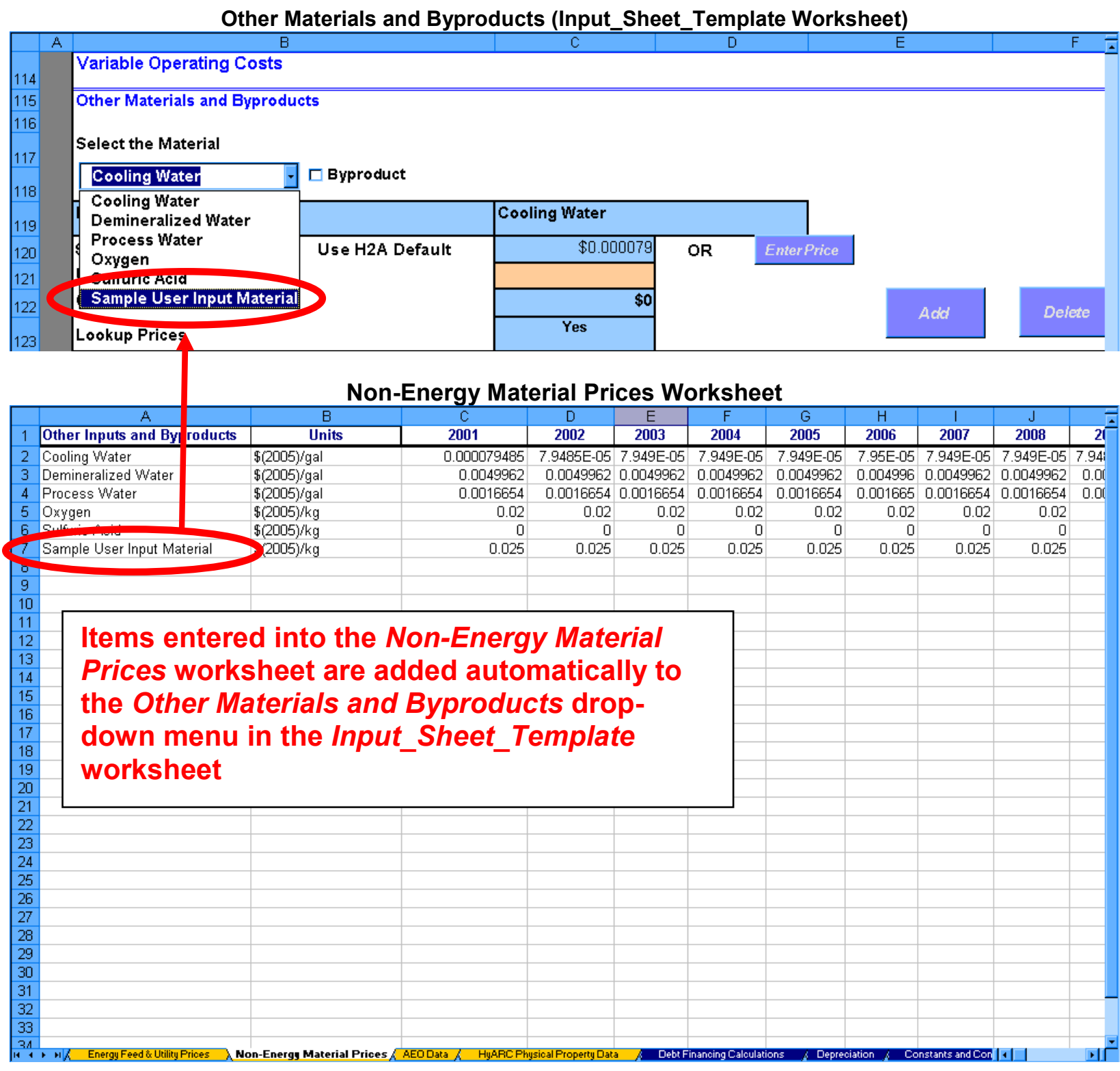




\section{AEO Data Worksheet}

The data in the AEO Data worksheet are the source of the energy price tables in the Energy Feed \& Utility Prices worksheet (page 38). For typical users, no actions are required or recommended within this worksheet. The worksheet contains four tables:

- AEO 2007 Energy Prices

- Based on report no. DOE/EIA-0383(2007), Table 3, Energy Prices by Sector and Source, release date full report February 2007

- Prices given in $\$(2005) / \mathrm{mmBTU}$

- AEO Reference Case 2005

- Based on report no. DOE/EIA-0383(2005), Table 3, Energy Prices by Sector and Source, release date full report January 2005

- Prices given in $\$(2003) / \mathrm{mmBTU}$

- AEO 2005 High A Case

- AEO 2005 Reference Case modified for high projected oil prices

- Details in Market Drivers, www.eia.doe.gov/oiaf/archive/aeo05/index.html

- Prices given in $\$(2003) / \mathrm{mmBTU}$

- Default case for all H2A production technology cases

- Price Ratios from PNNL Mini Climate Assessment Model (Mini-CAM)

- Details at www.pnl.gov/gtsp/research/minicam.stm

The first three tables contain EIA AEO data and projections through year 2030 and projections for years 2031-2070 extrapolated using the AEO projections and Mini-CAM Model results.

\section{AEO Data Worksheet}

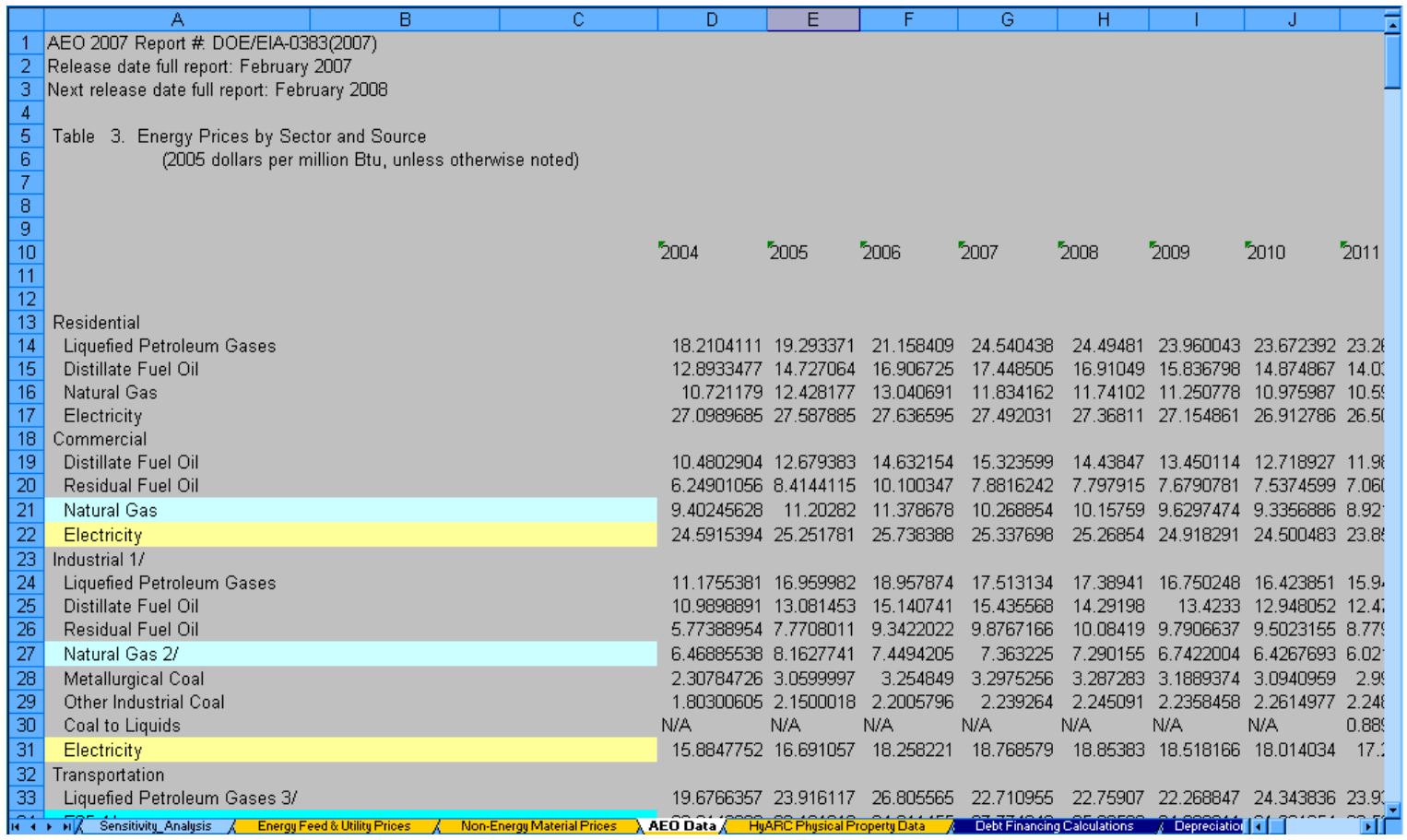




\section{HyARC Physical Property Data Worksheet}

The HyARC Physical Property Data worksheet contains constants and conversions used in energy feedstock, utility, and greenhouse gas emissions calculations. Most users will not need to add or change information in this worksheet; however, Tables $A, C 1$, and $C 2$ contain fields designed to accept user input.

Advanced users might have occasion to change information in Table $A$, the Energy Feedstock and Utility Properties table. For an example, see the "Advanced user" segment under Energy Feedstocks, Utilities, and Byproducts (page 13). You can also add new energy feedstocks, utilities, and byproducts

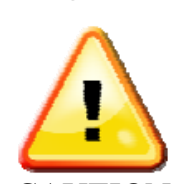

CAUTION to Table A using the User Defined Feeds within the Energy Feed

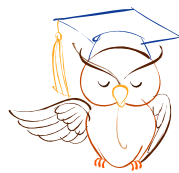

Advanced users only

Table C1 contains upstream energy and greenhouse gas emissions values for hydrogen feedstocks for hydrogen production facilities starting operations in years 2005-2019. Table C2 contains the same information for plants starting operations in years 2020 and beyond. These tables are used to calculate the upstream energy use and greenhouse gas emissions shown on the Results worksheet (see page 32). See page 38 to learn how to enter values for user-defined energy feedstocks and utilities. Unless otherwise noted, all values in these tables are given as LHV.

HyARC Physical Property Data Worksheet

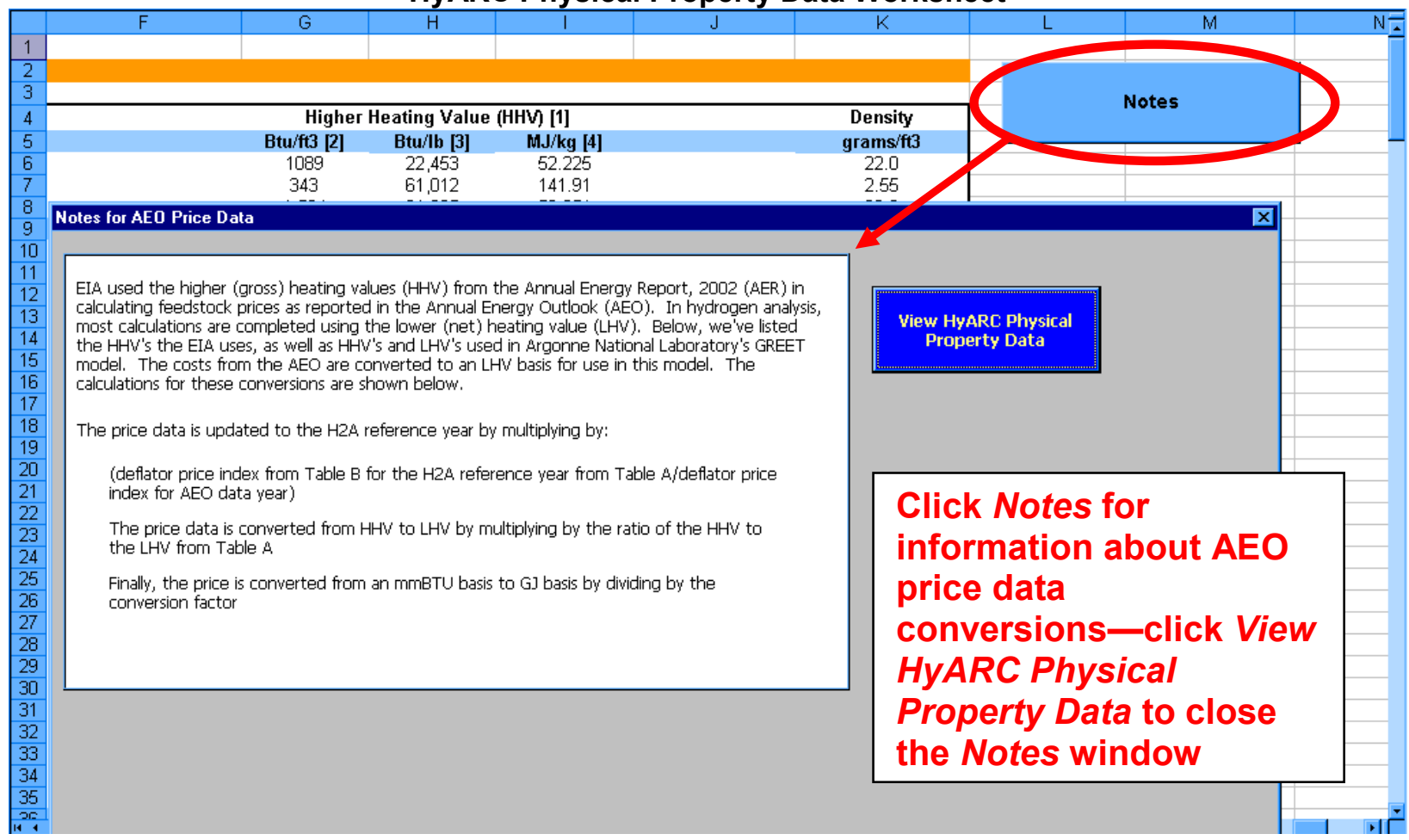




\section{References}

U.S. Department of Energy Hydrogen Program. Hydrogen Analysis Resource CenterHydrogen Properties. Web Site, accessed 11/9/07. Washington, DC: U.S. Department of Energy. http://hydrogen.pnl.gov/cocoon/morf/hydrogen/article/401.

The values for the HyARC Energy Constants and Assumptions table were downloaded from this Web site.

U.S. Department of Energy Hydrogen Program. Hydrogen Delivery Component Model version 2.0. Washington, DC: U.S. Department of Energy.

The upstream energy and greenhouse gas emissions information in Tables C1 and C2 came from the Hydrogen Delivery Component Model, Table 4a. The ultimate source of the information is the GREET Model, version 1.8b. 


\section{Debt Financing Calculations Worksheet}

If debt financing is selected on the Input_Sheet_Template worksheet, the Debt Financing Calculations worksheet amortizes the loan. The results are used in the H2A Model's cash flow analysis (see page 35). No user input is required within this worksheet.

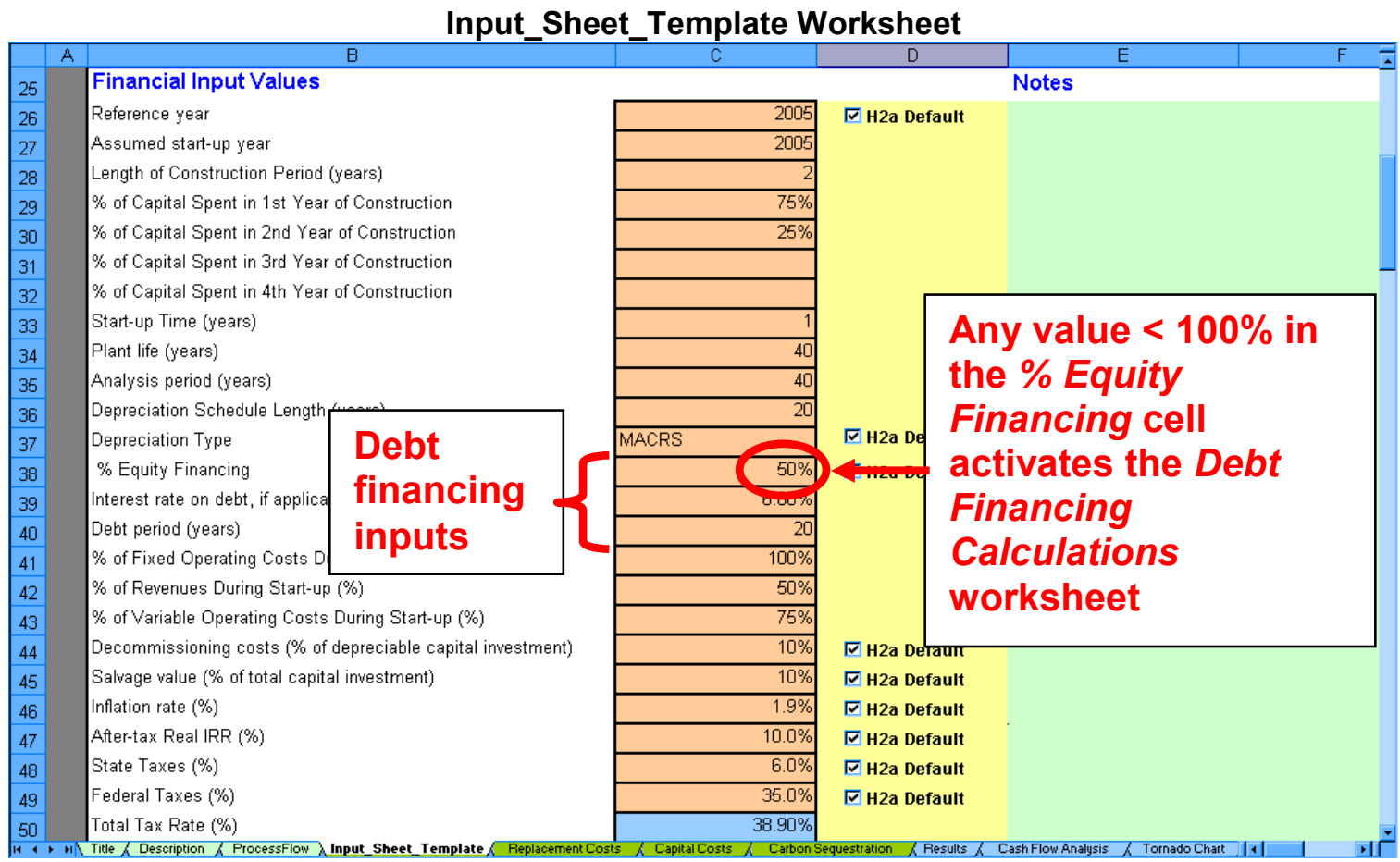

Debt Financing Calculations Worksheet Showing Amortization

\begin{tabular}{|c|c|c|c|c|c|c|c|c|c|}
\hline & $\mathrm{A}$ & $B$ & $\mathrm{C}$ & $\mathrm{D}$ & $\mathrm{E}$ & $\mathrm{F}$ & G & $\mathrm{H}$ & - \\
\hline 11 & \multicolumn{7}{|c|}{ ANNUAL LOAN CALCULATION (if debt financing is assumed) } & & \\
\hline 12 & & & & & & & & & \\
\hline 13 & Analysis Year & Loan Year & Principal Owed & Annual Payment & Interest & Principal Payment & New Principal & & \\
\hline 14 & 1 & 1 & $\$ 71,766,948$ & $\$ 6,256,970$ & $\$ 4,306,017$ & $\$ 1,950,953$ & $\$ 69,815,995$ & & \\
\hline 15 & 2 & 2 & $\$ 69,815,995$ & $\$ 6,256,970$ & $\$ 4,188,960$ & $\$ 2,068,010$ & $\$ 67,747,986$ & & \\
\hline 16 & 3 & 3 & $\$ 67,747,986$ & $\$ 6,256,970$ & $\$ 4,064,879$ & $\$ 2,192,090$ & $\$ 65,555,895$ & & \\
\hline 17 & 4 & 4 & $\$ 65,555,895$ & $\$ 6,256,970$ & $\$ 3,933,354$ & $\$ 2,323,616$ & $\$ 63,232,279$ & & \\
\hline 18 & 5 & 5 & $\$ 63,232,279$ & $\$ 6,256,970$ & $\$ 3,793,937$ & $\$ 2,463,033$ & $\$ 60,769,246$ & & \\
\hline 19 & 6 & 6 & $\$ 60,769,246$ & $\$ 6,256,970$ & $\$ 3,646,155$ & $\$ 2,610,815$ & $\$ 58,158,432$ & & \\
\hline 20 & 7 & 7 & $\$ 58,158,432$ & $\$ 6,256,970$ & $\$ 3,489,506$ & $\$ 2,767,464$ & $\$ 55,390,968$ & & \\
\hline 21 & 8 & 8 & $\$ 55,390,968$ & $\$ 6,256,970$ & $\$ 3,323,458$ & $\$ 2,933,511$ & $\$ 52,457,456$ & & \\
\hline 22 & 9 & 9 & $\$ 52,457,456$ & $\$ 6,256,970$ & $\$ 3,147,447$ & $\$ 3,109,522$ & $\$ 49,347,934$ & & \\
\hline 23 & 10 & 10 & $\$ 49,347,934$ & $\$ 6,256,970$ & $\$ 2,960,876$ & $\$ 3,296,094$ & $\$ 46,051,841$ & & \\
\hline 24 & 11 & 11 & $\$ 46,051,841$ & $\$ 6,256,970$ & $\$ 2,763,110$ & $\$ 3,493,859$ & $\$ 42,557,982$ & & \\
\hline 25 & 12 & 12 & $\$ 42,557,982$ & $\$ 6,256,970$ & $\$ 2,553,479$ & $\$ 3,703,491$ & $\$ 38,854,491$ & & \\
\hline 26 & 13 & 13 & $\$ 38,854,491$ & $\$ 6,256,970$ & $\$ 2,331,269$ & $\$ 3,925,700$ & $\$ 34,928,791$ & & \\
\hline 27 & 14 & 14 & $\$ 34,928,791$ & $\$ 6,256,970$ & $\$ 2,095,727$ & $\$ 4,161,242$ & $\$ 30,767,549$ & & \\
\hline 28 & 15 & 15 & $\$ 30,767,549$ & $\$ 6,256,970$ & $\$ 1,846,053$ & $\$ 4,410,917$ & $\$ 26,356,632$ & & \\
\hline 29 & 16 & 16 & $\$ 26,356,632$ & $\$ 6,256,970$ & $\$ 1,581,398$ & $\$ 4,675,572$ & $\$ 21,681,060$ & & \\
\hline 30 & 17 & 17 & $\$ 21,681,060$ & $\$ 6,256,970$ & $\$ 1,300,864$ & $\$ 4,956,106$ & $\$ 16,724,954$ & & \\
\hline 31 & 18 & 18 & $\$ 16,724,954$ & $\$ 6,256,970$ & $\$ 1,003,497$ & $\$ 5,253,472$ & $\$ 11,471,482$ & & \\
\hline 32 & 19 & 19 & $\$ 11,471,482$ & $\$ 6,256,970$ & $\$ 688,289$ & $\$ 5,568,681$ & $\$ 5,902,801$ & & \\
\hline 33 & 20 & 20 & $\$ 5,902,801$ & $\$ 6,256,970$ & $\$ 354,168$ & $\$ 5,902,801$ & $\$ 0$ & & \\
\hline 34 & 21 & & & & & & & & \\
\hline 35 & 22 & & & & & & & & \\
\hline 36 & 23 & & & & & & & & \\
\hline 37 & 24 & & & & & & & & \\
\hline
\end{tabular}




\section{Depreciation Worksheet}

This worksheet calculates depreciation for use in the H2A Model's cash flow analysis (see page 35). No user input is required within this worksheet.

Input_Sheet_Template Worksheet
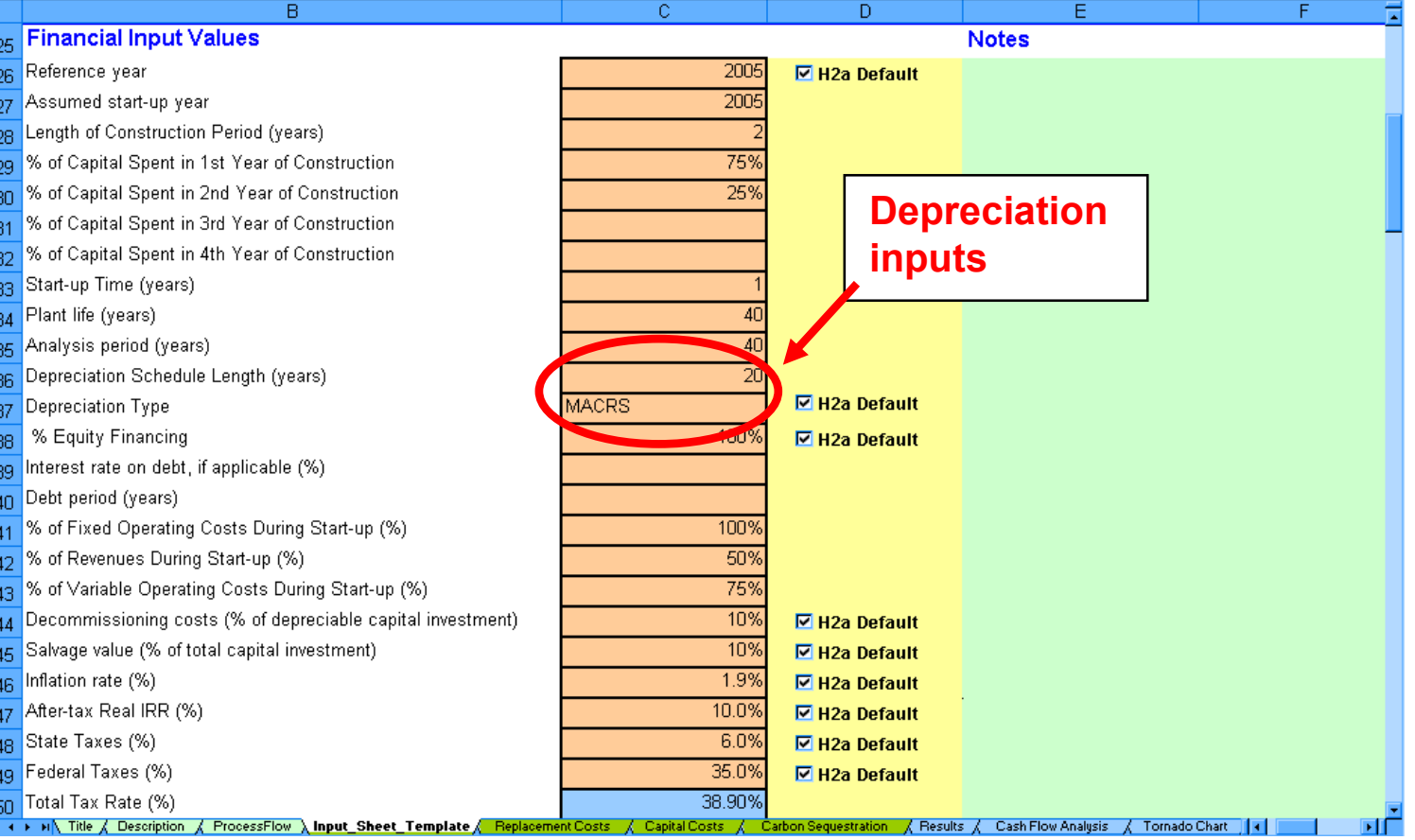

Depreciation Worksheet

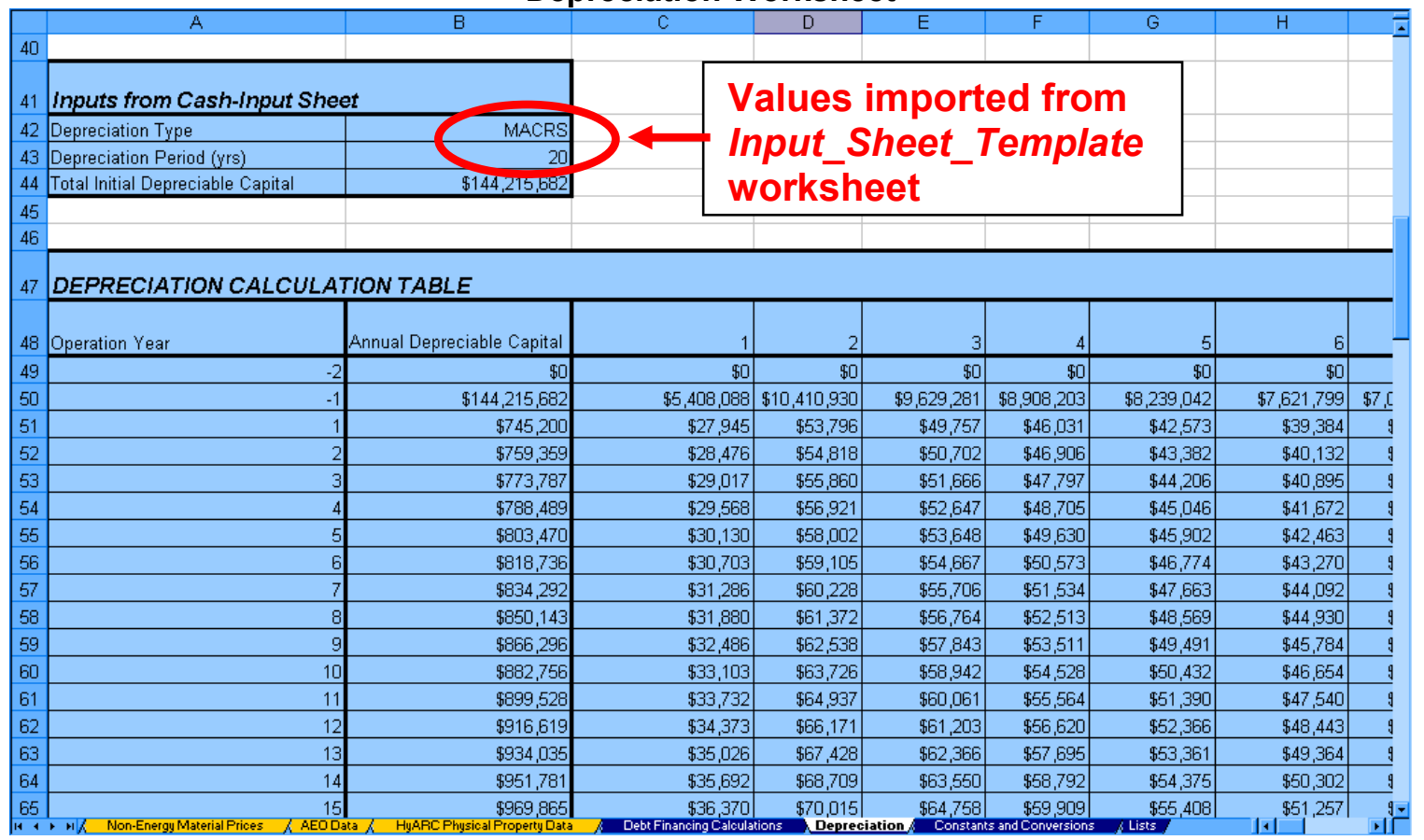




\section{Constants and Conversions Worksheet}

The constants and conversion factors listed on this worksheet are used in $\mathrm{H} 2 \mathrm{~A}$ calculations and included for users' reference. No user input is required within this worksheet.

\begin{tabular}{|c|c|c|c|c|c|c|c|c|c|c|c|}
\hline & $\mathrm{A}$ & $B$ & C & $\mathrm{D}$ & $E$ & $\mathrm{~F}$ & $G$ & $\mathrm{H}$ & 1 & J & F \\
\hline 1 & To Convert From & To & Multiply by: & & & & & & & & \\
\hline 2 & General & & & & & & & & & & \\
\hline 3 & miles & $\mathrm{km}$ & 1.6093 & $\mathrm{~km} / \mathrm{mile}$ & & & & & & & \\
\hline 4 & gallons & liters & 3.785 & $L_{\text {gal }}$ & & & & & & & \\
\hline 5 & MPG & $\mathrm{kWh} / \mathrm{km}$ & 0.018263969 & $(\mathrm{kWh} / \mathrm{km}) / \mathrm{MP}$ & & & & & & & \\
\hline 6 & $\operatorname{scf}$ & $\mathrm{Nm} 3$ & 0.026853 & $\mathrm{Nm} 3 / \mathrm{scf}$ & & & & & & & \\
\hline 7 & lb & $\mathrm{kg}$ & 0.453514739 & $\mathrm{~kg} / \mathrm{lb}$ & & & & & & & \\
\hline 8 & ncf & $\mathrm{Nm} 3$ & 0.028317 & $\mathrm{Nm} 3 / \mathrm{ncf}$ & & & & & & & \\
\hline 9 & $\mathrm{MPa}$ & psi & 145.038 & $\mathrm{psi} / \mathrm{MPa}$ & & & & & & & \\
\hline \multicolumn{12}{|c|}{10} \\
\hline 11 & Energy & & & & & & & & & & \\
\hline 12 & MJ & kWh & 0.277777778 & & & & & & & & \\
\hline 13 & gallon of gasoline eq (GGE) -convention & $\mathrm{kWh}$ & 34.02262529 & & & & & & & & \\
\hline 14 & $\mathrm{~kg} \mathrm{H} 2(\mathrm{LH})$ & GGE & 0.979331964 & & & & & & & & \\
\hline 15 & $\mathrm{~kg} \mathrm{H} 2(\mathrm{LHV})$ & kWh & 33.32926599 & 33.3194444 & & & & & & & \\
\hline 16 & $\mathrm{~kg} \mathrm{H} 2(\mathrm{LHV})$ & G.J & 0.119985358 & & & & & & & & \\
\hline 17 & btu & kWh & 0.000293083 & & & & & & & & \\
\hline 18 & mmBTU & G.J & 1.055 & & & & & & & & \\
\hline \multicolumn{12}{|c|}{19} \\
\hline \multicolumn{12}{|l|}{20} \\
\hline \multicolumn{3}{|c|}{21 Greenhouse Gas Emissions Factors } & & & & & & & & & \\
\hline 22 & $\mathrm{CO} 2$ & 1 & & & & & & & & & \\
\hline 23 & $\mathrm{CH} 4$ & 23 & & & & & & & & & \\
\hline 24 & $\mathrm{~N} 2 \mathrm{O}$ & 296 & & & & & & & & & \\
\hline \multicolumn{12}{|c|}{25} \\
\hline \multicolumn{12}{|l|}{26} \\
\hline \multicolumn{12}{|l|}{27} \\
\hline \multicolumn{12}{|l|}{28} \\
\hline \multicolumn{12}{|l|}{29} \\
\hline \multicolumn{12}{|l|}{30} \\
\hline \multicolumn{12}{|l|}{31} \\
\hline \multicolumn{12}{|l|}{32} \\
\hline 33 & & & & & & & & & & & \\
\hline 14 & - $n / K$ Non-Energy Material Prices $\quad$ K AEOData & L HyARCPhy & yysical Property Data & Dehtrionom & & & & & & & \\
\hline
\end{tabular}




\section{Lists Worksheet}

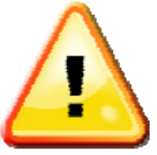

CAUTION

The Lists worksheet contains lists of variable labels that the H2A Production Model uses to perform all its calculations. Do not add, delete, or change anything on this worksheet. Modifying the lists could disable or introduce major errors into the model.

\section{Lists Worksheet}

\begin{tabular}{|c|c|c|c|c|c|c|c|c|}
\hline & $\bar{A}$ & B & C & $\bar{D}$ & $\mathrm{E}$ & $F$ & $\bar{G}$ & F \\
\hline 1 & Cancelled & & & & & & & \\
\hline \multicolumn{9}{|l|}{2} \\
\hline 3 & Use_Default & & Yes_No & & \multicolumn{2}{|l|}{ Temp_var_location } & Sensitivity_Variables & \\
\hline 4 & Use $\mathrm{H} 2 \mathrm{~A}$ Value & & Yes & & \multicolumn{2}{|l|}{0.025} & Operating Capacity Factor (fraction) & cap_factor \\
\hline 5 & Enter Value & & No & & & & Plant Design Capacity ( $\mathrm{kg}$ of $\mathrm{H} 2 /$ day) & design_cap \\
\hline 6 & & & & & & & Assumed start-up year & startup_yea \\
\hline 7 & Add_As_List & & \multicolumn{2}{|c|}{ Feed_Type_List } & & & Length of Construction Period (years) & construct \\
\hline 8 & Feedstock & & Feed & & & & Start-up Time (years) & start_time \\
\hline 9 & Utility & & Utility & & & & Plant life (years) & plant_life \\
\hline 10 & Byproduct & & Feed Utility & & & & Decommissioning costs (fraction of depreciable capital investment) & decom_per \\
\hline 11 & & & \multicolumn{2}{|c|}{ Feed Utility Byprod } & & & Salvage value (fraction of total capital investment) & salvage_pe \\
\hline 12 & & & Byproduct & & & & Inflation rate (fraction) & inflation_rat \\
\hline 13 & & & & & & & After-tax Real IRR (fraction) & real_irr \\
\hline 14 & Delete_As_List & & ColorList & & & & State Taxes (fraction) & state_tax_r \\
\hline 15 & Energy Feedstock & & Input & & & & Federal Taxes (fraction) & fed_tax_ratı \\
\hline 16 & Energy Utility & & Calculated & & & & WORKING CAPITAL (fraction of yearly change in operating costs) & WorkingCa| \\
\hline 17 & Energy Byproduct & & DropDown & & & & Total Direct Capital Cost & direct_cap \\
\hline 18 & Other Feed & & Information & & & & Total Capital Investment & total_cap \\
\hline 19 & Other Byproduct & & Userinfo & & & & Cost of land (\$/acre) & acre_cost \\
\hline 20 & All & & & & & & Labor Requirement (FTE) & FTEs \\
\hline 21 & & & & & & & G\&A rate (fraction of labor cost) & overhead_ra \\
\hline 22 & & & & & & & Property tax and insurance rate (fraction of total capital investment) & tax_ins_ratı \\
\hline 23 & & & & & & & Rent (\$/year) & rent \\
\hline 24 & & & & & & & Material costs for maintenance and repairs (\$/year) & material \\
\hline 25 & & & & & & & Production Maintenance and Repairs (\$/year) & prod_maint \\
\hline 26 & & & & & & & Waste treatment costs (\$/year) & waste_treat \\
\hline 27 & & & & & & & Solid waste disposal costs (\$/year) & solidwaste. \\
\hline 28 & & & & & & & CO2 sequestration capital costs (\$/year) & CO2_seq \\
\hline 29 & & & & & & & Feedstock Woody Biomass_metric Usage & Feedstock \\
\hline 30 & & & & & & & Feedstock Woody Biomass_metric Price & Feedstock \\
\hline 31 & & & & & & & & \\
\hline 32 & & & & & & & & \\
\hline 33 & & & & & & & & \\
\hline 34 & - i/ Non-Energy Mat & rices & SEOData & hysice & & (y) & Depreciation & \\
\hline
\end{tabular}




\section{Technical Support}

Information related to the new H2A Production Model will be posted on the $\mathrm{H} 2 \mathrm{~A}$ Web site as it becomes publicly available: www.hydrogen.energy.gov/h2a production.html. Visit the Web site to download copies of the model and technology cases.

For technical questions not answered by this guide or the Web site, contact:

Darlene Steward

National Renewable Energy Laboratory

303-275-3837

darlene steward@nrel.gov 


\section{Appendix 1: Carbon Sequestration Calculations and Sources}

This appendix briefly describes the inputs and calculations used within the Carbon Sequestration worksheet (which is used for the H2A central model only, see page 23). See the sources listed in References at the end of this appendix for detailed descriptions and derivations of the calculations. Note that McCollum and Ogden (2006) include $\mathrm{CO}_{2}$ pumps in their carbon sequestration calculations as well as compressors. Because super-critical $\mathrm{CO}_{2}$ exhibits liquid-like density at the pressures and temperatures of carbon sequestration, pumps or compressors can be used in this application. The choice of using pumps, compressors, or both depends on the scale of the carbon sequestration process. At the high production capacities of most H2A central model cases, the higher efficiency of compressors offsets their higher initial capital cost; industry feedback supports this contention. Therefore, the H2A central model includes only $\mathrm{CO}_{2}$ compressors, rather than pumps, in its carbon sequestration calculations.

The Carbon Sequestration worksheet is divided into four tables:

Table

Carbon Sequestration Information

Carbon Sequestration Input Values

Carbon Sequestration Calculations

Summary of Output Values
Purpose

Source of values for carbon sequestration calculations

Source of values for carbon sequestration calculations

Calculate carbon sequestration results

Display carbon sequestration results
User Input Required

No

Yes

No

No

See the screen captures of the tables below. The numbers on the left of each table correspond with the numbered descriptions of each field.

Carbon Sequestration Information

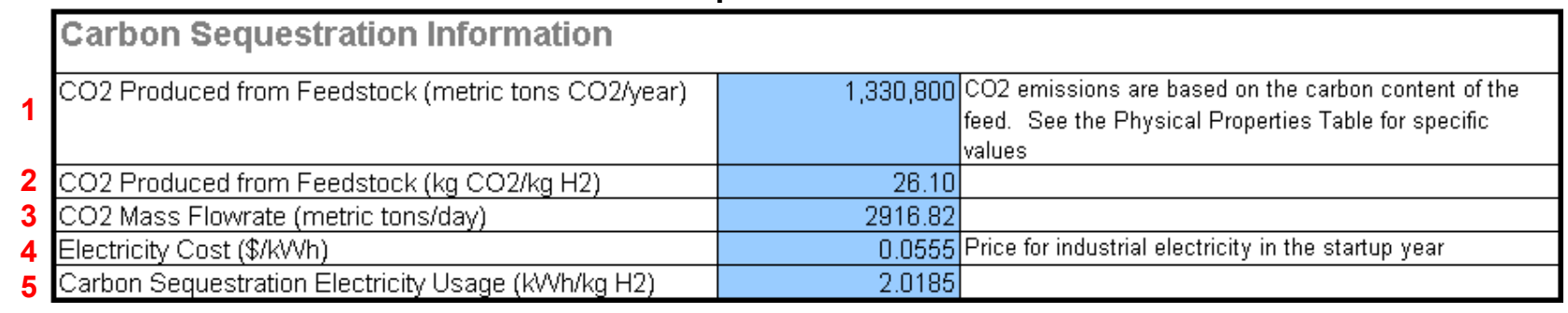

1, 2. $\mathrm{CO} 2$ Produced from Feedstock $-\mathrm{CO}_{2}$ emissions produced from the feedstock are calculated based on the properties of the feedstock and the amount of feedstock used in hydrogen production. The feedstock type and use information comes from the Input_Sheet_Template worksheet. The properties come from the HyARC Physical Property Data worksheet. 
3. $\mathrm{CO} 2$ Mass Flowrate-The $\mathrm{CO}_{2}$ mass flow rate (the mass of $\mathrm{CO}_{2}$ transported to the injection site each day) is calculated using the value for $\mathrm{CO}_{2}$ produced from feedstock (1) and the carbon capture efficiency (6).

4. Electricity Cost-The industrial electricity cost is drawn from the Energy Feed \& Utility Prices worksheet for each year of the calculations. The startup year cost is shown here.

5. Carbon Sequestration Electricity Usage-This value is calculated using the power requirement (21) from the Carbon Sequestration Calculations table (in the Carbon Sequestration worksheet) and the capacity factor and plant output from the Input_Sheet_Template worksheet.

Carbon Sequestration Input Values

\begin{tabular}{|c|c|c|c|}
\hline Carbon Sequestration Input Values & & & \\
\hline$6 \longdiv { \text { Carbon Capture Efficiency (\%) } }$ & $80.00 \%$ & V H2a Default & \\
\hline 7 CO2 capture process outlet pressure (psia) & 14.7 & V H2a Default & Inlet pressure for compression \\
\hline 8 CO2 capture credit (\$/metric ton CO2 captured) & $\$ 0.00$ & 『 H2a Default & \\
\hline 9 Operation and maintenance factor for compressors and & 0.040 & V H2a Default & \\
\hline 0 Operation and maintenance factor for $\mathrm{CO} 2$ pipeline & 0.025 & 『 H2a Default & \\
\hline 1 Capital cost for site screening and evaluation (per well) & $\$ 1,857,773$ & E H2a Default & \\
\hline 2 Number of injection wells & 1 & 『 H2a Default & \\
\hline 3 Well depth (m) & 1524 & V H2a Default & \\
\hline 4 Location factor & 1 & V H2a Default & 1 - USA, \\
\hline 5 Terrain Type & $<20 \%$ Mountainous & 『 H2a Default & \\
\hline 6 Terrain factor & 1.3 & & \\
\hline 7 Total CO2 pipeline length (miles) & 100 & V H2a Default & \\
\hline$8 \longdiv { \text { After Tax Real Capital Recovery Factor } }$ & 0.102 & & \\
\hline 9 Real Present Value of Depreciation & 0.487 & & \\
\hline 0 Approx Capital Charge Rate & 0.136 & & \\
\hline & & & \\
\hline
\end{tabular}

6. Carbon Capture Efficiency-Input the percentage of $\mathrm{CO}_{2}$ emissions captured here (note: only $\mathrm{CO}_{2}$ emissions from feedstock processing can be captured). This value is used in the calculation of $\mathrm{CO}_{2}$ mass flow rate (3). The default value is $80 \%$.

7. $\mathrm{CO} 2$ Capture Process Outlet Pressure-Input the value for the pressure of $\mathrm{CO}_{2}$ exiting the capture phase and entering the compression phase here. This value becomes $\mathrm{P}_{\text {initial }}$ in the $\mathrm{CO}_{2}$ compression calculations (23). The default value is 14.7 psia (atmospheric pressure).

8. $\mathrm{CO} 2$ Capture Credit-Input the value for $\mathrm{CO}_{2}$ capture credits here. If a value is entered, the credits offset operation and maintenance costs (29). The default value is zero.

9. Operation and Maintenance Factor for Compressors_-Input the compressor operation and maintenance factor here. The model multiplies this value times the compressor capital cost to determine annual compressor operation and maintenance cost (24). The default value is 0.04 .

10. Operation and Maintenance Factor for CO2 Pipeline - Input the pipeline operation and maintenance factor here. The model multiplies this value times the pipeline capital cost to determine annual pipeline operation and maintenance cost (28). The default value is 0.025 . 
11. Capital Cost for Site Screening and Evaluation (per well)_Input the per-well capital cost for site screening and evaluation here. This value is multiplied times the number of wells to become $\mathrm{C}_{\text {site }}$ in the $\mathrm{CO}_{2}$ compression calculations (25). The default value is $\$ 1,857,773$.

12. Number of Injection Wells-Input the number of injection wells here. This value is used in the calculations for drilling and injection equipment capital costs as well as injection operation and maintenance costs $(\mathbf{2 5}, \mathbf{2 6})$. The default value is 1 well, which is the typical number needed for injecting 10,000 metric tons/day or less using a 0.15 -m-diameter injection pipe. For an iterative process for calculating number of wells needed, see McCollum and Ogden (2006), page 15.

13. Well Depth - Input well depth here. This value is used in the calculations for drilling capital cost as well as injection operation and maintenance costs $(\mathbf{2 5}, \mathbf{2 6})$. The default value is $1,524 \mathrm{~m}$, which is the base case for gas reservoirs in McCollum and Ogden (2006), page 15 (Table 3). Benson (2000) describes California oil and gas reservoirs as no deeper than $1,500 \mathrm{~m}$.

14. Location Factor-Select a location factor from the drop-down menu. A location factor of 1 corresponds to location in the United States, Canada, Europe, Japan, or Australia. A location factor of 1.2 corresponds to location in the United Kingdom. This value is used in the calculation for pipeline capital cost; a higher location factor increases the cost (27). The default value is 1 .

15, 16. Terrain Type/Terrain Factor-Select a terrain type from the drop-down menu. Each terrain type corresponds to a specific terrain factor, which is automatically entered into the Terrain Factor field as follows:

- cultivated land $=1.1$

- grassland $=1$

- wooded $=1.05$

- jungle $=1.1$

- stony desert $=1.1$

- $<20 \%$ mountainous $=1.3$

- $>50 \%$ mountainous $=1.5$

This value is used in the calculation for pipeline capital cost; a higher terrain factor increases the cost (27). The default value is 1.3 ( $<20 \%$ mountainous).

17. Total CO2 Pipeline Length-Input total pipeline length here. This value is used in the calculation for pipeline capital cost (27). The default value is 100 miles. Required $\mathrm{CO}_{2}$ transportation distances (i.e., required pipeline lengths) vary by location.

18-20. These factors (after tax real capital recovery factor, real present value of depreciation, and approximate capital charge rate) are automatically calculated using values from the Input_Sheet_Template worksheet and financial calculations. They are used in the carbon sequestration calculations for capital, electrical, and O\&M cost per metric ton of $\mathrm{CO}_{2}$ sequestered. The capital and operating costs for carbon sequestration are also included in the model's discounted cash flow calculations-see the Cash Flow Analysis (page 35) and Results (page 32) sections. The results shown on the Results worksheet are for the entire plant. 
21-28. The Carbon Sequestration Calculations table shows calculations based on the input and calculation tables described above as well as default values and constants. The upper half of the table (21-24) calculates compressor costs, including a power requirement calculation for multi-stage compression (21). The lower half of the table (25-28) calculates injection and pipeline costs. See McCollum and Ogden (2006) for details about the calculations. Do not change any of the cells in this table directly.

29. The Summary of Outputs table summarizes the major results of the carbon sequestration calculations. The costs are for $\mathrm{CO}_{2}$ compression, transportation to the sequestration site, and injection. Costs for $\mathrm{CO}_{2}$ capture are assumed to be included in the production facility's capital and operating costs and are not included here. Costs are shown in reference year dollars. Do not change any of the cells in this table directly.

The calculations for the cost of sequestration per metric ton of $\mathrm{CO}_{2}$ are based on the capital recovery factor (CRF) method rather than a rigorous discounted cash flow method, which is used for the H2A Model's hydrogen production calculations. Although the CRF method is not quite as rigorous, the results are comparable when the same economic parameters are used.

30. The approximate indirect capital costs due to carbon sequestration are calculated by multiplying total indirect capital costs by the ratio of carbon sequestration direct capital costs to total direct capital costs. This approximation is for information only; it does not participate in the model's calculations. 
Carbon Sequestration Calculations

Carbon Sequestration Calculations CO2 Compressor Costs

21 Power Requirement

$W \mathrm{si}=\left(1000 /\left(24^{\star} 3600\right)\right)^{\star}\left(\mathrm{m}^{\star} \mathrm{Zs} \mathrm{s}^{*} \mathrm{R}^{\star} \mathrm{Tin} /\left(\mathrm{M}^{\star} h i s\right)^{\star}(\mathrm{ks} /(\mathrm{ks}-1))^{\star}\left[(\mathrm{CR})^{\mathrm{n}}((\mathrm{ks}-1) / \mathrm{ks})-1\right]\right.$

where

CRmax (maximum allowable compression ratio)

Outlet Pressure Desired

$N$ stages needed:

Tin (inlet temperature)

hin (isentropic efficiency)

CR needed

$\mathrm{Z} 1$ (compressability factor or $\mathrm{CO} 2$ )

k1 (ratio of Specific Heats for $\mathrm{CO}$ )

Pinitial (stage inlet pressure) $\mathrm{MPa}$

Pfinal (stage outlet pressure) $\mathrm{MPa}$

W1 (stage power) kW

Stage 5

Z5

Pinitial

Pfinal

W5

Stage 9

$\mathrm{Z9}$
$\mathrm{k} 9$

Pinitial

Pfinal

w9

$13,056 \mathrm{~kW}$

Electrical Costs

Ecomp $=$ electricity cost ${ }^{*} W$ comp $^{*}$ (capacity factor $24^{*} 365$ )

23 Capital Costs

C comp $=$ mtrain*Ntrain ${ }^{*}\left[\left(0.13 \times 10^{n} 6\right)^{*}(\text { mtrain })^{n}\right.$

$0.71+\left(1.40 \times 10^{\circ} 6\right)^{*}(\text { mtrain })^{\Upsilon}-0.60^{*} \ln ($ Pcut-off/Pinitial $\left.)\right]$

where

mtrain (compressor train mass flow)

Ntrain (number of paralel compressor trains)

Pcut-off

Pinitial

24 O\&M Costs

O\&Mannual $=\mathrm{C}_{\text {comp }}{ }^{*} \mathrm{O} \&$ Mfactor

where

O\&Mfactor

1.807

$15^{7} \mathrm{MPa}$

9

$323.15^{\top} \mathrm{K}$

$0.74^{\circ}$

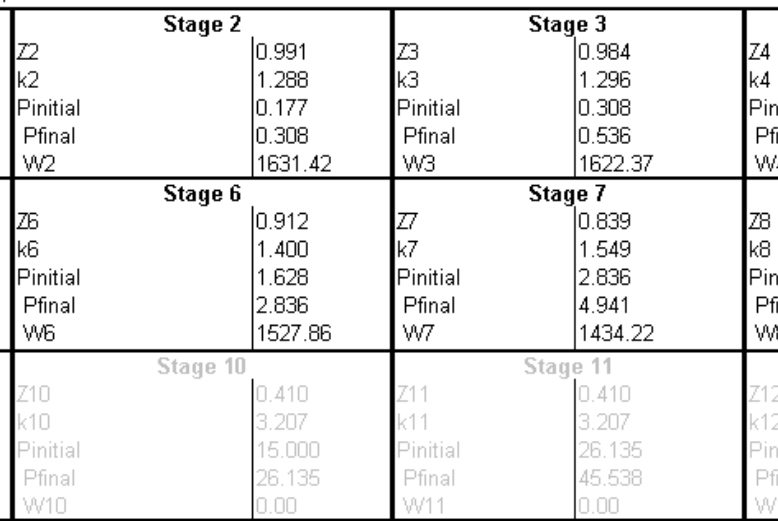

777.45

$\$ \quad 5,711,356 \$ / y r$

$\$ 28,950,657 \$$

$33.76 \mathrm{~kg} / \mathrm{s}$

1

$2175.6 \mathrm{psi}$

$14.7 \mathrm{psi}$

$\$ \quad 1,158,026 \$ / y r$

0.04

CO2 Injection Costs

Capital Costs

25 Capital cost of site screening and evaluation

Cequip $=$ number of wells $s^{\star}\left[49,433^{\star}(\mathrm{CO} 2\right.$

flowrate $/\left(280^{*}\right.$ Nwell $\left.\left.)\right)^{\wedge} 0.5\right]$

Cdrill $=$ Nwell ${ }^{\star} 10^{\wedge} 6^{\star} 0.1063^{\star} e^{\wedge}\left(0.0008^{\star} d\right)$

Cinj $=$ Csite +Cequip +Cdrill

26 o\&M Costs

O\&Mdaily

O\&Mcons

O\&Msur

O\&Msubsur

o\&Mitotal

CO2 Pipeline Costs

27 Capital Cost Requirement

Ccap=location factorterrain facto $r^{*}$ pipeline

length $(\mathrm{m})^{\star}\left(9970^{*}\left(\mathrm{CO} 2 \text { flowrate }{ }^{\wedge} 0.35\right)^{*}\right.$ (pipeline

lenqth $\left.(\mathrm{m})^{\wedge} 0.13\right)$ )

Pipeline capital cost per mile

$\$ \quad 159,549$

$\$ \quad 359,770$

$\$ 2,377,092$

\$ 7,596 Nwell*7596

\$ 20,295 Nwell 20295

\$ 49,769 Nwell*[15,420*(m/(280*

Nwell) $)^{0.51}$

\$ 7,087 Nwell*(5669*(d/1219))

$\$ \quad 84,748$ \$/yr

28 O\&M Costs

O\&Mannual $=$ Ccap $^{\star} 0$ \&Mfactor

$\$ \quad 65,465,510.85 \$$

$\$ \quad 654,655.11 \$ / m i$

$\$ \quad 1,636,637.77 \$ / y г$ 


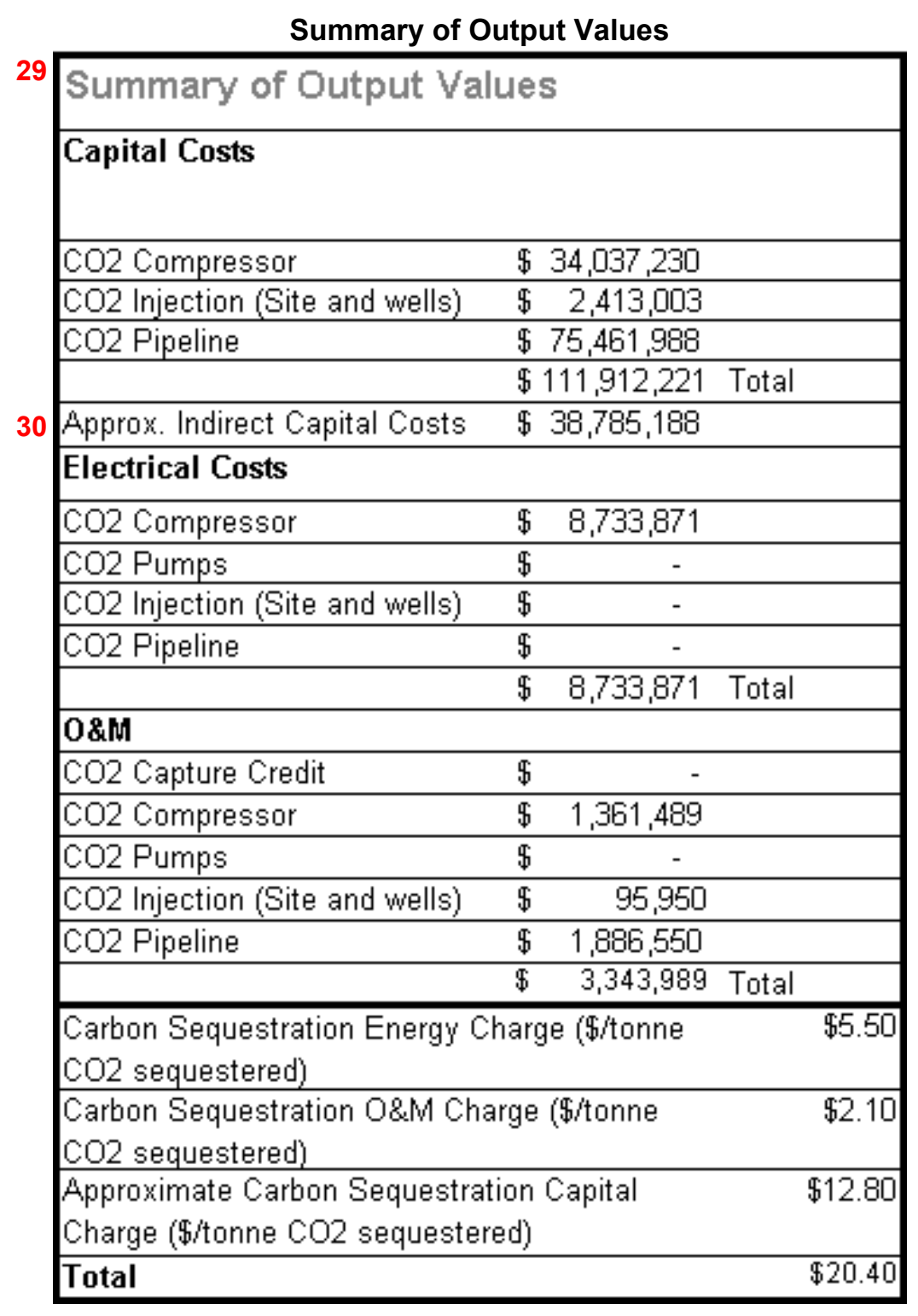

\section{References}

The calculations used in the Carbon Sequestration worksheet were developed by Directed Technologies, Inc. and the National Renewable Energy Laboratory based on information from compressor/turbine manufacturer MAN Turbo and the following publications:

Benson, S.M. (2000). Comparison of Three Options for Geologic Sequestration of CO2-A Case Study for California. LBNL-46365. Berkeley, CA: Lawrence Berkeley National Laboratory. http://repositories.cdlib.org//bnl/LBNL-46365.

This study examines the distribution of carbon emissions from fossil fuel power plants in California and their proximity to active or depleted oil and gas fields and brine formationsreservoirs that might be suitable for carbon sequestration. It also assesses the feasibility of sequestering $\mathrm{CO}_{2}$ from California fossil fuel plants in these reservoirs. 
Chen, S.G.; Lu, Y.; Rostam-Abadi, M.; Nyman, D.J.; Dracos, J.S.; Varagani, Rajani. (2004). Carbon Dioxide Capture and Transportation Options in the Illinois Basin. Champaign, IL: Illinois State Geological Survey. http://sequestration.org/publish/MGSC year1report.pdf.

This report describes $\mathrm{CO}_{2}$ capture options from large stationary emission sources in the Illinois Basin, focusing on coal-fired power plants. It includes information on pipeline costs.

McCollum, D.L.; Ogden, J.M. (2006). Techno-Economic Models for Carbon Dioxide Compression, Transport, and Storage \& Correlations for Estimating Carbon Dioxide Density and Viscosity. UCD—ITS—RR-06-14. Davis, CA: Institute of Transportation Studies, University of California, Davis.

http://hydrogen.its.ucdavis.edu/publications/2006pubs/resolveuid/7c6a2993156155db8d3209 af679b4cdb.

This report is divided into three sections:

- Techno-Economic Models for Carbon Dioxide Compression, Transport, and Storage contains models for estimating the engineering requirements and costs of carbon capture and storage (CCS) infrastructure.

- Simple Correlations for Estimating Carbon Dioxide Density and Viscosity as a Function of Temperature and Pressure describes simple correlations - which are functions of only temperature and pressure-for estimating the density and viscosity of $\mathrm{CO}_{2}$ within the range of operating temperatures and pressures that might be encountered in CCS applications.

- Comparing Techno-Economic Models for Pipeline Transport of Carbon Dioxide illustrates an approach used to compare several recent techno-economic models for estimating $\mathrm{CO}_{2}$ pipeline sizes and costs, resulting in a new $\mathrm{CO}_{2}$ pipeline capital cost model that is a function only of flow rate and pipeline length. 


\section{Appendix 2: Forecourt Hydrogen Delivery Calculations}

This appendix briefly describes the inputs and calculations used within the Refueling Station worksheet (which is used for the H2A forecourt model only, see page 25). The Refueling Station worksheet is itself a relatively complex model (see schematic below); it is based on refueling station modeling from the H2A Delivery Components Model and the Hydrogen Delivery Scenario Analysis Model (HDSAM). It calculates optimal hydrogen compression, storage, and dispensing costs for a station with a capacity of up to $6,000 \mathrm{~kg}$ of hydrogen per day and a convenience store.

In contrast to the H2A Delivery Components Model, which assumes hydrogen is delivered via pipeline, the Refueling Station worksheet assumes hydrogen is produced onsite. Because hydrogen supply is more likely to be disrupted by planned and unplanned outages of the onsite production unit, additional storage is required; a user-input field (in the Refueling Station Scenario Inputs table) accounts for the additional low-pressure storage requirement. The default value is slightly more than one half $(58.3 \%)$ of the plant's daily production capacity.

The table descriptions below give an overview of the worksheet's functions and some default values. See the sources listed in References at the end of this appendix for detailed information.

Schematic of Complex Data Flow within Refueling Station Worksheet

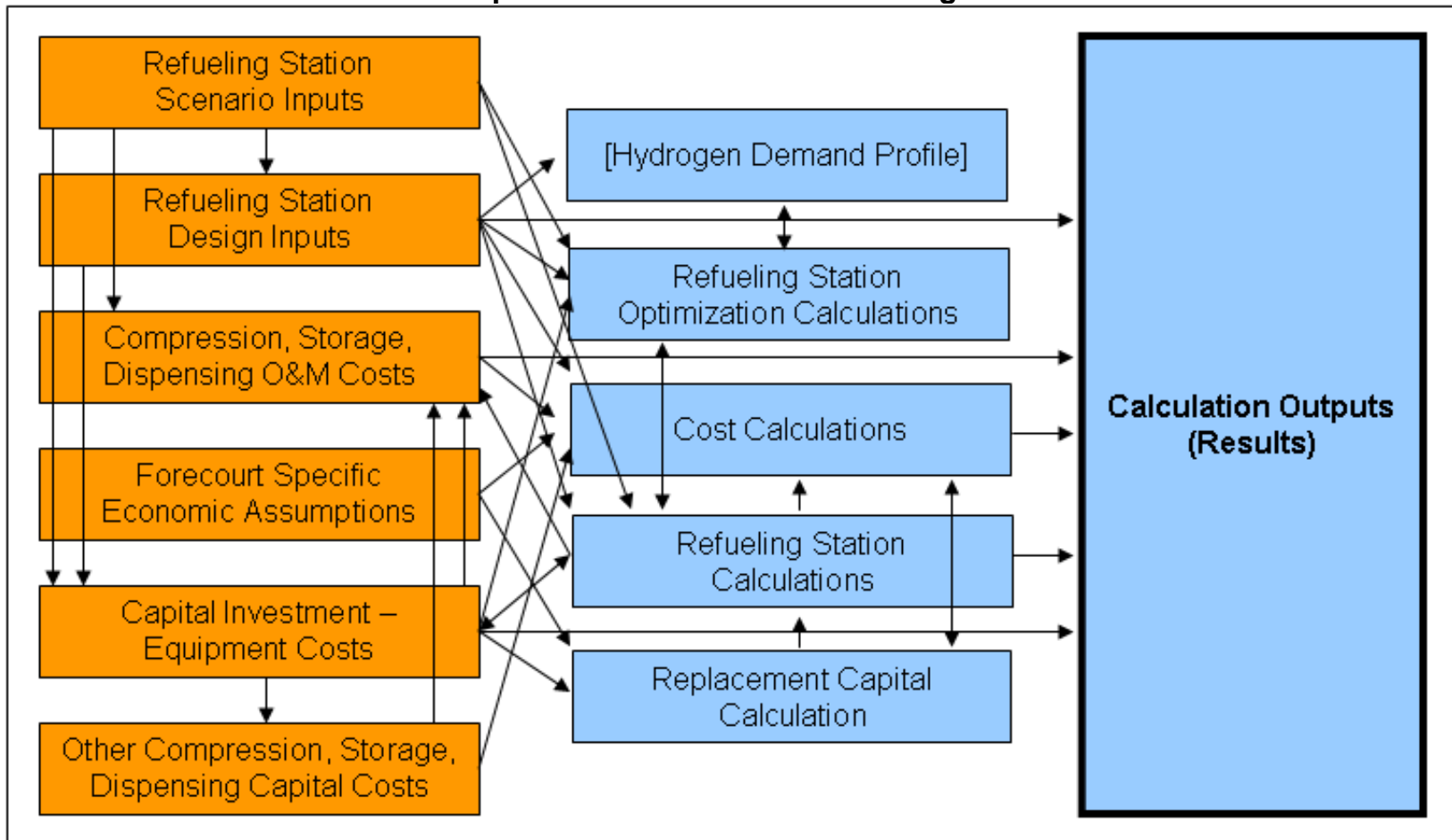

Note: The Input_Sheet_Template worksheet also provides inputs to the Refueling Station worksheet.

\section{Calculation Outputs (Results)}

The three Calculation Outputs tables summarize the major results of the Refueling Station calculations: 
- Results - Cost Breakdown per kg H2

- Results - Capital and Operating Costs

- Results - Other CSD Parameters.

The Calculation Outputs tables receive input from the Refueling Station Design Inputs; Compression, Storage, Dispensing O\&M Costs; Cost Calculations, Refueling Station Calculations; and Capital Investment-Equipment Costs tables. No user input is required. The Cost Breakdown per kg H2 results are output to the main H2A Results worksheet; see the schematic on page 26 .

\section{Forecourt Specific Economic Assumptions}

Input or accept the default values for depreciation and component lifetime values here. The values are output to the Cost Calculations and Replacement Capital Calculation tables.

\section{Refueling Station Design Inputs}

Input refueling station design characteristics here. The default values assume a hydrogen pressure of 300 psi exiting the production process. The hydrogen is compressed to $2,500 \mathrm{psi}$ for storage; this relatively low-pressure storage was found to be economical.

Using the default values, vehicles fueling at the station take a fill pressure of 5,000 psi after equilibration to standard temperature; thus, the default maximum cascade charging system pressure is $6,250 \mathrm{psi}$, which allows the vehicle to refuel within 3 minutes and allows for overpressure to compensate for temperature increases during refueling. The cascade charging system has three pressure vessels, each with a 21.3-kg capacity and a maximum pressure of $6,250 \mathrm{psi}$. There can be more than one bank of three cascade charging vessels depending on the size of the refueling station. To satisfy vehicle filling dynamics, each vessel operates under a different minimum pressure: $6,000,4,350$, and 2,000 psi. The default compressor values are described in Nexant et al. (2008).

The Refueling Station Design Inputs table receives input from the Refueling Station Scenario Inputs table. Its values are output to the Refueling Station Optimization Calculations, Cost Calculations, Refueling Station Calculations, and Calculation Outputs tables as well as the Hydrogen Demand Profile.

\section{Refueling Station Scenario Inputs}

Input details about the refueling station's design and operation here. About half the fields in the Value column contain notes that describe the meaning of the values; read them by selecting each field.

The default values are based on a station with six dispensers operating 18 hours per day (6:00 AM to 12:00 AM). The $58.3 \%$ low-pressure storage vessel excess capacity provides about a half day of backup storage for use during unplanned shutdowns.

The land area a hydrogen refueling station requires is determined by daily average fuel demand, setback distances (as determined by the National Fire Protection Association for safety purposes), and delivery method. For the purposes of characterizing the default station's area and storage vessel dimensions, the assumptions for a station with pipeline hydrogen delivery given in Nexant et al. (2008) were used. 
The Refueling Station Scenario Inputs values output to the Refueling Station Design Inputs, Refueling Station Calculations, and Refueling Station Optimization Calculations tables.

\section{Capital Investment-Equipment Costs}

The top part of this table gives you the option of accepting H2A-defined compressor, dispenser, storage, and electrical costs or entering your own values. Select "yes" in the dropdown menu to accept the H2A costs as described in the Notes fields. If you select "yes" for all of the pieces of equipment, you do not need to provide further input to this table. If you select "no" for one or more pieces of equipment, you must input values in the bottom part of the table as described in the Notes fields.

The bottom part of the table calculates the installed cost of each piece of equipment and calculates total initial capital investment. Equipment characteristics in the Value column come from the Refueling Station Scenario Inputs, Refueling Station Design Inputs, and Refueling Station Calculations tables. The Capital Investment-Equipment Costs values output to the Refueling Station Calculations; Refueling Station Optimization Calculations; Replacement Capital Calculation; Other Compression, Storage, Dispensing Capital Costs; and Calculation Outputs tables.

\section{Other Compression, Storage, Dispensing Capital Costs}

Input or accept the default values for indirect compression, storage, and dispensing capital costs - as a percentage of the direct capital costs-in the orange cells. The blue cells automatically multiply the percentages by the total direct capital cost from the Capital Investment-Equipment Costs table. The Total Capital Investment value sums the direct and indirect capital costs. The Total Land/Other Capital Costs value (which sums the indirect costs) outputs to the Cost Calculations table.

\section{Compression, Storage, Dispensing O\&M Costs}

Input labor and other operating and maintenance costs here. The default labor costs are based on a refueling station open 365 days per year, dispensing an average of $1,050 \mathrm{~kg}$ of hydrogen per day. The convenience store at such a station employs 1.5 people; $33 \%$ of the labor is associated with fuel dispensing. For stations with capacities other than $1,050 \mathrm{~kg} /$ day, labor hours scale linearly as a function of station size, i.e., labor hours per year $=$ store hours per day $\times 365 \times 0.33 \times 1.5 \times$ (station capacity $/ 1,050$ ). The labor rate is $\$ 10 / \mathrm{hr}$ plus $20 \%$ for overhead and G\&A.

The Compression, Storage, Dispensing O\&M Costs table receives input from the Refueling Station Scenario Inputs; Capital Investment-Equipment Costs; Other Compression, Storage, Dispensing Capital Costs; and Refueling Station Calculations tables as well as the Input_Sheet_Template worksheet. Its values are output to the Cost Calculations and Calculation Outputs tables.

\section{Calculation Tables: Optimizing Refueling Station Design and Cost}

The five tables following the Compression, Storage, Dispensing O\&M Costs table work together to calculate optimal refueling station design, operation, and cost:

\section{- Refueling Station Calculations}


- Refueling Station Optimization Calculations

- Cost Calculations

- Replacement Capital Calculation

- Hydrogen Demand Profile (untitled table at bottom of worksheet).

No user input is required for these tables. The schematic on page 56 shows the data flow among the various calculation and input tables (the Input_Sheet_Template worksheet also provides data to the calculation tables).

The refueling station optimization calculations are based on the following inputs and assumptions:

- Chevron daily and hourly hydrogen demand profiles

- Assumed spike in demand at the beginning of each hour

- Cost of the compressor, cascade, and electrical upgrades

- Minimum and maximum pressures in each of the cascade vessels

- Vehicle filling dynamics (tank capacity, fill time, linger time, etc.)

- Number of compressors in operation and in standby modes

- Number of dispensers and the average hose occupied fraction during peak hour.

The optimization methodology-from the H2A Delivery Models-is based on a simple logic. The amount of hydrogen and the pressures in each of the cascade vessels are tracked at the critical points of the demand profile, and a decision is made regarding the size of the compressor and cascade system to satisfy the demand with minimum cost. The selected design parameters are those that satisfy the demand profile at all of its critical points. See Nexant et al. (2008) for optimization methodology details.

\section{References}

Nexant et al. (scheduled publication 2008). H2A Hydrogen Delivery Infrastructure Analysis Models and Conventional Pathway Options Analysis Results. DE-FG36-05G015032. Washington, DC: U.S. Department of Energy. www.hydrogen.energy.gov/systems analysis.html.

This report contains results of an analysis of infrastructure options for hydrogen delivery and distribution to refueling stations from central, semi-central, and distributed production facilities. The H2A Production Model's Refueling Station worksheet is based on the refueling station characteristics and calculations described in this report.

U.S. Department of Energy Hydrogen Program. DOE H2A Delivery Analysis. Web Site. Washington, DC: U.S. Department of Energy. www.hydrogen.energy.gov/h2a delivery.html.

This Web site includes descriptions of the H2A Delivery Components Model and HDSAM as well as user's guides for both models. 


\section{Appendix 3: Default Values and Assumptions}

The following default values and assumptions apply to the $\mathrm{H} 2 \mathrm{~A}$ central and forecourt models, unless a specific technology case specifies otherwise:

Analysis Methodology

Analysis Period

Average Burdened Labor Rate for Staff

Capacity Factor

Central Storage

$\mathrm{CO}_{2}$ Capture Credit

$\mathrm{CO}_{2}$ Production Taxes

Construction Period and Cash Flow

Co-produced and Cogenerated

Electricity Price

Decommissioning

Depreciation Type and Schedule for Initial Depreciable Capital Cost

Facility Life

Forecourt Compressed Hydrogen Storage

G\&A Rate

Hydrogen Pressure at Central Gate

Hydrogen Purity

Hydrogen Storage Pressure at Forecourt

Income Taxes
Discounted cash flow (DCF) model that calculates a levelized hydrogen cost yielding a prescribed IRR

40 years for central model; 20 years for forecourt model

$\$ 50 /$ hour for central model; $\$ 15 /$ hour for forecourt model

$90 \%$ for central model with case exceptions; $85.2 \%$ for forecourt model

Optional buffer only as required for efficient operations Not included in base cases (default value $=0$ ) Not included in base cases (default value $=0$ )

Varies per case for central model; 1 year for forecourt model

$\$ 30 / \mathrm{MWh}$

$10 \%$ of initial capital for central model, with case exceptions; $0 \%$ for forecourt model

MACRS: 20 years for central model with case exceptions; 5 years for compressors, 7 years for remainder of plant for forecourt model

40 years for central model with case exceptions; 20 years for forecourt model with case exceptions

$117 \%$ of maximum daily production

$20 \%$ of the staff labor costs above

300 psig; if higher pressure is inherent to the process, apply pumping power credit for pressure $>300$ psig

98\% minimum; CO < 10 ppm, sulfur < 10 ppm

6,250 psig

$35 \%$ federal; $6 \%$ state; $38.9 \%$ effective 
Inflation Rate

Land Cost

$\mathrm{O}_{2}$ Credit

Process Contingency

Project Contingency

Property Taxes and Business

Insurance

Reference Financial Structure

Reference Year Dollars

Sales Tax

Salvage Value

Sensitivity Variables and Ranges

Technology Development Stage

Working Capital Rate
$1.9 \%$, but with resultant price of hydrogen in reference year constant dollars

$\$ 5,000 / a c r e$ purchased for central model;

$\$ 0.5 / \mathrm{sqft} / \mathrm{month}$ for long-term lease for forecourt model

Not included in base cases

$\%$ adjustment to the total initial capital cost such that the result incorporates the mean or expected overall performance

$\%$ adjustment to the total initial capital cost such that the result represents the mean or expected cost value; periodic replacement capital includes project contingency

$2 \% /$ year of the total initial capital cost

$100 \%$ equity with $10 \%$ IRR; includes levelized hydrogen price plot for $0 \%-25 \%$ IRR; model allows debt financing

2005 , to be adjusted at half-decade increments (e.g., 2005, 2010)

Not included on basis that facilities and related purchases are wholesale and through a general contractor entity

$10 \%$ of initial capital for central model, with case exceptions; $0 \%$ for forecourt model

Based on applying best judgment of $10 \%$ and $90 \%$ confidence limit extremes to the most significant baseline cost and performance parameters

All central and forecourt model cost estimates are based on mature, commercial facilities

$15 \%$ of the annual change in total operating costs 


\section{Appendix 4: Derivations and Definitions}

\section{Derivation of Forecourt Production Unit Operating Capacity Factor}

The following calculations show how $85.2 \%$ was chosen as the standard operating capacity factor for forecourt production systems. (Source: Directed Technologies, Inc.)

$$
\text { CF }=100 \%-R_{\text {season }}-R_{\text {planned }}-R_{\text {unplanned }}-R_{\text {extra }}
$$

Where:

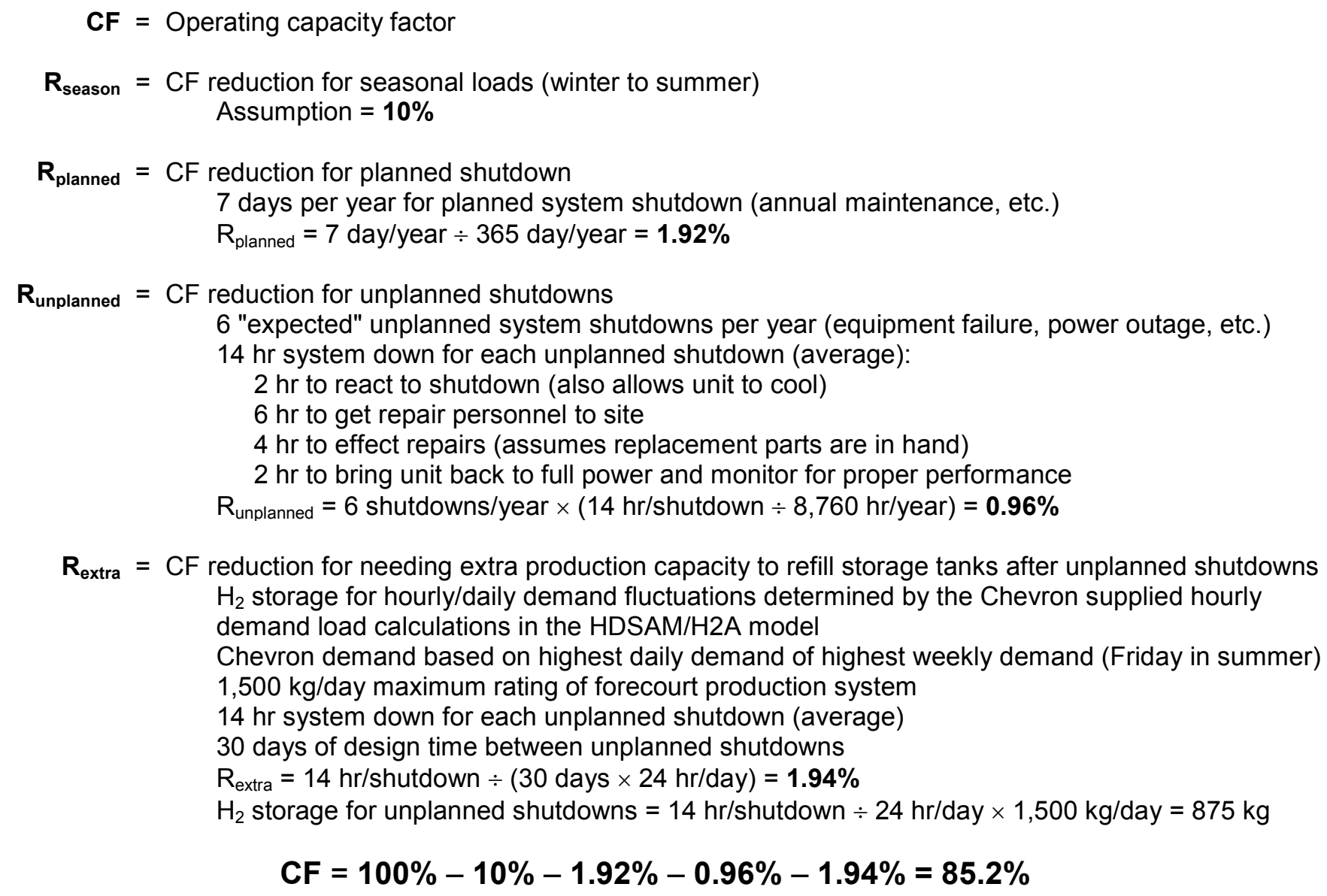

\section{Definitions}

Working capital A measure of a business' daily operating liquidity, calculated by subtracting current liabilities from current assets. Working capital is considered a part of operating capital, along with fixed assets such as facilities and equipment. Also known as net working capital. 


\section{Index}

AEO data, 38, 41

Assumptions, 60

Byproducts

check box, 16

defining, 12-14, 38

deleting entries, 13

Calculate Cost button, 10

error message, 6

Capital costs, 14-15, 19

Capital equipment, 19

Carbon sequestration, 23-24, 49-55

calculations, 53

information, 49

input values, 50

O\&M costs, 17

output values, 54

worksheet, 14

Cash flow analysis, 35

Cells, color coding, 4

Central hydrogen production, i

$\mathrm{CH} 4$ emissions, 33

$\mathrm{CO} 2,23$

Color coding, 10

Convenience store refueling station, 25

Conversion factors, 46

Cost analysis, 3

Debt financing, 44

Default values, 60

Definitions, 62

Delete entry, 6, 13, 16, 29

Depreciation, 45

Efficiency, 33

Emissions summary, 33

Energy Data table, 33

Energy Feed \& Utility Prices worksheet, 38 errors, 7

Energy inputs, 33

Errors, 4

Exporting, 29

Feedstocks

conversion efficiency, 12

defining, 12-14, 38

deleting entries, 13

Financial characteristics, 11

Fixed operating costs, 15

Forecourt hydrogen delivery, 56-60

Forecourt hydrogen production, $\mathrm{i}$

Greenhouse gases, 34

GREET model, 33, 34

HyARC physical property data, 38, 42

Importing existing cases, 27

Information worksheets, 8

Input_Sheet_Template worksheet, 10-17

error message, 5
Installed costs, 19

LHV. See Lower heating value

Lists worksheet, 47

errors, 7

Lower heating value, 12

N2O emissions, 33

Non-Energy Material Prices worksheet, 40

Other materials and byproducts, defining, 16

Plant output, calculating, 11

Plant scaling, 4, 20-22

baseline values, 20

capacity range, 20

factor exponent, 20

methods, 21

worksheet, 20

Price

data table, selecting, 12

defining, 38

in startup year, 12

Printing, 29

Process material costs. See Variable operating costs

Production analysis. See Cost analysis

Project Info button, 10

Refueling station

calculations, 56

costs, 58

design, 57

O\&M costs, 17

worksheet, 14

Refueling Station worksheet, 25-26

Replacement costs, 17, 18

Results, 32-35

Sensitivity analysis, 30-31

Sensitivity Analysis worksheet, 37

Support, 48

Symbols used, 4

Toolkit, 27

Toolkit button, 10

Toolkit window, 10

Tornado chart, 4, 31

errors, 6

worksheet, 36

Units, changing, 13

Use Default Values button, 10

example, 11

problems, 5

Utilities

defining, 12-14, 38

deleting entries, 13

Variable operating costs, 15

Worksheet

data flow, 1, 2

organization, 1 


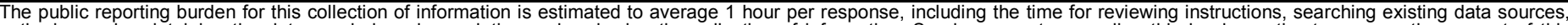

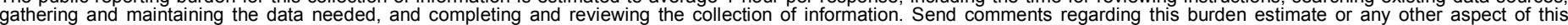

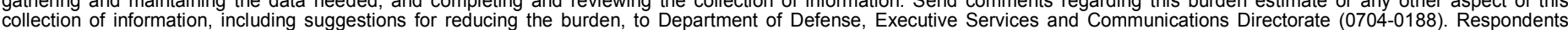

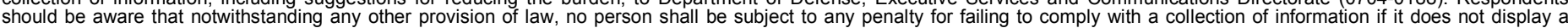

should be awa that notwithstanding

PLEASE DO NOT RETURN YOUR FORM TO THE ABOVE ORGANIZATION.

\begin{tabular}{l|l|l|l} 
1. REPORT DATE $(D D-M M-Y Y Y Y)$ & 2. & REPORT TYPE & 3. DATES COVERED (FrOm - TO)
\end{tabular}

September 2008

Technical Report

4.
TITLE AND SUBTITLE
H2A Production Model, Version 2 User Guide

5a. CONTRACT NUMBER

DE-AC36-99-GO10337

5b. GRANT NUMBER

5c. PROGRAM ELEMENT NUMBER

6. AUTHOR(S)

D. Steward, T. Ramsden, and J. Zuboy

5d. PROJECT NUMBER

NREL/TP-560-43983

5e. TASK NUMBER

$\mathrm{H} 2782150$

5f. WORK UNIT NUMBER
7. PERFORMING ORGANIZATION NAME(S) AND ADDRESS(ES)

National Renewable Energy Laboratory

1617 Cole Blvd.

Golden, CO 80401-3393
8. PERFORMING ORGANIZATION

REPORT NUMBER

NREL/TP-560-43983

9. SPONSORING/MONITORING AGENCY NAME(S) AND ADDRESS(ES)

10. SPONSOR/MONITOR'S ACRONYM(S) NREL

11. SPONSORING/MONITORING AGENCY REPORT NUMBER

12. DISTRIBUTION AVAILABILITY STATEMENT

National Technical Information Service

U.S. Department of Commerce

5285 Port Royal Road

Springfield, VA 22161

13. SUPPLEMENTARY NOTES

14. ABSTRACT (Maximum 200 Words)

The H2A Production Model analyzes the technical and economic aspects of central and forecourt hydrogen production technologies. Using a standard discounted cash flow rate of return methodology, it determines the minimum hydrogen selling price, including a specified after-tax internal rate of return from the production technology. Users have the option of accepting default technology input values-such as capital costs, operating costs, and capacity factor-from established H2A production technology cases or entering custom values. Users can also modify the model's financial inputs. This new version of the H2A Production Model features enhanced usability and functionality. Input fields are consolidated and simplified. New capabilities include performing sensitivity analyses and scaling analyses to various plant sizes. This User Guide helps users already familiar with the basic tenets of $\mathrm{H} 2 \mathrm{~A}$ hydrogen production cost analysis get started using the new version of the model. It introduces the basic elements of the model then describes the function and use of each of its worksheets.

\section{SUBJECT TERMS}

H2A; hydrogen model; hydrogen cost; user guide; H2A documentation; hydrogen production; Darlene Steward; Todd Ramsden; Jarett Zuboy

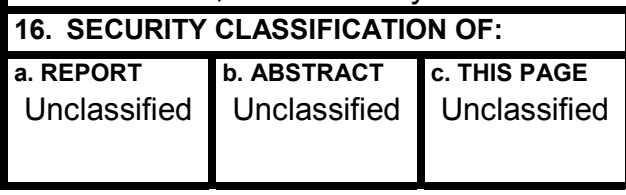

\begin{tabular}{|c|c|} 
17. LIMITATION \\
OF ABSTRACT \\
UL
\end{tabular}

19a. NAME OF RESPONSIBLE PERSON

19b. TELEPHONE NUMBER (Include area code) 